\title{
FLUXOS MÁXIMOS EM REDES: \\ Algoritmos e Estruturas de Dados
}

\section{Roberto Duó}

\author{
DISSERTAÇÃO APRESENTADA \\ $\mathrm{AO}$ \\ INSTITUTO DE MATEMÁTICA E ESTATÍSTICA \\ DA \\ UNIVERSIDADE DE SAAO PAULO \\ PARA OBTEN( IO I)O (IRAI I)E \\ MESTRE LN \\ MATEMÁTICA APLIC:ADA
}

Área de Concentração: Ciência da Computação

Orientadora: Professora Dr $\underline{\text { a }}$ Yoshiko Wakabayashi 


\title{
Resumo
}

Neste trabalho estudamos vários algoritmos para o problema do fluxo máximo, procurando enfatizar as idéias que surgiram e como foram aprimoradas. Dado que os algoritmos mais recentes utilizam estruturas de dados sofisticadas, como árvores enviesadas e árvores dinâmicas, incluimos aqui um estudo completo e detalhado de tais estruturas. Finalmente, apresentamos e analisamos a complexidade computacional de um algoritmo recente de GoldbergTarjan, que usa essas estruturas, e descrevemos aspectos relativos à sua implementação.

\begin{abstract}
In this work we study the max-flow problem. with emplasis on its algorithmic aspects. We describe a number of algorithms showing the main ideas that appeared and their successive refinements. Since the most recent algorithms use sophisticated data structures, like biased trees and dynamic trees, we present here a complete and detailed study of such structures. Finally, we describe and analyse the computational complexity of a recent algorithm due to Goldberg and Tarjan, and mention details concerning its implementation.
\end{abstract}


Aos meus pais

e esposa 


\section{Agradecimentos}

À minha orientadora, Professora Yoshiko, pela sugestão do tema e pelo acompanhamento do desenvolvimento do mesmo.

Ao meu amigo, Fábio Lotti Oliva, pelo incentivo no início da minha pósgraduação.

Aos meus amigos, Stephen Kassner e Cristina Gomes Fernandes, pelo acompanhamento do desenvolvimento do tema da dissertação.

Aos meus amigos, Dilma, Carlos e Coelho por enviarem artigos do exterior.

Ao meu amigo, Daniel Panário, por ceder a capa da sua tese.

À minha amiga Wania, por dar um jeito na impressora.

À minha professora Nami, por conselhos e sugestões.

À VILLARES, que cedeu cerca de $15 \%$ do meu tempo de trabalho, possibilitando o desenvolvimento do meu mestrado.

Aos professores do IME que incentivam a pós-graduação dos que trabalham fora deste instituto.

À Edna, pelo carinho e paciência nos momentos mais difíceis. 


\section{Índice}

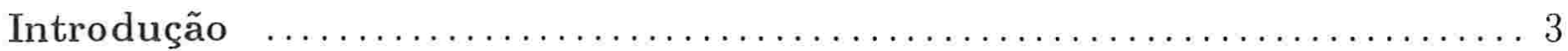

Capítulo 1 Algoritmos para o Problema do Fluxo Máximo .......... 5

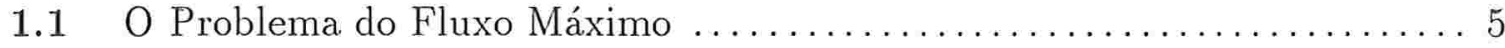

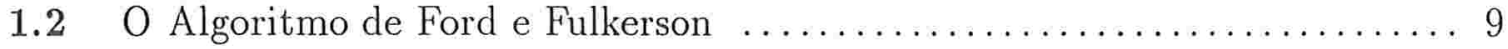

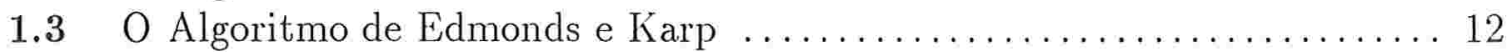

1.4 O Algoritmo de Dinic .................................. 14

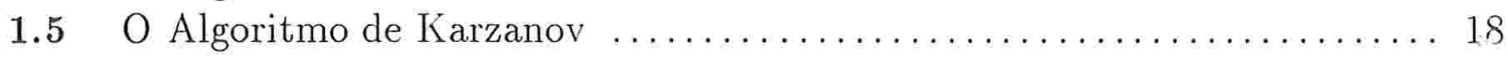

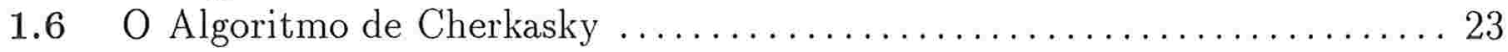

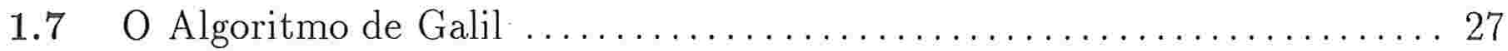

1.8 O Algoritmo de Malhotra, Kumar e Maheshwari . ................. 33

1.9 O Algoritmo de Galil e Naamad ............................ 34

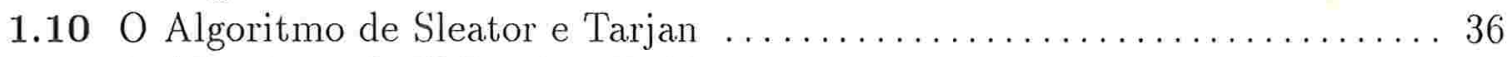

1.11 O Algoritmo de Shiloach e Vishkin . ....................... 37

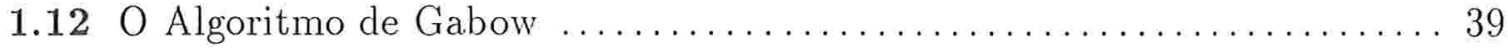

Capítulo 2 Árvores de Busca Enviesadas . . . . . . . . . . . . . . . 41

2.1 Árvores de Busca Localmente Enviesadas . . . . . . . . . . . . . . . . . 44

2.2 Árvores de Busca Globalmente Enviesadas . . . . . . . . . . . . . . . . 58

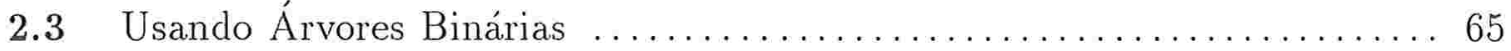

Capítulo 3 Árvores Dinâmicas ............................... 75

3.1 O Problema das Árvores Dinâmicas ......................... 75

3.2 Representando Árvores como Conjunto de Caminhos .............. 76

3.3 Como Implementar as Operaçôes sobre Caminhos ….............. 85

3.4 Uma Implementaçào mais Sofisticada ...................... 93

Capítulo 4 O Algoritmo de Goldberg e Tarjan . . . . . . . . . . . . . . . 103

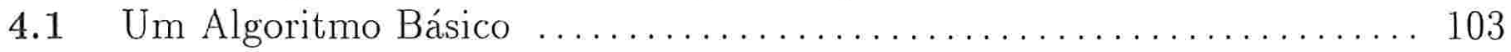

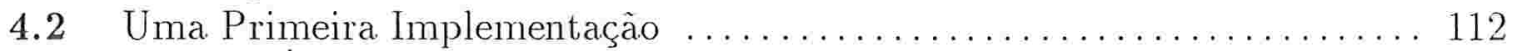

4.3 Usando Árvores Dinâmicas .................................. 117

4.4 Comparando o Algoritmo de Goldberg-Tarjan com os do Capítulo 1 . . 123

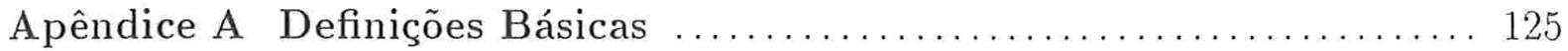

A pêndice B Glossário ................................... 128

Apêndice C Sobre a Implementação ............................ 131

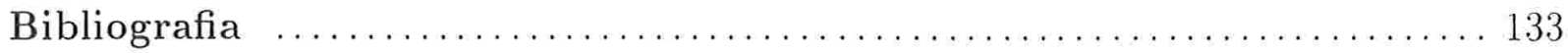




\section{Introdução}

Neste trabalho estudaremos o problema do fluxo máximo, abordando aspectos relativos à evolução dos algoritmos que surgiram, e dando ênfase especial a um tipo de estrutura de dados que tem sido muito utilizada em algoritmos mais recentes. O problema do fluxo máximo tem sido objeto de muito estudo, desde 1956, quando Ford e Fulkerson [9] publicaram um artigo apresentando um primeiro algoritmo. Desde então, algoritmos cada vez mais eficientes vêm sendo desenvolvidos. Neste trabalho serão mencionados vários algoritmos, procurando enfatizar as idéias que surgiram e como foram aprimoradas. Como veremos, a evolução das idéias atingiu um ponto em que o próximo aspecto a ser explorado passou a ser o uso de estrutura de dados mais sofisticadas. Neste contexto, as chamadas árvores dinâmicas, têm um papel muito importante - razão pela qual decidimos incluir o seu estudo neste trabalho. Procuramos apresentar os conceitos e os resultados teóricos sobre tais estruturas - coletando artigos bastante sucintos - de modo a facilitar a compreensào dos resultados e também tornar este trabalho completo e auto-contido com relação à análise da complexidade de um algoritmo que descrevemos e implementamos.

Para a leitura deste trabalho são suficientes apenas os conceitos básicos da teoria de grafos e análise de algoritmos, sendo particularmente indicada para alunos de pósgraduação na área de Ciência da Computação.

No primeiro capítulo, apresentaremos onze algoritmos que resolvem o referido problema. No capitulo 2 estudaremos um tipo de estrutura de dados conhecido como árvores enviesadas, enquanto que no capítulo 3, estudaremos o problema das árvores dinâmicas, usando os resultados apresentados no capítulo 2. Finalmente, no último capítulo discutiremos um algoritmo recente de Goldberg e Tarjan para o problema do fluxo máximo, cuja implementaçào usa fortemente a estrutura de dados estudada nos dois capítulos anteriores. Este capítulo é finalizado com uma seçào que seleciona as idéias dos algoritmos apresentados no primeiro capítulo, que estào presentes no algoritmo de Goldberg e Tarjan.

A seguir, exibimos uma tabela com os vários algoritmos que serão mencionados neste trabalho. As complexidades de tempo (pior caso) dos algoritmos, apresentadas na quarta coluna, estão expressas em termos do número $n$ de vértices, do número $m$ de arestas do grafo e do limite superior $C$ das capacidades das arestas. Para os algoritmos em que a. complexidade de tempo esta expressa em termos de $C$, é suposto que as capacidades são inteiras. 


\begin{tabular}{|r|c|l|l|c|}
\hline$\#$ & Ano & Autor & Tempo de execução & Referência \\
\hline 1 & 1956 & Ford e Fulkerson & $O(n m C)$ & {$[9]$} \\
2 & 1969 & Edmonds e Karp & $O\left(n m^{2}\right)$ & {$[7]$} \\
3 & 1970 & Dinic & $O\left(n^{2} m\right)$ & {$[6]$} \\
4 & 1974 & Karzanov & $O\left(n^{3}\right)$ & {$[15]$} \\
5 & 1977 & Cherkasky & $O\left(n^{2} m^{\frac{1}{2}}\right)$ & {$[4]$} \\
6 & 1978 & Malhotra, Kumar & $O\left(n^{3}\right)$ & {$[16]$} \\
& & e Maheshwari & & \\
7 & 1978 & Galil & $O\left(n^{\frac{5}{3}} m^{\frac{2}{3}}\right)$ & {$[12]$} \\
8 & 1978 & Galil e Naamad & $O\left(n m(\lg n)^{2}\right)$ & {$[13]$} \\
9 & 1980 & Sleator e Tarjan & $O(n m \lg n)$ & {$[18]$} \\
10 & 1982 & Shiloach e Vishkin & $O\left(n^{3}\right)$ & {$[17]$} \\
11 & 1983 & Gabow & $O(n m \lg C)$ & {$[11]$} \\
12 & 1986 & Goldberg e Tarjan & $O\left(n^{3}\right)$ & {$[14]$} \\
13 & 1986 & Goldberg e Tarjan & $O\left(n m \lg \left(\frac{n^{2}}{m}\right)\right)$ & {$[14]$} \\
14 & 1986 & Ahuja e Orlin & $O\left(n m+n^{2} \lg C\right)$ & {$[2]$} \\
\hline
\end{tabular}

Os onze primeiros algoritmos desta tabela serão estudados no capítulo 1 . O algoritmo de Galil e Naamad usa, implicitamente, árvores dinâmicas; já o algoritmo de Sleator e Tarjan usa diretamente árvores dinâmicas. Assim, ambos podem ser melhor compreendidos após a leitura dos capítulos 2 e 3.

Neste trabalho damos uma ênfase especial ao algoritmo de Goldberg e Tarjan, por ser um dos algoritmos mais eficientes para o problema do fluxo máximo. Fizemos uma implementação deste algoritmo (em um microcomputador do tipo PC-XT), visando conhecer as dificuldades práticas no uso de estruturas de dados mais sofisticadas e, principalmente, porque acreditamos que, sem fazer a implementação não poderíamos considerar o aprendizado completo. De fato, foi na fase de implementaçào que algumas dúvidas foram esclarecidas e pudemos melhor compreender a teoria. No apêndice C discutimos alguns aspectos relativos à implementação que fizemos.

No apêndice A apresentamos os conceitos básicos da teoria de grafos, principalmente sobre árvores, que serão usados neste trabalho.

$\mathrm{O}$ apêndice $\mathrm{B}$ contém um índice de todas as definições apresentadas neste trabalho. 


\section{Capítulo 1}

\section{ALGORITMOS PARA O PROBLEMA DO FLUXO MÁXIMO}

Neste capítulo descreveremos o problema do fluxo máximo e apresentaremos vários algoritmos que resolvem este problema, indicando as novas idéias que foram incorporadas pelos diversos autores, mostrando, desta forma, a evoluçào dos algoritmos. Omitiremos algumas demonstraçôes e detalhes de alguns algoritmos.

\subsection{O Problema do Fluxo Máximo}

A descrição do problema, que será feita aqui, é baseada na definição de fluxo encontrada no livro de Ford e Fulkerson [10] publicado em 1962. Como veremos mais tarde, a formulação original é diferente desta.

Neste capítulo, utilizaremos a seguinte notaçào:

Seja $G=(V, A)$ um grafo orientado, $X . J \subseteq V \cdot \imath \in V$, e g uma funçào $g: A \rightarrow \Re$. Então $g(X, Y)$ denota a seguinte soma:

$$
g(X, Y)=\sum_{\substack{(x, y) \in A \\ x \in X, y \in Y}} g((x, y)) .
$$

Além disso,

$$
g(v, X)=g(\{v\}, X) \text { e } g(X, v)=g(X,\{v\}) .
$$


Definição 1.1 : Uma rede é uma quádrupla $(G, s, t, c)$, onde $G=(V, A)$ é um grafo orientado, $s$ e $t$ são vértices distintos de $V$ e $c$ é uma funçâo, $c: A \rightarrow \Re^{+}$. Chamaremos $s$ de vértice origem, $t$ de vértice destino e $c$ de função capacidade.

A menos de menção em contrário, no que segue, $G$ será um grafo com conjunto de vértices $V$ e conjunto de arestas A, ou seja, $G=(V, A)$. Além disso, $|V| \geq 2$ e $|A| \geq 1$.

Definição 1.2 : Um fluxo numa rede $(G, s, t, c)$ é uma função $f: A \rightarrow \Re$ tal que:

$$
\begin{gathered}
f(v, V)=f(V, v) \quad \forall v \in V-\{s, t\} \quad \text { e } \\
0 \leq f(v, w) \leq c(v, w), \quad \forall(v, w) \in A .
\end{gathered}
$$

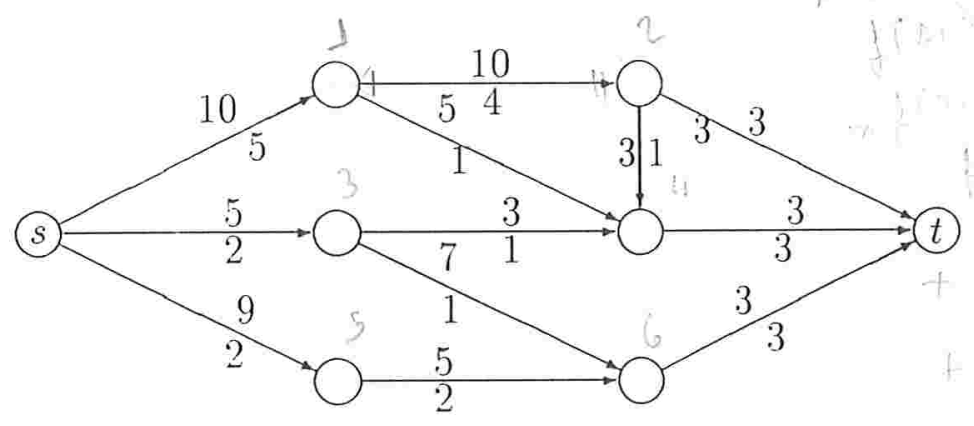

Figura 1.1 : Una rede (G.s.t,c) com um fluxo $f$. Em ca.da aresta o número acima (à esquerda) dela indica a sua capacidade e o número abaixo (à direita) dela indica o fluxo em tal aresta.

Definição 1.3 : Seja $R=(G, s, t, c)$ uma rede e $f$ um fluxo em $R$. O valor do fluxo $f$, denotado por valor $(f)$, é definido como:

$$
f(s, V)-f(V, s) . /
$$

Na rede da figura 1.1 temos que valor $(f)=9$.

Observação: É fácil ver que, em qualquer rede $(G, s, t, c)$ com fluxo $f$, vale a seguinte 
igualdade: $f(s, V)-f(V, s)=f(V, t)-f(t, V)$. Deixaremos esta demonstração a cargo do leitor.

Definição 1.4 : Um fluxo $f$ numa rede $R$ é chamado fluxo máximo se em $R$ não existe nenhum outro fluxo cujo valor é maior que valor $(f)$.

O fluxo indicado na rede da figura 1.1 é máximo. O leitor poderá se convencer disso a partir da observação acima, notando que $f(V, t)=c(V, t)$.

Denotaremos por PFM, o Problema do Fluxo Máximo, assim definido:

Dada uma rede $R=(G, s, t, c)$, determinar em $R$ um fluxo máximo.

Lema 1.1 : Em toda rede $R=(G, s, t, c)$, existe um fluxo máximo.

Prova: Para provar este lema, basta observar que o problema do fluxo máximo é um problema de programação linear. Tal problema é viável, pois $f=0$ é um fluxo e, além disso é um problema limitado (devido a restriçào imposta pela funçào capacidade).

Quem não tem familiaridade com programaçào linear, basta observar que cada fluxo pode ser visto como um ponto no espaço $\Re^{m}$, onde $m$ é o número de arestas do grafo $G$, e que o conjunto dos fluxos é um conjunto fechado e limitado do $\Re^{m}$. Como a funçào valor $(f)$ definida em tal conjunto é contínua, ela atinge o máximo em algum ponto do conjunto.

Como já mencionamos, a formulaçào original do problema do fluxo máximo, apresentada por Ford e Fulkerson [10] em 1956, difere da que apresentamos. A título de ilustração, faremos aqui esta outra descrição e provaremos que ambas as formulaçòes são equivalentes. Para isso, precisamos introduzir algumas definiçòes.

Definição 1.5 : Um caminho de fluxo numa rede $(G, s, t, c)$ é um par $(C ; k)$, onde $C$ é um caminho orientado de $s$ a $t$ e $k$ é um número não negativo.

Definição 1.6 : Um F-fluxo numa rede $(G, s, t, c)$ é uma coleção $F$ de caminhos de fluxo, $F=\left\{\left(C_{i} ; k_{i}\right): i=1, \ldots, p\right\}$, tal que:

$$
\forall(v \cdot w) \in A . \quad \sum_{i:(v \cdot w) \in C_{i}} k_{i} \leq c(v \cdot w) .
$$


Definição 1.7 : O valor de um F-fluxo $F, F=\left\{\left(C_{i} ; k_{i}\right): i=1, \ldots, p\right\}$, é definido como:

$$
\operatorname{val}(F)=\sum_{i=1}^{p} k_{i}
$$

Utilizando essas definições, podemos agora formular a versão original do problema do fluxo máximo, que será denotado por PFM':

Dada uma rede $R=(G, s, t, c)$, determinar em $R$ um F-fluxo de valor máximo.

Lema 1.2 : Os problemas $P F M$ e $P F M^{\prime}$ 'são equivalentes.

Prova: Seja $R=(G, s, t, c)$ uma rede. Dado um $F$-fluxo $F, F=\left\{\left(C_{i} ; k_{i}\right): i=1, \ldots, p\right\}$, em $R$, podemos construir um fluxo $f$ em $R \operatorname{com} \operatorname{valor}(f)=\operatorname{val}(F)$, da seguinte maneira:

$$
f(v, w)=\sum_{i:(v, w) \in C_{i}} k_{i} \quad \text { para } \operatorname{todo}(v, w) \in A .
$$

É fácil verificar que $f$ assim definido é um fluxo com valor $(f)=\operatorname{val}(F)$.

Precisamos mostrar agora que dado um fluxo $f$ em $R$, existe um $F$-fluxo $F$, tal que $\operatorname{val}(F)=\operatorname{valor}(f)$. Demonstraremos esta afirmaçào a.través do algoritmo FFluxo, que recebe como entrada um fluxo $f$ em $R$ e constrói um F-fluxo $F$, tal que $\operatorname{val}(F)=\operatorname{valor}(f)$.

algoritmo FFluxo (rede $(G, s, t, c)$; fluxo $f$ ):

caminho $C$;

F-fluxo $F$;

grafo $H$

$F=\emptyset$;

. $H=$ subgrafo de $G$ formado pelas arestas $a$ tais que $f(a)>0$;

.enquanto valor $(f)$ em $H$ é positivo faça

- procure, em $H$, um caminho orientado $C$ de $s$ a $t$;

$k=\min \{f(a) \mid a \in C\}$

$F=F \cup(C ; k)$;

- para toda aresta $a \in C$ faça

$$
f(a)=f(a)-k \text {; }
$$

- $H=$ subgrafo de $H$ formado pelas arestas $a$ tais que $f(a)>0$;

- $f=$ restrição de $f$ às arestas de $H$;

.retorne $F$; 
Precisamos mostrar que o algoritmo é correto. Primeiramente devemos notar que, em qualquer passo do algoritmo, $f$ é um fluxo em $H$, pois quando diminuímos o fluxo ao longo de um caminho orientado de $s$ a $t$, não desobedecemos as condições de fluxo. Além disso, se valor $(f)$ é não nulo, então existe um caminho de $s$ a $t$ ( isto segue da observação feita após a definição 1.3 ). Para finalizar, basta notar que, quando acrescentamos um caminho de fluxo $(C ; k)$, a $F$, o valor de $f$ é decrescido de $k$. Logo, no final do algoritmo $\operatorname{val}(F)=\operatorname{valor}(f)$. O processo é finito pois em cada passo do algoritmo o fluxo em pelo menos uma aresta é anulado.

No decorrer deste trabalho faremos uso das definiçôes 1.1 e 1.2 e nos referiremos somente ao PFM.

Denotaremos $|V|$ por $n$ e $|A|$ por $m$. Suporemos que $G$ é conexo. Sob estas hipóteses, podemos inferir que $n-1 \leq m \leq n^{2}-n / 2$ ( observe que a definição de grafo fornecida no apêndice não comporta arestas múltiplas e nem laços).

\subsection{O Algoritmo de Ford e Fulkerson}

Esta seção é dedicada à descriçào do algoritmo proposto por Ford e Fulkerson em 1956 (cf. [9]). Antes disso, veremos alguns resultados e algumas definições.

Definição 1.8 : Seja $R=(G, s, t, c)$ uma rede e $K$ um conjunto de arestas de $G$. Dizemos que $K$ é um corte em $R$, se existe $S \subset V \operatorname{com} s \in S$ e $t \in \bar{S}$, tal que

$$
K=\{(v, w) \in A \mid v \in S \text { e } w \in \bar{S}\} .
$$

Definição 1.9 : Seja $R=(G, s, t, c)$ uma rede e $K$ um corte em $R$. Definimos capacidade de $K, \operatorname{cap}(K)$, como sendo a soma das capacidades de suas arestas. Dizemos que $K$ é um corte mínimo se em $R$ nào existe outro corte cuja capacidade é menor que cap $(K)$.

Lema 1.3 : Seja $R=(G, s, t, c)$ uma rede, $S \subset V, s \in S . t \in \bar{S}$ e $f$ um fluxo em $R$. Entâo

$$
\text { valor }(f)=f(S, \bar{S})-f\left(\bar{S}, S^{\prime}\right)
$$

Prova: Pelas definiçôes 1.2 e 1.3 ,

$$
\operatorname{valor}(f)=f(s, V)-f(V, s) \text { e } f(v, V)=f(V, v) \quad \forall v \in V-\{s, t\} .
$$


Logo,

$$
\begin{aligned}
& \quad f(s, V)-f(V, s)=f(S, V)-f(V, S)=f(S, S \cup \bar{S})-f(S \cup \bar{S}, S)= \\
& =(f(S, S)+f(S, \bar{S}))-(f(S, S)+f(\bar{S}, S))=f(S, \bar{S})-f(\bar{S}, S) .
\end{aligned}
$$

Lema 1.4: Se $f$ é um fluxo e $K$ é um corte em uma rede, entào

$$
\operatorname{valor}(f) \leq \operatorname{cap}\left(K^{\prime}\right)
$$

Prova: Imediata, a partir do lema 1.3.

Definição 1.10 : Seja $R=(G, s, t, c)$ uma rede e $f$ um fluxo em $R$. Dizemos que um caminho $\mathcal{S}=\left(s=v_{0}, a_{1}, v_{1}, \ldots, a_{k}, v_{k}=t\right)$ em $G$, é um caminho $f$-aumentador em $R$, se para todo $i, \quad i=1, \ldots, k$, ou $a_{i}=\left(v_{i-1}, v_{i}\right)$ e $f\left(a_{i}\right)<c\left(a_{i}\right)$, ou $a_{i}=\left(v_{i}, v_{i-1}\right)$ e $f\left(a_{i}\right)>0$. Além disso, dizemos que uma aresta $a_{i}$ de $\mathcal{S}$ avança em $S$ se $a_{i}=\left(v_{i-1}, v_{i}\right)$; e recua, caso contrário. Às vezes dizemos simplesmente caminho aumentador, devendo ficar claro pelo contexto qual é o fluxo a que estamos nos referindo.

Lema 1.5 : Seja $R=\left(C_{i}, s, t, c\right)$ uma rede e $f$ um fluxo em $R$. Se em $R$ existe um caminho $f$-aumentador, entào existe um fluxo $f^{\prime}$ em $R$, tal que valor $\left(f^{\prime}\right)>\operatorname{valor}(f)$.

Prova: Seja $\mathcal{S}=\left(s=v_{0}, a_{1}, v_{1}, \ldots, a_{k}, v_{k}=t\right)$ um caminho $f$-aumentador e sejam $A_{1}=\{a \in A \mid a$ avança em $\mathcal{S}\}$ e $A_{2}=\{a \in A \mid a$ recua em $\mathcal{S}\}$,

$\epsilon_{1}=\min \left\{c(a)-f(a) \mid a \in A_{1}\right\}, \epsilon_{2}=\min \left\{f(a) \mid a \in A_{2}\right\}$ e $\epsilon=\min \left\{\epsilon_{1}, \epsilon_{2}\right\}$.

Seja $f^{\prime}: A \rightarrow \Re$ assim definido:

$$
f^{\prime}(a)= \begin{cases}f(a)+\epsilon & \text { se } a \in A_{1}, \\ f(a)-\epsilon & \text { se } a \in A_{2}, \\ f(a) & \text { caso contrário. }\end{cases}
$$

É fácil verificar que $f^{\prime}$ é um fluxo e valor $\left(f^{\prime}\right)=\operatorname{valor}(f)+\epsilon$. Como $\epsilon$ é positivo, o resultado segue.

Teorema 1.1: (Fluxo máximo-corte mínimo) Numa rede, o valor de um fluxo máximo é igual à capacidade de um corte mínimo. 
Prova: Seja $R=(G, s, t, c)$ uma rede. Pelo lema 1.4, é suficiente provarmos a existência em $R$ de um fluxo $f$ e um corte $K$ tal que valor $(f)=\operatorname{cap}(K)$.

Seja $f$ um fluxo máximo em $R$ ( tal fluxo existe pelo lema 1.1) e $S \subset V$ definido recursivamente, a partir de $f$, como segue:

(1) $s \in S$;

(2) se $(v, w) \in A, v \in S$ e $f(v, w)<c(v, w)$ então $w \in S$;

(3) se $(v, w) \in A, w \in S$ e $f(v, w)>0$ então $v \in S$.

Suponha por absurdo que $t \in S$. Então existe um caminho aumentador em $R$, e portanto, pelo lema 1.5, $f$ não é máximo. Logo, $t \notin S$. Neste caso, o conjunto $K=\{(v, w) \in A \mid v \in S$ e $w \in \bar{S}\}$ é um corte em $R$. Pelo lema 1.3, temos que valor $(f)=f(S, \bar{S})-f(\bar{S}, S)$. Pela definição de $S$, temos que $f(S, \bar{S})=\operatorname{cap}_{\infty}(K)$ e $f(\bar{S}, S)=$ 0 . Logo, valor $(f)=\operatorname{cap}(K)$.

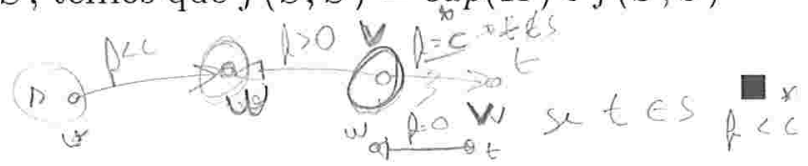

Corolário: Seja $f$ um fluxo numa rede $R$. Então $f$ é máximo se e somente se não existe caminho aumentador em $R$.

Prova: Segue do lema 1.5 e da demonstraçào do teorema 1.1.

O algoritmo de Ford e Fulkerson baseia-se fundamentalmente no conceito de caminho aumentador. Ele recebe como entrada uma rede com capacidades racionais e constrói um fluxo máximo (no final desta seção comentamos a razào de impormos tal restrição). A seguir temos a sua descrição:

algoritmo $F F$ (rede $(G, s, t, c)$ ):

fluxo $f$;

caminho $\mathcal{S}$;

$. f=0$;

repita

- procure um caminho aumentador $\mathcal{S}$;

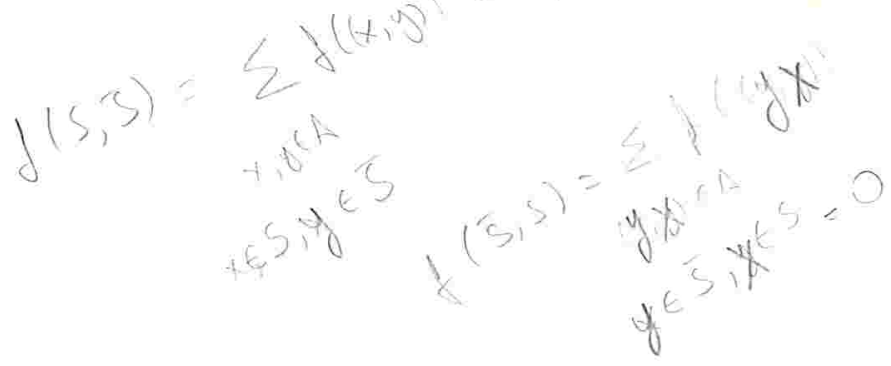

- se foi encontrado um caminho aumentador

então aumente o fluxo $f$ procedendo da maneira sugerida na prova do lema 1.5 ;

.até que não exista caminho aumentador;

.retorne $f$;

A procura do caminho aumentador é feita através de um processo de rotulação (sem um crtério de escolha bem determinado). O comando "aumente o fluxo $f$ procedendo da maneira sugerida na prova do lema 1.5" será chamado de aumentaçào. Uma iteração 
ou passo do algoritmo se refere à uma iteração do comando repita.

A verificação de que o algoritmo é correto, quando as capacidades são todas racionais, segue do corolário do teorema 1.1 .

Note que se o valor de um fluxo máximo é $M$ e as capacidades são todas inteiras, então este algoritmo termina no máximo em $M$ passos, pois o valor do fluxo aumenta de pelo menos uma unidade em cada passo. Podemos então concluir que, se as capacidades forem racionais, o algoritmo também encontra um fluxo máximo. No entanto, quando há capacidades irracionais o método que descrevemos pode convergir para um fluxo que não é um fluxo máximo. Um exemplo deste caso pode ser encontrado em [10].

\subsection{O Algoritmo de Edmonds e Karp}

Edmonds e Karp [7] foram os primeiros a desenvolver um algoritmo polinomial para o problema do fluxo máximo. Chamaremos de Eli o algoritmo desses autores.

A diferença fundamental entre o algoritmo de EK e o algoritmo de FF está na maneira de se procurar um caminho aumentador. No algoritmo EK esta procura é feita através de uma busca em largura. Fazendo a busca em largura, em cada iteraçào é encontrado um caminho aumentador de tamanho mínimo.

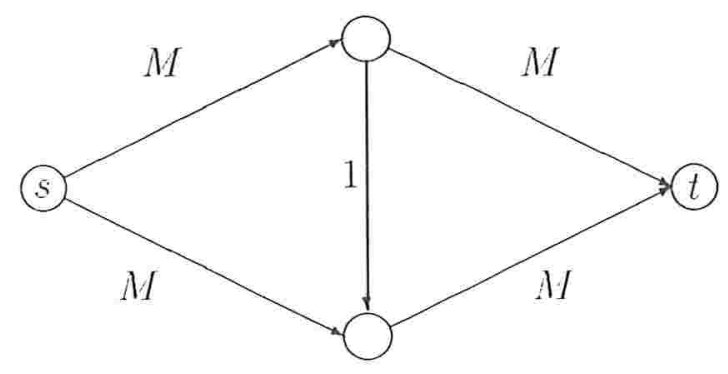

Figura 1.2 : Uma rede especial. As arestas têm capacidades $M$ e 1 , onde $M$ é um inteiro positivo. O algoritmo $F F$, quando aplicado a esta rede, pode realizar $2 M$ aumentaçòes, enquanto que o algoritmo Eli realizará apenas duas.

Faremos a demonstraçào da complexidade do algoritmo Eh, para introduzir os novos conceitos que surgiram com este algoritmo. 
Definição 1.11 : Seja $R=(G, s, t, c)$ uma rede e $f$ um fluxo em $R$. Definimos grafo residual $G_{f}$ como sendo o grafo $G_{f}=\left(V_{f}, A_{f}\right)$, onde:

$$
\begin{aligned}
& V_{f}=V \quad \mathrm{e} \\
& A_{f}=\{(v, w) \in A \mid f(v, w)<c(v, w)\} \quad \cup \quad\{(v, w) \in(V, V) \mid(w, v) \in A \text { e } f(w, v)>0\} .
\end{aligned}
$$

Definição 1.12 : Seja $R$ uma rede onde foi aplicado o algoritmo $E K, \mathcal{S}$ o caminho aumentador escolhido pelo algoritmo durante uma determinada iteraçào, e $f$ o fluxo após a aumentação. Dizemos que uma aresta $a$ de $\mathcal{S}$ se torna saturada nesta iteração se, ou $a$ avança em $\mathcal{S}$ e $f(a)=c(a)$, ou $a$ recua em $\mathcal{S}$ e $f(a)=0$.

Lema 1.6 : Durante a execução do algoritmo, a distância de $s$ a um vértice qualquer, nos correspondentes grafos residuais, nunca decresce.

Prova: Chamemos de $d(v)$ a distância de $s$ a $v$ no grafo residual correspondente a uma determinada iteração. Seja $V_{i}=\{v \in V \mid d(v)=i\}$. Assim, na iteração seguinte (após a. aumentação) o novo grafo residual só pode ganhar arestas $(v, w), \operatorname{com} v \in V_{k}$ e $w \in V_{k-1}$. Logo, a distância de $s$ a $v$ no novo grafo residual nào pode decrescer.

Lema 1.7 : Durante a execução do algoritmo EK, o número máximo de vezes que uma determinada aresta do grafo se torna saturada é $n$.

Prova: Seja $d_{k}(u)$ a distância de $s$ a $u$ no grafo residual da iteração $k$. Seja $(v, w)$ uma aresta qualquer do grafo $G$ que foi saturada na iteraçào $i$ do algoritmo. Suponha que $(v, w)$ avançava no caminho aumentador. Entào $d_{i}(w)=d_{i}(v)+1$. Para a aresta $(v, w)$ poder ser saturada novamente, digamos em uma iteraçào $p$, entào em alguma iteração $j, i<j \leq p$, ela deverá estar no caminho aumentador como uma aresta que recua; e portanto, $d_{j}(v)=d_{j}(w)+1$. Logo, pelo lema 1.6, $d_{p}(v) \geq d_{i}(v)+2$. Suponha agora que a aresta $(v, w)$ recuava no caminho aumentador da iteraçào $i$. Analogamente, podemos concluir que $d_{p}(w) \geq d_{i}(w)+2$. Como a distância de $s$ a qualquer vértice do grafo residual, em qualquer iteração, não é maior que $n$, o número máximo de saturaçòes da aresta $(v, w)$ durante a execução do algoritmo é $n$. 
Teorema 1.2 : O algoritmo $E K$ tem complexidade $O\left(n m^{2}\right)$.

Prova: Como em cada passo do algoritmo pelo menos uma aresta é saturada, pelo lema 1.7, no máximo $\mathrm{nm}$ passos precisam ser executados. Como cada passo necessita de $O(\mathrm{~m})$ tempo (busca em largura), o algoritmo requer, no pior caso, $O\left(\mathrm{~nm}^{2}\right)$ tempo.

Além deste algoritmo, Edmonds e Karp propuseram um outro algoritmo, que em cada passo escolhe um caminho aumentador que causa o maior aumento no valor do fluxo. Os autores provaram que se as capacidades das arestas forem inteiras este novo algoritmo fará $O\left(n^{2} \lg n+n^{2} \lg \bar{c}\right)$ aumentações, onde $\bar{c}$ é a média das capacidades de todas as arestas do grafo.

\subsection{O Algoritmo de Dinic}

Dinic [6], em 1970, desenvolveu, independentemente, um outro algoritmo polinomial para o problema do fluxo máximo. Chamaremos de Di o algoritmo de Dinic.

A diferença fundamental entre o algoritmo Eli e o algoritmo Dié o fato de que o algoritmo $D i$ tenta reaproveitar uma busca em largura executada, procurando não apenas um caminho, mas se possivel vários. Assim, quando é feita uma busca em largura e verifica-se que a distância de $s$ a $t$ é $k$, procura-se todos os caminhos aumentadores de tamanho $k$ antes de se fazer uma outra busca em largura.

O trabalho de Dinic evidenciou o seguinte subproblema:

Dada uma rede $R=(G, s, t, c)$, onde $G$ é um grafo formado por caminhos orientados de $s$ a $t$, de tamanho $k$, encontre um fluxo, para o qual não existe um caminho aumentador de tamanho menor ou igual a. $k$. 
Este problema é conhecido como o subproblema (ou fase) de Dinic. Dinic propôs um algoritmo de complexidade $O(m n)$ que resolve este subproblema. O algoritmo geral consiste de chamadas sucessivas deste 'subalgoritmo', até que não exista mais nenhum caminho aumentador de $s$ a $t$.

Definição 1.13 : Dada uma rede $R=(G, s, t, c)$ e um fluxo $f$, dizemos que o grafo formado pelos caminhos orientados mínimos de $s$ a $t$ em $G_{f}$, é o grafo induzido por $f$ em $G$. Este grafo será denotado por $G^{f}$.

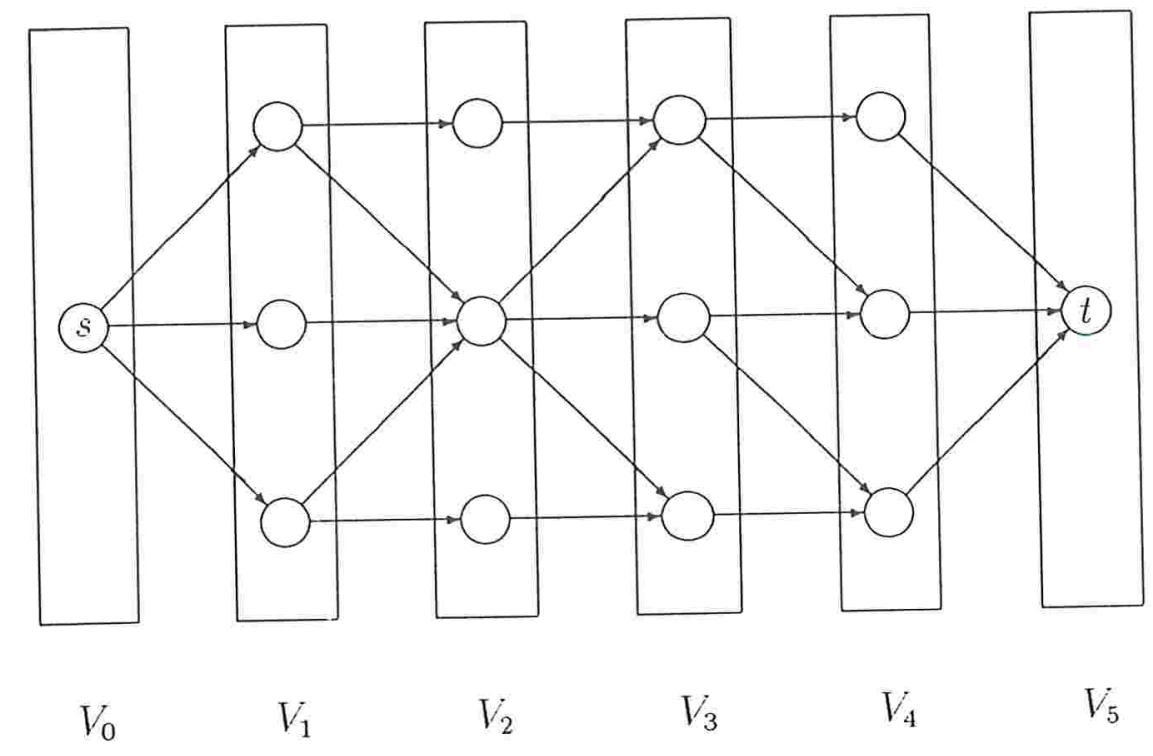

Figura 1.3 : Um grafo formado por caminhos de $s$ a $t$, de comprimento 5. Cada conjunto $V_{k}$ contém os vértices $v$ tais que a distância de $s$ a. $v$ é $k$.

O algoritmo faz uso de uma função, DSP, que resolve o subproblema de Dinic, e que será detalhada mais tarde. A seguir, temos o algoritmo de Dinic. 
algoritmo Di (rede $(G, s, t, c))$ :

fluxo $f$;

capacidade $c_{f}$;

vértice $v, w$;

$. f=0$;

repita

- compute $G^{f}$

para toda aresta $(v, w)$ em $G^{f}$ faça

se $(v, w)$ é uma aresta de $G$

então $c_{f}(v, w)=c(v, w)-f(v, w)$

senão $c_{f}(v, w)=f(w, v)$;

se $G^{f} \neq(\emptyset, \emptyset)$

então $f=f+D S P\left(G^{f}, c_{f}\right)$;

.até que $G^{f}=(\emptyset, \emptyset)$;

Para computar $G^{f}$, podemos fazer uma busca em largura a partir de $s$, até encontrar $t$, e uma outra de $t$ até $s$, pelos vértices já visitados. Este processo necessita $O(m)$ tempo.

Vejamos agora como implementar a funçào DSP. Para simplificar, daremos um atributo para cada vértice e outro para cada aresta. Assim, um vértice pode ser aberto ou fechado. Da mesma maneira, uma aresta pode ser aberta ou fechada. Uma aresta é considerada fechada, se ela está saturada ou está entrando em um vértice fechado; caso contrário, ela é considerada aberta. Um vértice é considerado fechado, se todas as arestas que saem dele estâo fechadas; um vértice que não é fechado é considerado aberto. Além disso, manteremos uma lista da arestas abertas que saem de um vértice. No início, todas as arestas e todos os vértices estào abertos. Chamaremos de $\alpha(v)$, a lista das arestas abertas que saem do vértice $v$, e de $\beta(v)$, a lista das arestas que entram no vértice $v$. Diremos que uma aresta (v, w) é fechada pelo algoritmo, se (v. w) é eliminada de $\alpha(v)$. Além disso, diremos que um vértice $v$ é fechado pelo algoritmo, se toda aresta $(w, v)$, entrando em $v$, é fechada pelo algoritmo.

O algoritmo procura caminhos de $s$ a $t$. formado por arestas abertas. Quando encontra um caminho, aumenta o fluxo $f$ a.o longo deste caminho e fecha todas as arestas saturadas deste caminho. Se todas as arestas que saem de um vértice $v$ estào fechadas $(\alpha(v)=\emptyset)$, então este vértice é fechado pelo algoritmo. O algoritmo proposto por Dinic, reaproveita o caminho de $s$ até o início da primeira aresta saturada, no entanto, isto não influencia na complexidade do algoritmo. Vejamos agora o algoritmo. 
função $D S P$ (grafo induzido $G$; capacidade $c$ ):

vértice $v, w, z, \bar{w}, \bar{z}$;

caminho $C$;

fluxo $f$;

.compute $\alpha(v)$ e $\beta(v)$ para todo $v \in V$;

$. f=0$;

$. v=s$

. $C=s$;

.enquanto $\alpha(s) \neq \emptyset$ faça

- enquanto $v \neq t$ e $\alpha(v) \neq \emptyset$ faça

- $\quad \operatorname{seja}(v, w) \in \alpha(v)$;

- acrescenta $w$ no caminho $C$;

$v=w$

. se $v \neq t$

então $C=C-v$;

para todo $(w, v) \in \beta(v)$ faça $/^{*}$ fecha $v * /$

elimine $(w, v)$ de $\alpha(w) ; / *$ fecha $(w, v) * /$

$v=$ último vértice de $C$

senão aumente o fluxo $f$ ao longo de $C$;

para toda aresta saturada $(w, z)$ de $C$ faça

elimine $(w, z)$ de $\alpha(w)$ :

seja $(\bar{w}, \bar{z})$ a aresta de $C$ mais próxima de s que foi saturada:

$v=\bar{w}$;

elimine de $C$ todos os vértices de $\bar{z}$ até $t$;

.retorne $f$;

Teorema 1.3: O tempo de execuçào da funçào DSP é $O(n m)$, no pior caso.

Prova: Denotemos por af o número de arestas fechadas durante a execuçào do algoritmo, $c a$ o número de aumentaçòes realizadas pelo algoritmo e $d(t)$ a distância de $s$ a $t$ em $G$. Então o tempo de execução do algoritmo DSP é, no pior caso, $O(a f+(c a d(t))$. Obviamente af $\leq m$ e $d(t) \leq n$. Cada caminho aumentador satura pelo menos uma aresta, $\operatorname{logo} c a \leq m$. Portanto, o tempo de execuçào da funçâo DSP é, no pior caso, $O(m+n m)$, ou seja, $O(m n)$.

Teorema 1.4 : O tempo de execuçào do algoritmo Di é, no pior caso, $O\left(n^{2} m\right)$.

Prova: Como cada fase do algoritmo de Dinic aumenta a distância de $s$ a $t$ de pelo menos um, o algoritmo termina após $n$ fases, no máximo. Logo, pelo teorema 1.3 segue o 
resultado.

Depois que surgiu o algoritmo de Dinic, vários outros algoritmos foram desenvolvidos, cada qual propondo uma nova versão mais eficiente para resolver o subproblema de Dinic. Note que no algoritmo $E K$, podemos identificar o subproblema, que é resolvido em $O(n m)$ tempo.

\subsection{O Algoritmo de Karzanov}

Em 1974, Karzanov propôs um novo algoritmo para resolver o subproblema de Dinic. Tal algoritmo necessita de $O\left(n^{2}\right)$ tempo. Assim, a complexidade do algoritmo de Karzanov é $O\left(n^{3}\right)$. Além do artigo original de Karzanov [15], pode-se encontrar a descriçâo de seu algoritmo no livro de Even [\$] ou no artigo de Galil [12]. Antes de descrevermos o algoritmo, faremos algumas definições.

Definição 1.14 : Seja $R=(G, s, t, c)$ uma rede. Uma funçào $f: A \rightarrow \Re$ é admissível em $R$ se $f(v, w) \leq c(v, w)$ para todo $(v, w) \in A$.

Definição 1.15 : Seja $R=(G, s, t, c)$ uma rede e $f$ uma função admissível em $R$. Um vértice $v$ é $f$-bloqueado se, para todo caminho orientado de $v$ a $t$ existe uma aresta $(v, w)$ tal que $f(v, w)=c(v, w)$.

Definição 1.16 : Seja $R=(G, s, t, c)$ uma rede e $f$ uma funçào admissível. O excesso de (fluxo em) um vértice $v \in V$, denotado por $e(v)$, é definido como

$$
e(v)=\sum_{(w, v) \in A} f(w, v)-\sum_{(v, w) \in A} f(v, w) .
$$

Dizemos que um vértice $v$ está balanceado se $\epsilon(v)=0$. 
Definição 1.17: Seja $R=(G, s, t, c)$ uma rede. Uma função $f: A \rightarrow \Re$ é um préfluxo se:

(1) $f$ é admissível,

(2) $s$ é $f$-bloqueado,

(3) $e(v) \geq 0$ para todo vértice $v$ em $V-\{s\}$ e

(4) para todo vértice $v$ tal que $e(v)>0, v$ é $f$-bloqueado.

O algoritmo principal faz uso de duas funçòes: Empurra e Balanceia.

A função Empurra, constrói um pré-fluxo $f^{\prime}$ a partir de uma função admissível $f$, tentando enviar a maior quantidade de fluxo possivel para $t$.

A função Balanceia, balanceia vértices bloqueados pelo pré-fluxo $f$, alterando $f$, até que $f$ deixe de ser um pré-fluxo.

Antes de descrever as funçòes Empurra e Balanceia, vamos descrever outras funçôes mais básicas. Para facilitar, chamaremos de $V_{i}$ à camada $i$, isto é, o conjunto dos vértices que estão à distância $i$ de $s$. As listas $\alpha(v)$ e $\beta(v)$ sào como definidas na seção anterior.

função EmpurraVértice ( vértice $v$; capacidade $c$; fluxo $f$ ):

vértice $w$;

booleano b;

real $\delta$;

$. b=$ falso;

.enquanto $\alpha(v) \neq \emptyset$ e $e(v)>0$ faça

. tome $(v, w) \in \alpha(v)$;

. $\delta=\min \{c(v, w)-f(v, w), e(v)\}$

. $f(v, w)=f(v, w)+\delta$

. $e(v)=e(v)-\delta$

. $e(w)=e(w)+\delta$;

- coloque $(v, \delta)$ na pilha Histórico $(w)$;

. se $c(v, w)=f(v, w)$

então elimine $(v, w)$ de $\alpha(v) ; / *$ fecha $(v, w) * /$

. $b=b$ ou $(w \neq t)$

retorne $b$; 
função EmpurraCamada (inteiro $i$; capacidade c ; fluxo $f$ ):

booleano b;

vértice $v$;

$. b=$ falso;

.para todo $v \in V_{i}$ faça

. $b=b$ ou EmpurraVértice $(v, c, f)$;

retorne $b$;

função BalanceiaVértice (vértice $v$; fluxo $f$ ):

real $\delta, x$;

booleano b;

vértice w;

$. b=$ verdadeiro;

.enquanto $e(v)>0$ faça

- retire $(w, \delta)$ da pilha Histórico( $v)$;

$x=\min \{\delta, e(v)\}$

. $f(w, v)=f(w, v)-x$

. $e(v)=e(v)-x$

$e(w)=e(w)+x$

$b=b$ e $(\alpha(w)=\emptyset)$;

para todo $(w, v) \in \beta(v)$ faça $/ *$ fecha $v^{*} /$;

elimine $(w, v)$ de $\alpha(w)$ :

retorne $b$;

função BalanceiaCamada ( inteiro i; fluxo f):

booleano b;

vértice v;

$. b=$ verdadeiro;

.para todo $v \in V_{i}$ tal que $\epsilon(v)>0$ faça

- $b=b$ e BalanceiaVértice $(v, f)$;

retorne $b$;

Com estas funções. podemos escrever o algoritmo de Kiarzanov, que chamaremos de KSP, da seguinte maneira: 


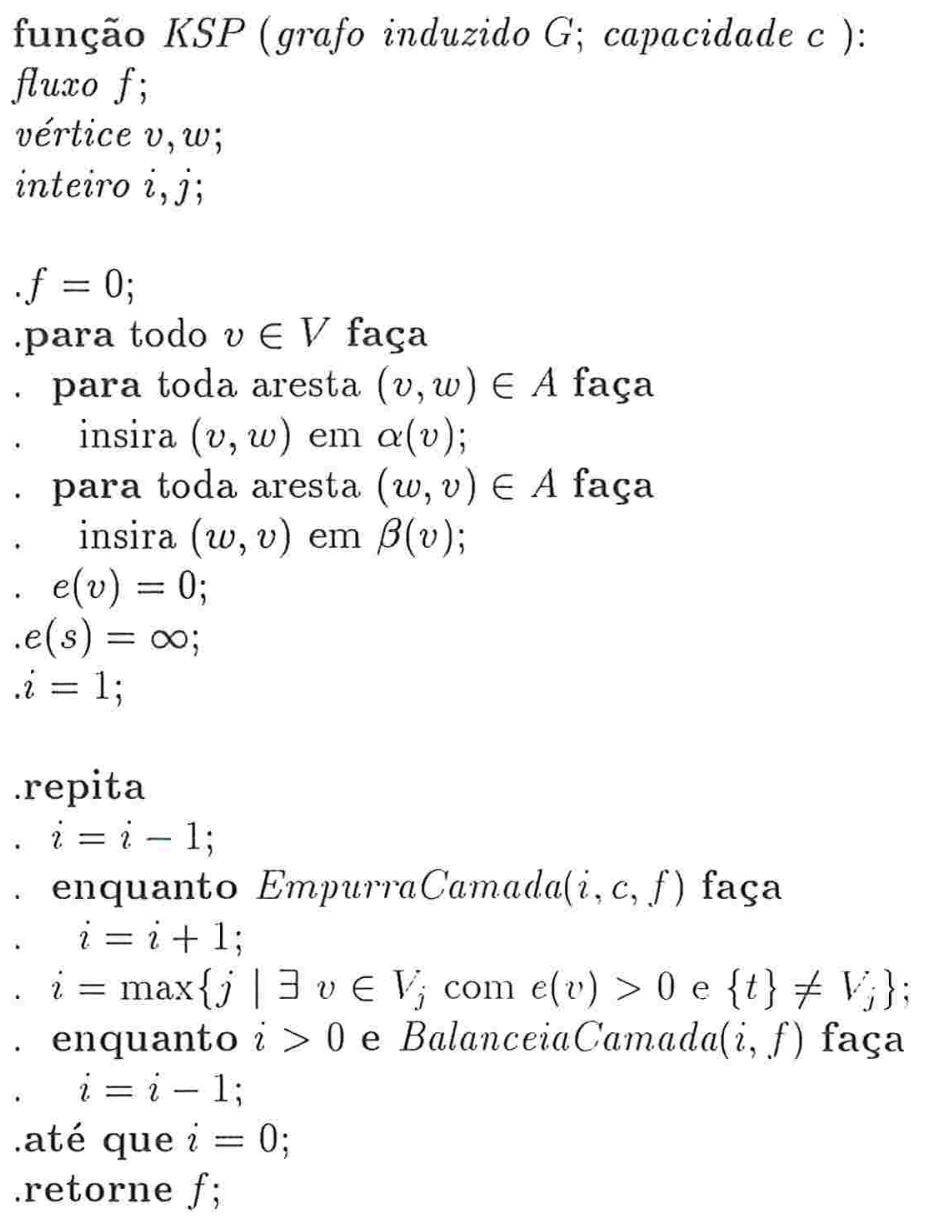

Lema 1.8 : As três afirmaçòes abaixo são verdadeiras:

1. Logo após uma seqüência de chamadas da função EmpurraCamada, f é um pré-fluxo.

2. Antes de cada execução da função BalanceiaCamada, f é um pré-fluxo.

3. Quando a funçào Balanceia Vértice $(v, f)$ é executada, $v$ está $f$-bloqueado.

Prova: Será feita por induçào. Na primeira seqüência de EmpurraCamadas, isto é verdade, pois um vértice somente fica com excesso positivo quando todas as arestas que saem dele estão saturadas. Logo, a base da indução é também verdadeira para as afirmações (2) e (3).

Suponha que a operaçào BalanceiaC $a$ mada( $i .$.$) . devolve verdadeiro. Seja v$ tal que $\alpha(v)=\emptyset$. Então $v$ está $f$-bloqueado pois as arestas eliminadas de $\alpha(v)$ ou estào saturadas ou foram eliminadas durante a execução de uma funçào BalanceiaCamada anterior. Se a. operação Balanceia Camada $(i,$.$) devolve verdadeiro, o fluxo foi alterado apenas nas arestas$ $(v, w)$ tais que $\alpha(v)=\emptyset$, e portanto, pela afirmaçào anterior, $v$ deve ser $f$-bloqueado. Logo, as afirmações (2) e (3) continuam valendo para a camada $i-1$. Entào, antes de 
uma seqüência de execuções da operação EmpurraCamada, as restrições de pré-fluxo valem para todos os vértice de $V$, com exceção de alguns vértices de $V_{i}$. Logo após executar esta seqüência de EmpurraCamadas, todo vértice $v$ com excesso positivo estará $f$-bloqueado, pois para toda aresta $(v, w)$ temos que, ou $(v, w)$ está saturada ou $w$ está $f$-bloqueado. Logo, $f$ é um pré-fluxo, e a afirmação (1) é verdadeira.

Lema 1.9 : A função BalanceiaVértice é chamada no máximo uma vez por vértice.

Prova: Quando a função BalanceiaVértice $(v,$.$) é chamada, todas as arestas (w, v) \in \beta(v)$ são fechadas. Logo, $v$ não receberá mais fluxo através da função EmpurraVértice e nem através da função BalanceiaCamada, pois esta funçào só devolve fluxo para quem cedeu. Logo, não ocorrerá outras chamadas da função Balanceia Vértice para o vértice $v$.

Lema 1.10 : A função EmpurraVértice é chamada no máximo $O\left(n^{2}\right)$ vezes durante a execução do algoritmo.

Prova: Pelo lema 1.9, o número máximo de seqüências de execuções da função BalanceiaCamada é $n$. Como numa seqüência de operações EmpurraCamada são executadas no máximo $n$ operações Empurra Vértice, durante a execução do algoritmo podem ser executadas no máximo $n^{2}$ operaçòes Empurra Vértice.

Teorema 1.5: A função KSP requer tempo $O\left(n^{2}\right)$.

Prova: O tempo gasto nas operaçòes Bulunccial'amadı é $O(m)$. O tempo gasto nas operações Empurra Vértice é $O(1)$ por vértice saturado mais $O(1)$ por execução da mesma, pois no máximo uma aresta não é saturada. Pelo lema 1.10 segue o teorema.

Tarjan [20], em 1983, propôs uma nova versão para o algoritmo de Karzanov. Esta nova versão resultou em um algoritmo que possui a mesma complexidade, mas que é muito mais simples, necessita de menos memória e segundo o autor é mais eficiente na. prática. 


\subsection{O Algoritmo de Cherkasky}

Cherkasky [4] refinou o algoritmo de Karzanov, obtendo um algoritmo melhor quando o grafo não é denso. Além do artigo original em russo, podemos encontrar maiores detalhes sobre este algoritmo no artigo de Galil [12].

A idéia de Cherkasky é agrupar as camadas em conjuntos disjuntos de camadas, que serão chamados super-camadas, e empurrar fluxo de uma super-camada para outra, usando um algoritmo semelhante ao subalgoritmo de Dinic.

Definição 1.18 : Uma super-camada $S C$ é um conjunto $S C=\left\{V_{p}, V_{p+1}, \ldots, V_{q}\right\}$ de camadas, onde $V_{p}$ e $V_{q}$ sâo respectivamente o início e o fim desta super-camada. As camadas que são fim de super-camadas são chamadas de camadas especiais. E mais, todo vértice de uma camada especial é um vértice especial.

As camadas $\left\{V_{0}, V_{1}, V_{2}, \ldots, V_{k}=\{t\}\right\}$ são particionadas em super-camadas $\left\{S C_{0}, S C_{1}, \ldots, S C_{l}\right\}$ de tal maneira que $S C_{0}=\left\{V_{0}\right\}$, o início de $S C_{i+1}$ e o fim de $S C_{i}$ são duas camadas consecutivas e $\{t\}$ é uma camada especial. Além disso,

$$
\left|S C_{i}\right| \leq x \quad \text { e } \quad \sum_{V_{q} \text { éspecial }}\left|V_{q}\right| \leq K^{\prime}
$$

onde $x$ e $K$ são dois parâmetros que serào escolhidos mais tarde.

O algoritmo faz uso de uma funçào Empurra Vértice, diferente da seçào anterior. Esta função recebe um vértice e tenta enviar seu excesso para um vértice de uma camada. do fim da sua super-camada. Ela faz isto da mesma maneira que a funçào DSP, definida na seção 1.4, faz para mauciar fluxo de s para t. Além disso, retornará 'verdadeiro', se conseguir enviar algum fluxo e a última camada nào for $\{t\}$. As funçòes EmpurraCamada e BalanceiaCamada são idênticas às cla seçào anterior. 


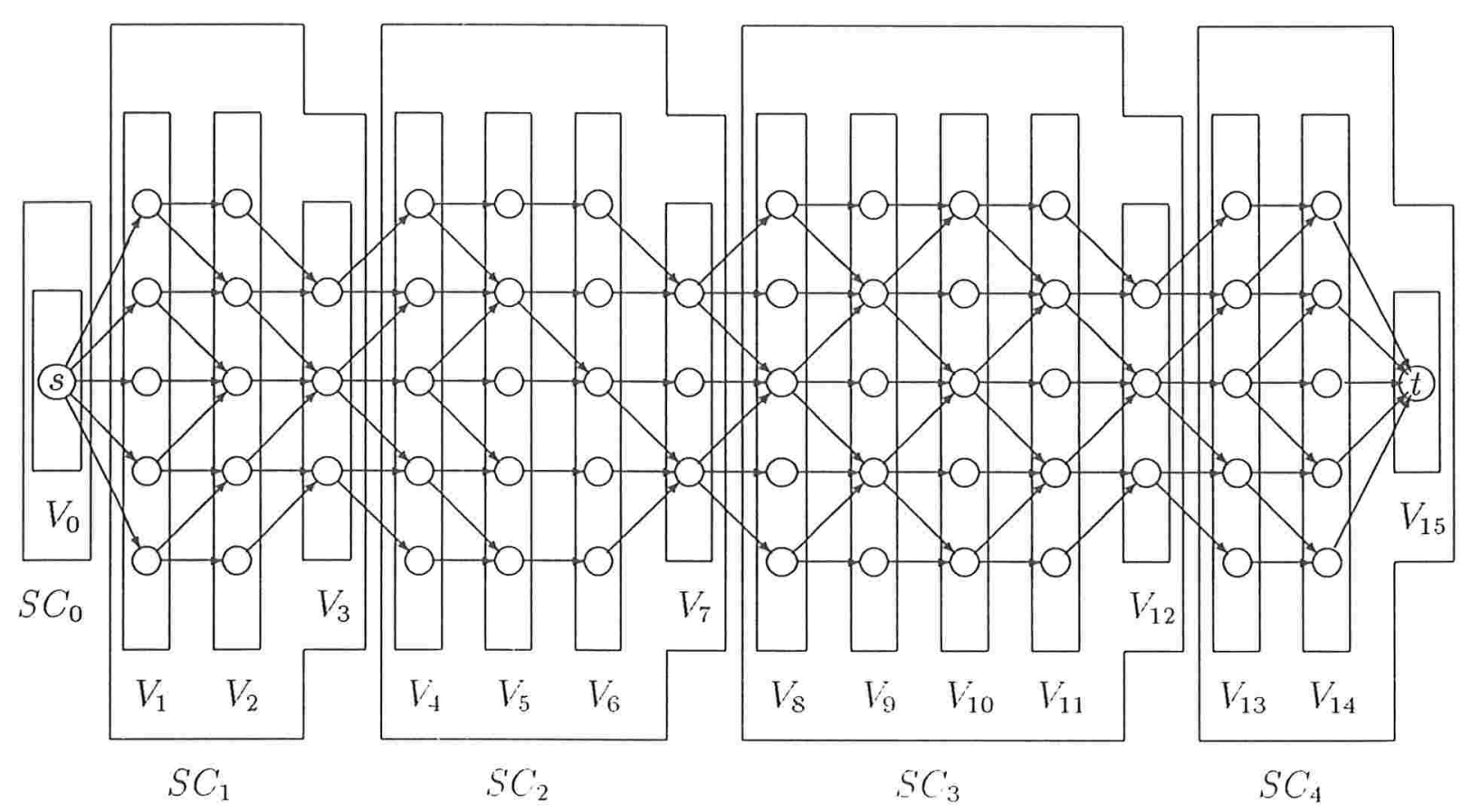

Figura 1.4 : Um grafo constituido por caminhos de $s$ a $t$. de comprimento 15 e particionado em super camadas.

A seguir, descreveremos as funções EmpurraSuperCamada e BalanceiaSuperCamada. Para facilitar, chamaremos de fim(i), o índice da camada que é fim da super-camada i. No exemplo da figura 1.4, fim(2)=7 e $f i m(4)=15$.

função EmpurraSuperCamada (inteiro i; capacidade c; fluxo $f$ ): .retorne EmpurraCamada(fim $(i-1), c, f)$;

função BalanceiaSuper Camada (inteiro i; capacidade c; fluxo $f$ ): booleano $b$;

inteiro $j$;

$. b=$ verdadeiro;

para $j$ de $f i m(i)$ até fim $(i-1)+1$ faça

- BalanceiaCamada $(j, f)$;

- $b=b$ e não (EmpurraCamada $(j-i, c, f)$ );

retorne $b$; 
O algoritmo principal é muito semelhante ao algoritmo de Karzanov.

função CSP (grafo induzido $G$; capacidade c ):

fluxo $f$;

vértice $v, w$;

inteiro $i, j$;

$. f=0$

.para todo $v \in V$ faça

- para toda aresta $(v, w) \in A$ faça

- $\quad$ insira $(v, w)$ em $\alpha(v)$;

- para toda aresta $(w, v) \in A$ faça

insira $(w, v)$ em $\beta(v)$;

$. e(s)=\infty$;

$i=0$;

.particione as camadas em super-camadas;

repita

- enquanto EmpurraSuperCamada(i,c,f) faça

- $i=i+1$;

. $i=\max \left\{j \mid \exists v \in V_{f i m(j)} \operatorname{com} e(v)>0\right\}$;

- enquanto $i>0$ e BalanceiaSuperCamada $(i, c, f)$ faça

. $\quad i=i-1$

. $i=i-1$

.até que $i=0$;

retorne $f$;

O modo de particionar as camadas, em conjuntos de super-camadas, será explicado no final desta seção.

$\mathrm{Na}$ verdade, as pilhas Histórico $(v)$ podem ser eliminadas, mas nào mostraremos como fazer isto. Esta reduçào é explicada no artigo de Galil [12].

Lema 1.11 : As três afirmaçòes abaixo sào verdadeiras:

1. Logo após uma seqüência de chamadas da funçào EmpurraSuperCamada, $f$ é um préfluxo;

2. antes de cada execuçào da funçào BalanceiaSuperCamada, f é um pré-fluxo;

3. quando a funçào Balanceia Vértice $(v, f)$ é executada. ve está $f$-bloqueado.

Prova: Análoga à prova do lema 1.8. 
Lema 1.12 : A função Balanceia Vértice é chamada no máximo uma vez para cada vértice especial.

Prova: Análoga à prova do lema 1.9.

Lema 1.13 : Durante a execução do algoritmo a funçào EmpurraVértice é chamada pela função EmpurraSuperCamada no máximo $K^{2}$ vezes.

Prova: Análoga à prova do lema 1.10.

Definição 1.19 : Chamamos de micro-fonte, um vértice que ficou com excesso positivo durante uma chamada da funçào Balanceia Vértice.

Observe que se uma micro-fonte ocorre na camada $i$, a funçào EmpurraCamada $(i, c, f)$ tentará empurrar seu excesso para a camada final da super-camada.

Definição 1.20 : Chamamos de redução de fluxo de uma aresta $(w, v)$, a operação de se reduzir o fluxo $f(w, v)$ pela funçâo BalanceiaVértice $(v, f)$.

Lema 1.14: O número máximo de ocorrência de micro-fontes é $O(m)$ e o número de reduções de fluxo é $O(x m$ ) .

Prova: Seja $\bar{A}$ o conjunto das arestas onde o fluxo foi reduzido durante a execução da função BalanceiaSuperCamada( $(,, .,$.$) e seja \bar{V}$ o conjunto dos vértices incidentes nestas arestas. Diremos que uma aresta $(v, w)$ é boa, se $(v, v) \in \bar{A}$ e ela está sendo reduzida pela primeira ou última vez; e ruim, caso contrário. Podemos inferir que o número de ocorrências de arestas boas é no máximo $2 \mathrm{~m}$. Para cada vértice $v \in \bar{V}$ escolheremos arbitrariamente uma aresta saindo de $v$ e diremos que esta aresta é especial. Para cada vértice $v$, diremos que $v$ possui um caminho especial, que é aquele formado pelas arestas especiais, até encontrar uma aresta boa. Pelo lema 1.12, toda aresta de $\bar{A}$ entre dois vértices das duas últimas camadas de uma super camada é uma aresta boa. De acordo com a definição, se dois caminhos especiais têm um vértice em comum, então um dos caminhos conterá o outro. Considere agora um caminho especial de um vértice que é micro-fonte e seja $(w, v)$ uma aresta deste caminho, que deve ser ruim. Logo, $v$ foi balanceado numa etapa anterior do algoritmo, e portanto, $v$ não pode ser uma microfonte. Então os caminhos especiais de micro-fontes sào disjuntos nos vértices. Logo, o número máximo de ocorrências de micro-fontes é $2 m$ (número de arestas boas). 
Por outro lado, o número de reduções de fluxo é igual ao número de arestas boas mais o número de arestas ruins. De acordo com a definição de caminhos especiais, podemos ter no máximo $x$ caminhos especiais para cada aresta boa. Logo, o número de reduções é $O(x m)$.

Teorema 1.6 : O tempo de execuçâo do algoritmo de Cherkasky é, no pior caso, $O\left(\left(K^{2}+m\right) x\right)$.

Prova: O tempo gasto para executar todas as operações EmpurraVértice é $O(1)$ por saturação de aresta mais $O(x)$ por execução da mesma. Pelos lemas 1.13 e 1.14, obtemos que $O\left(\left(K^{2}+m\right) x\right)$ é o tempo gasto para executar todas as operações EmpurraVértice. Ainda pelo lema 1.14, o tempo gasto em Balaceia Vértice é $O(x \mathrm{~m})$. Portanto, o tempo total gasto pelo algoritmo é $O\left(\left(K^{2}+m\right) x\right)$.

Vejamos agora como fazer a partição em super-camadas, supondo $x$ conhecido. A escolha das super-camadas será feita a partir da escolha das camadas especiais. Em primeiro lugar, faça $S C_{0}=\{s\}$. Divida as demais camadas em conjuntos de $\left\lfloor\frac{x}{2}\right\rfloor$ camadas. Para cada um destes conjuntos de camadas, escolha para camada especial, a camada com menor número de elementos (no último bloco escolha $t$, mesmo que ocorra empate). Tais camadas definem o fim de cada super-camada. Construa as super-camadas a partir das camadas especiais. Com esta escolha temos que:

$$
\left\lfloor\frac{x}{2}\right\rfloor \sum_{V_{j}}\left|V_{\text {e especial }}\right| \leq n+1 .
$$

Ou seja, $x K=O(n)$. Assim, se escolhermos $x=\left\lfloor\frac{n}{\sqrt{m}}\right\rfloor$, teremos $K=O(\sqrt{m})$ e a. complexidade do algoritmo de Cherkasky será $O(n \sqrt{m})$.

\subsection{O Algoritmo de Galil}

O algoritmo de Galil [12] é um refinamento do algoritmo de Cherkasky. A inovação está na construção de uma floresta em cada super-camada, procurando com isso diminuir o trabalho das funçôes EmpurraSuperCamada e BalanceiaSuperCamada. Estas florestas sâo construídas no início do algoritmo e alteradas dinamicamente durante a execuça do mesmo. 
Para cada super-camada $S C_{i}, i>0$, associamos uma floresta $F_{i}$. As folhas da floresta $F_{i}$ são vértices em $V_{f i m(i-1)}$ e as raízes são vértices em $V_{f i m(i)}$. Os vértices que possuem mais de uma aresta aberta entrando, bem como as folhas e as raízes, serão chamados junçôes e os demais vértices abertos serào chamados vértices pequenos. Uma aresta grande aresta, $(\hat{u}, \hat{v})$, corresponderá a um caminho de $\hat{u}$ até $\hat{v}$ de vértices pequenos, onde $\hat{u}$ e $\hat{v}$ são junçôes. Assim, uma floresta será uma floresta maximal, de arestas grandes. Veja figura 1.5. Chamaremos de arestas pequenas, as arestas do grafo.

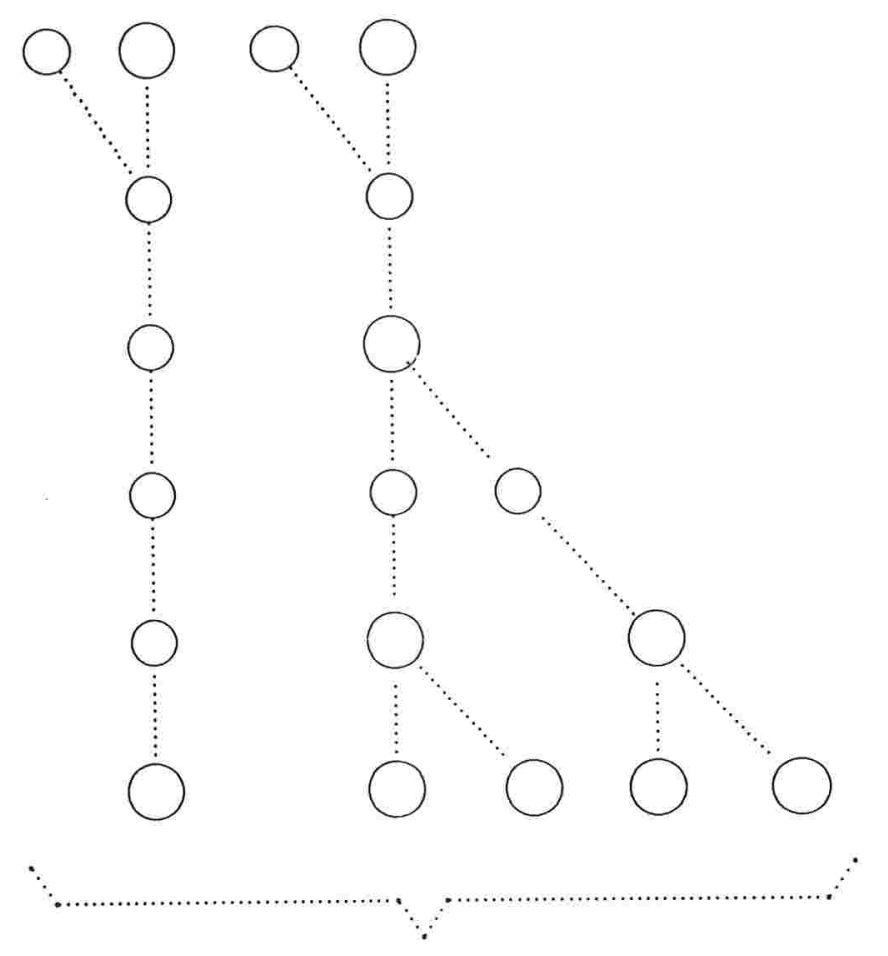

a) Arestas pequenas, junçôes e vértices pequenos

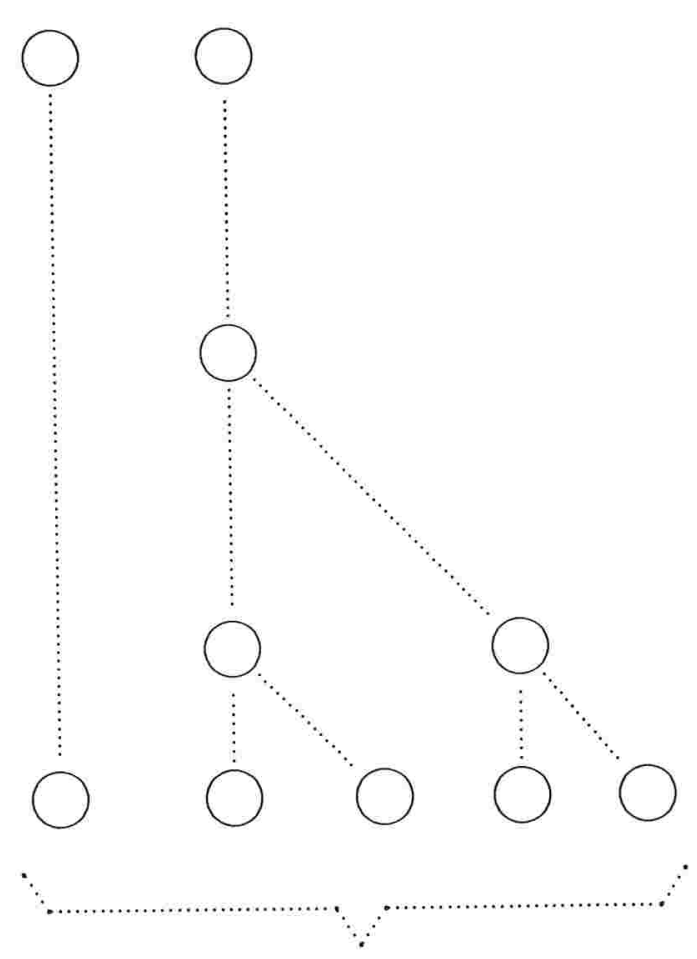

b) Arestas grandes e junções

Figura 1.5 : Uma floresta para uma super-camada. 
Cada aresta grande, $\hat{a}$, possui uma lista $L a(\hat{a})$ de suas arestas pequenas. Além disso, possui dois tipos de fluxo: FluxoAnterior e FluxoAtual. FluxoAtual corresponde ao fluxo adicionado na última chamada da função EmpurraCamada, e FluxoAnterior corresponde ao fluxo adicionado em outras chamadas. Cada aresta pequena, pode já possuir um fluxo. Se a é uma aresta pequena, em uma aresta grande $\hat{a}$, o fluxo total de $a$, Fluxo Total( $a$ ), pode ser computado como o fluxo corrente de $a$, somado ao FluxoAnterior $(\hat{a})$ e ao FluxoAtual $(\hat{a})$. Cada aresta grande $\hat{a}$, possui uma capacidade (residual) $c(\hat{a})$,

$$
c(\hat{a})=\min \{(c(a)-\text { FluroTotal }(a)) \mid a \in L a(\hat{a})\} .
$$

Cada junção $\hat{v}$, possui uma lista, $L v(\hat{v})$, das arestas grandes entrando em $\hat{v}$ e $\mathrm{o}$ valor do excesso de $\hat{v}, e(\hat{v})$.

As árvores são alteradas através das funções Remove e Reconecta. A função Remove elimina uma aresta grande. A função Reconect a tenta reconectar a junção que era início da aresta grande removida, ou a uma outra árvore, ou a um vértice da camada final da super-camada.

A função Remove $(\hat{a})$, calcula Fluxo Total( $a)$ de toda aresta $a$ em $L a(\hat{a})$, fechando as arestas saturadas. Além disso, a função Remove, elimina $\hat{a}=(\hat{w}, \hat{v})$ de $L v(\hat{v})$. Após esta eliminação, se obtivermos $|L v(\hat{v})|=1, \hat{v}$ não poderá continuar sendo uma junção. Neste caso, se $\hat{a}_{1}$ e $\hat{a}_{2}$ sào as duas arestas grandes entrando e saindo de $\hat{v}$ respectivamente, uma nova aresta $\tilde{a}$ deve ser criada em substituiçâo às arestas grandes $\hat{a}_{1}$ e $\hat{a}_{2}$. Para tanto, calcule Fluxo Total $(a)$, para toda aresta $a$ em $\hat{a}_{1}$ ou $\hat{a}_{2}$. Construa $L a(\tilde{a})$, concatenando $\hat{a}_{1}$ e $\hat{a}_{2}$. Faça $c(\tilde{a})=\min \left\{c\left(\hat{a}_{1}\right), c\left(\hat{a}_{2}\right)\right\}$, FluxoAnterior $=$ FluxoAtual $=0$ e coloque $\tilde{a}$ em $L v(\hat{z})$, onde $\hat{z}$ é a junção na qual $\hat{a}_{2}$ estava entrando. Assim, o tempo gasto para executar uma função Remove é $O(x)$.

Ao eliminar uma aresta grande saindo do vértice $\hat{v}$. é necessário reconectar $\hat{v}$, ou a um vértice da última camada da super-camada, ou a uma outra aresta grande (se possível). Para reconectar um vértice, percorre-se as arestas pequenas, procurando vértices de arestas grandes, vértices da última camada, ou vértices fechados; neste último caso, fecha-se todas as arestas entrando neste vértice e continua-se a busca a partir do vértice anterior. Eventuaimente Reconecta $(\hat{v})$ pode fallar. Neste caso, fecha-se $\hat{v}$, e $\hat{v}$ deixará de ser uma junção, mas isto será tratado pela funçào que chamou Reconecta $(\hat{v})$. Se Reconecta encontrar um vértice pequeno $w$ de uma aresta grande, este vértice passará a. ser uma junção, e outras arestas grandes devem ser criadas, num processo inverso à remoção de uma junção. Assim o tempo gasto em um Reconecta é $O(l+x)=O((l+1) x)$, onde $l$ é o número de arestas fechadas durante a execução da função. 
Agora podemos descrever a nova função EmpurraSuperCamada. Esta função é constituída de duas fases. Na primeira fase, é enviada a maior quantidade de fluxo possivel, através das arestas grandes, para os vértices da camada final da super-camada. Cada aresta grande que se torna saturada, é inserida numa pilha $P$ ( detalhes sobre $P$ serâo dados mais adiante). A segunda fase vai removendo as arestas de $P$. Cada aresta grande $\hat{a}=(\hat{v}, \hat{w})$ removida de $P$, é removida da floresta através da funçào Remove. Além disso, procura-se reconectar $\hat{v}$ através da função Reconecta. Em caso de $\hat{v}$ ser reconectado, tenta-se mandar seu fluxo, ou até a raiz da árvore reconectada, ou até encontrar uma aresta grande saturada. No caso de não ser possível reconectar $\hat{v}, \hat{v}$ é balanceado, e toda aresta grande de $L v(\hat{v})$ é colocada na pilha.

A pilha $P$ contém pilhas $P_{i}$ de arestas grandes saindo de $V_{i}$. As pilhas $P_{i}$ são listas duplamente ligadas. Além disso, $P_{j_{1}}$ é considerado próximo do topo de $P_{j_{2}}$, se $j_{1}>j_{2}$. Assim, para remover um elemento do topo de $P$ é necessário procurar $i$ tal que $i=\max \left\{j \mid P_{j} \neq \emptyset\right\}$, que gasta $O(x)$ tempo. Se ao inserirmos uma aresta em $P$, guardarmos a posição dela na pilha, podemos eliminar arestas do interior de $P$ em tempo constante.

Suponha que uma funçào Remove elimine uma junçào $\hat{v}$. Sejam $\left(\hat{w}_{1}, \hat{v}\right)$ e $\left(\hat{v}, \hat{w}_{2}\right)$, as arestas grandes entrando e saindo de $\hat{v}$, respectivamente. Se $\left(\hat{v}_{1}, \hat{v}\right)$ estava na pilha $\left(\left(\hat{v}, \hat{w}_{2}\right)\right.$ não poderia estar na pilha $)$ ela deverá ser eliminada da mesma e a nova aresta $\left(\hat{w}_{1}, \hat{w}_{2}\right)$ deverá ser inserida.

Suponha agora que a funçào Reconecta crie uma nova junçào $\hat{v}$ e duas novas arestas grandes $\left(\hat{w}_{1}, \hat{v}\right)$ e $\left(\hat{v}, \hat{w}_{2}\right)$. Se a aresta grancle $\left(\hat{w}_{1}, \hat{w}_{2}\right)$ estava na pilha, ela deverá ser eliminada da mesma, e pelo menos uma das duas arestas grandes criadas deve ser inserida na pilha. Cada nova aresta grande gerada deverá ser inserida na pilha, quando uma das suas arestas pequenas estiver saturada ou quando ela estiver saindo de um vértice fechado.

A seguir, temos a funçào EmpurraSuperCamada. 
função EmpurraSuperCamada (inteiro $i$; capacidade c; fluxo $f$; pilha $P$ ):

inteiro $j$;

booleano b;

junçấo $\hat{v}, \hat{w}, \tilde{v}, \tilde{w}, \hat{w}^{\prime}$;

grande aresta $\hat{a}, \tilde{a}$;

real $\delta$;

l* Fase I*/

.para $j=f i m(i-1)$ até $f i m(i)-1$ faça

- para cada junção $\hat{v} \in V_{j}$ faça

seja $\hat{a}=(\hat{v}, \hat{w})$ a aresta grande saindo de $\hat{v} ;$

FluxoAnterior $(\hat{a})=$ FluxoAnterior $(\hat{a})+\operatorname{FluxoAtual}(\hat{a})$;

$\delta=\min \{e(\hat{v}), c(\hat{a})\}$

$e(\hat{v})=e(\hat{v})-\delta$

$e(\hat{w})=e(\hat{w})+\delta$

$c(\hat{a})=c(\hat{a})-\delta ;$

FluxoAtual $(\hat{a})=\delta$;

se $c(\hat{a})=0$

então insira $\hat{a}$ em $P$;

/* Fase II */

.enquanto $P$ não está vazia faça

remova $\hat{a}=(\hat{v}, \hat{v})$ de $P$;

- Remove $(\hat{a})$

- se Reconecta $(\hat{v})$ e $e(\hat{v})>0$

então para toda aresta $\hat{a}=(\hat{v}, \tilde{w})$ no caminho de $\hat{v}$ a $\hat{w} \in V_{\text {fim(i) }}$,

ou $\left(\hat{w}, \hat{w}^{\prime}\right) \in P$ faça

$\delta=\min \{e(\tilde{v}), c(\tilde{a})\}$;

$e(\hat{v})=e(\hat{v})-\delta ;$

$e(\dot{w})=e(\hat{w})+\delta ;$

$c(\hat{a})=c(\hat{a})-\delta$

FluxoAtuall $(\hat{a})=$ FluxoAtuall $(\hat{a})+\delta$;

se $c(\hat{a})=0$

então insira $\hat{a}$ em $P$

senão se $\hat{v} \notin V_{\text {fim (i) }}$

então Balanceia.Junçầo $(\hat{v}, f)$;

para $\dot{a} \in L v(\hat{v})$ faça

insira à em $P$; 
Quando eliminamos uma junção, devemos balanceá-la, e podemos fazer isto facilmente, alterando a função Remove. A função BalanceiaJunção pode ser implementada de maneira semelhante à função BalanceiaVértice, e neste caso, a função

EmpurraSuperCamada deveria atualizar a pilha Histórico ou usar uma outra implementação que dispensa a pilha Histórico, mas omitiremos esta outra implementação, que pode ser encontrada no artigo de Galil [12].

Lema 1.15 : O tempo necessário para executar a função EmpurraSuperCamada $(i, ., .,$. é $O\left(K_{i}+x r\right)$, onde $K_{i}=\left|V_{f m(i-1)}\right|$ è $r$ é o número de arestas fechadas durante a execução desta função.

Prova: O tempo gasto na fase I é $O\left(K_{i}\right)$. O tempo gasto em uma função Reconecta é $O((l+1) x)$, onde $l$ é o número de arestas fechadas pelo Reconecta. Mas a função Remove, que é executada em tempo $O(x)$, fecha pelo menos uma aresta. O tempo gasto para balancear um vértice $\hat{v}$ é no máximo $|L v(\hat{v})|$, que é limitado pelo número de vezes em que acrescentamos fluxo nele; logo, este tempo nào precisa ser computado.

A função BalanceiaSuperCamada, descrita na seção anterior, necessitará de algumas modificaçôes. A funçào ao encontrar uma micro-fonte $v$, procurará um caminho por arestas pequenas até encontrar um vértice em $V_{\text {fim(i) }}$, um vértice fechado ou um vértice de uma grande aresta. Nos dois primeiros casos, a funçào procede de maneira idêntica à da secção anterior. No último caso, as arestas grandes serào percorridas, e seus fluxos transferidos para suas arestas pequenas. No caso de alguma aresta grande se tornar saturada, ela é inserida em $P$. Usando a pilha, após algumas aplicaçòes das funçòes Remove e Reconecta, que são feitas de maneira semelhante como foi feito na funçào EmpurraSuperCamada, a floresta estará recomposta.

O tempo de todas as execuçòes da funçào BalanceiaSuper Camada é $O(z+y x+l x)$, onde $z$ é o número de reduçòes de fluxo, $y$ é o número de ocorrências de micro-fontes e $l$ é o número de arestas fechadas durante a execuçào da funçào.

Como os lemas 1.13 e 1.14 continuam valendo, temos que o tempo total do algoritmo é $O\left(K^{2}+m x\right)$. Escolhendo agora $K=O\left((\mathrm{~mm})^{\frac{1}{2}}\right)$. temos que o tempo total do algoritmo é $O\left((n m)^{\frac{2}{3}}\right)$. 


\subsection{O Algoritmo de Malhotra, Kumar e Mahesh- wari}

Em 1978, Malhotra, Kumar e Maheshwari [16] propuseram um algoritmo para resolver o subproblema de Dinic, independente dos algoritmos de Karzanov, Cherkasky e Galil. O tempo necessário para executar este algoritmo é o mesmo obtido por Karzanov, porém o algoritmo é muito mais simples.

Definição 1.21 : Seja $R=(G, s, t, c)$ uma rede e $f$ um fluxo em $R$. Para cada vértice $v$, definimos fluxo potencial de $v, p_{f}(v)$, da seguinte maneira:

$$
\begin{aligned}
p_{f}(v)=\min \left\{\sum_{(v, w) \in A}(c(v, w)-f(v, w)), \sum_{(w, v) \in A}(c(w, v)-f(w, v))\right\} \quad(v \in V-\{s, t\}), \\
p_{f}(s)=\sum_{(s, w) \in A}(c(s, w)-f(s, w)) \\
p_{f}(t)=\sum_{(w, t) \in A}(c(w, t)-f(w, t)) .
\end{aligned}
$$

Lema 1.16: Seja $v$ um vértice tal que $p_{f}(v)=\min \left\{p_{f}(w) \mid w \in V\right\}$. Entào existe um fluxo $f^{\prime}$ tal que valor $\left(f^{\prime}\right)=\operatorname{valor}(f)+p_{f}(v)$.

Prova: Pela forma como foi definido $p_{f}(v)$, é fácil ver que podemos aumentar o fluxo nas arestas que estão entrando em (saindo de) v de modo que a soma destes aumentos sejam iguais a $p_{f}(v)$, sem desobedecermos as restriçòes de capacidade. Desta forma, se $v$ está na camada $V_{i}$, após ter incrementado $f$, os vértices que estào com excesso positivo estão em $V_{i+1}$, e aqueles com excesso negativo estâo $\mathrm{em} V_{i-1}$. Note que, para cada $j>i$, podemos balancear os vértices de $V_{j}$ com excesso positivo, passando seu excesso para camada $V_{j+1}$, desde que o excesso seja inferior ao seu potencial de fluxo. Mas isto sempre ocorre pelo modo como $v$ foi escolhido. Indutivamente, podemos ir balanceando os vértices de todas as camadas superiores a $V_{i}$ até chegar a $V_{k}=\{t\}$. De forma análoga, podemos ir balanceando todos os vértices com excesso negativo até chegar a $V_{0}=\{s\}$. Assim, após balancear todas as camadas obtemos um fluxo igual a valor $(f)+p_{f}(v)$. 
A demonstração do lema 1.16 sugere um algoritmo para o subproblema de Dinic.

função $M K M S P$ (grafo induzido $G$; capacidade c ):

fluxo $f$;

vértice $v, w$;

$. f=0$;

.enquanto $\nexists V_{i}=\emptyset$ faça

- selecione $v \in V$ tal que $p_{f}(v)=\min \left\{p_{f}(v) \mid v \in V\right\}$

- incremente $f$ da maneira sugerida na demonstração do lema 1.16;

- remova as arestas saturadas e os vértices que ficaram isolados;

- atualiza $p_{f}$ e remova todos os vértices $w \operatorname{com} p_{f}(w)=0$;

.retorne $f$;

Cada iteração da função $M K S P$ necessita de $O\left(n+m_{i}\right)$ tempo, onde $m_{i}$ é o número de arestas removidas na iteraçào $i$. Como sào necessárias no máximo $n$ iteraçòes o tempo total requerido pela função é $O\left(n^{2}+m\right)=O\left(n^{2}\right)$. Assim. o algoritmo de Malhotra, Kumar e Maheshwari para encontrar um fluxo máximo tem complexidade $O\left(n^{3}\right)$.

\subsection{O Algoritmo de Galil e Naamad}

Em 1980, Galil e Naamad [13] propuseram outro algoritmo para resolver o subproblema. de Dinic. Este algoritmo necessita $O\left(m \lg ^{2} n\right)$ tempo. O referido algoritmo é melhor que todos os anteriores para $m=O\left(n^{2-\epsilon}\right), \epsilon>0$ e $n$ suficientemente grande.

Este algoritmo é semelhante ao algoritmo de Dinic. A diferença fundamental está no fato de que todos os caminhos percorridos são armazenados em fragmentos de caminhos. Quando um caminho aumentador é encontrado, são eliminadas as arestas saturadas, e preservados os fragmentos restantes deste caminho. Se durante a procura de um caminho aumentador, esbarramos em um fragmento de caminho, este será aproveitado melhorando o tempo de procura dos caminhos aumentadores. A seguir, descrevemos o algoritmo. 
função GNSP (grafo induzido $G$; capacidade c):

caminho $C, C^{\prime}$;

vértice $v$;

aresta $a$;

fluxo $f$;

$. v=s$

$. C=\emptyset$

$. f=0$;

.enquanto $\alpha(s) \neq \emptyset$ faça

. se $\alpha(v)=\emptyset$

então seja $a$ a última aresta deste caminho;

$v=$ início de $a$;

elimine $a$ de $\alpha(v)$;

elimine $a$ de $C$

senão se $v$ não está em nenhum caminho

então seja $a$ a próxima aresta de $\alpha(v)$;

$$
C^{\prime}=a
$$

senão divida o caminho de $v$ na aresta entrando em $v$;

$C^{\prime}=$ segunda metade do caminho;

$C=C$ concatenado com $C^{\prime}$ :

$v=$ fim de $C^{\prime}$;

se $v=t$

então aumente o fluxo $f$ através de $C$;

divida $C$ nas arestas saturadas, fechando-as;

$v=$ início da aresta saturada mais próxima de $s$;

retorne $f$;

Daremos agora detalhes da estrutura de dados. Em primeiro lugar, os caminhos serão representados por (2-3) árvores balanceadas e ordenadas. As folhas das árvores armazenarão as arestas. Cada nó interno, $x$, de uma árvore, representa o caminho, Cam $(x)$, das arestas associadas às suas folhas, na ordem das mesmas. Cada nó interno $x$ tem um fluxo $f(x)$, bem como uma capacidade $c(x)$, associados a.o seu caminho. Assim, o fluxo de cada aresta a, Fluxo Totall $(a)$, será a somatória de $f(x)$, para todo $x$. ancestral de $a$. Além disso,

$$
c(x)=\min _{a \in \operatorname{Cam}(x)}\{(c(a)-\text { FluxoTotal }(a)\} .
$$

Em um nó $x$, podemos, eventualmente, transferir seu fluxo para seus filhos, através dos seguintes comandos: 
.para todo $x_{i}$, filho de $x$, faça

- $f\left(x_{i}\right)=f\left(x_{i}\right)+f(x)$;

. $c\left(x_{i}\right)=c\left(x_{i}\right)-f(x)$

$f(x)=0$;

Esta transferência de fluxo é usada para concatenar caminhos. Porém, omitiremos maiores detalhes.

O aumento do fluxo, nos caminhos aumentadores, pode ser feita com os seguintes comandos:

$f(r)=f(r)+c(r)$

$. c(r)=0$

Após aumentar o fluxo. temos que localizar as arestas saturadas e eliminá-las.

Cada operação de concatenaçào ou divisão de caminho pode ser realizada em tempo $O(\lg n)$. O tempo total gasto em eliminaçòes de arestas é $O(m \lg n)$. O número de concatenações é no máximo $O(m \lg n)$. Galil e Naamad, demonstraram a última afirmaçào através de um lema combinatorial (cf. [13]). Este tratamento dado aos caminhos é essencialmente a utilização das árvores dinâmicas, com árvores balanceadas, que veremos no capítulo 3. Neste capítulo, poderemos ver outra demonstração deste fato no teorema 3.2 .

\subsection{O Algoritmo de Sleator e Tarjan}

O algoritmo de Sleator e Tarjan [18] é essencialmente o algoritmo de GNSP. A diferença está na utilização de árvores enviesadas, ao invés de árvores balanceadas. Esta modificação fornece um algoritmo de complexidade $O(m \lg n)$ para cada fase de Dinic.

Na descriçào do algoritmo, usaremos as funçòes sobre árvores dinâmicas: raiz, enxerta, poda, atualiza, customin, custo e pai, que estào definidas no capítulo 3.

O algoritmo armazena várias árvores, que correspondem aos caminhos percorridos. O custo (necessário para a utilizaçào das árvores dinâmicas) de cada aresta é a capacidade residual da mesma. No início, cada árvore é um vértices isolado do grafo.

Vejamos a seguir, uma descrição do algoritmo. 
função STSP (grafo induzido $G$; capacidade c ):

vértice $v, w$;

fluxo $f$;

$. v=s$

.enquanto $\alpha(s) \neq \emptyset$ faça

. se $v \neq t$

então se $\exists(v, w) \in \alpha(v)$

então $\operatorname{enxerta}(v, w$, capacidade residual $(v, w))$;

$v=\operatorname{raiz}(v)$

senão para toda aresta $(w, v) \in \beta(v)$ faça

se $(w, v) \in$ alguma árvore

então $\operatorname{poda}(w)$

elimine $(w, v)$ de $\alpha(w)$

senão atualiza(s,custo( customin(s)));

enquanto customin $(s)=0$ faça

elimine $(v, p a i(v))$ de $\alpha(v)$;

$\operatorname{poda}(v)$

.calcule $f$ através das capacidades residuais:

retorne $f$;

Este algoritmo executa $O(m)$ operações sobre árvores dinâmicas. E como veremos no capítulo 3, todas estas operaçôes podem ser executadas em tempo $O(m \lg n)$.

\subsection{O algoritmo de Shiloach e Vishkin}

Em 1982, Shiloach e Vishkin [17] apresentaram um novo algoritmo paralelo para o subproblema de Dinic. A implementaçào seqüencial deste algoritmo necessita de tempo $O\left(n^{3}\right)$.

O algoritmo usa as operações Empurra Vértice e Balanceia Vértice, definidas para o algoritmo de Karzanov. No entanto, a ordem de execução destas operações é diferente. O algoritmo utiliza uma fila $F$, onde são armazenados todos os vértices com excesso positivo.

A seguir, damos a descriçào do algoritmo: 
função SVSP (grafo induzido G; capacidade c ):

fluxo $f$;

vértice $v$;

fila F;

$f=0$;

$. e(s)=\sum_{(s, v) \in A} c(s, v)$;

.EmpurraVértice $(s, c, f)$;

armazene os vértices não balanceados em $F$;

.enquanto $F \neq \emptyset$ faça

- remova $v$ de $F$;

- EmpurraVértice $(v, c, f)$ :

- BalanceiaVértice $(v, f)$;

- armazene os vértices nào balanceados em $F$;

retorne $f$;

Faremos uma demonstraçào da complexidade deste algoritmo, diferente da demonstração encontrada no artigo original [17], por julgarmos mais simples. Antes vejamos uma definição.

Definição 1.22 : Seja v um vértice que foi balanceado na iteraçào $i$. Definiremos. indutivamente, o conjunto dos vértices que receberam fluxo de $v$ da seguinte maneira: $R_{0}(v)$ é o conjunto dos vértices que receberam fluxo de $v$ durante a execuçào da função BalanceiaCamada $(v, f)$ e, $R_{j+1}(v)$ sào os vértices que receberam fluxo através da função EmpurraVértice, aplicada aos vértices de $R_{j}(v)$. Além disso, definimos $R_{0}(s)$ como sendo o conjunto dos vértices $v$ tal que $(s, v) \in A$.

Lema 1.17 : Quando a operaçào Balanceia Vértice é aplicada a um vértice com excesso positivo, o excesso deste vértice nào tornará mais positivo.

Prova: Análoga à demonstraçào do lema 1.9.

Lema 1.18 : Toda vez que um vértice $v$ fica com excesso positivo, deve existir $w$ tal que $v \in R_{j}(w)$ para algum $j$. inteiro, maior ou igual a zero.

Prova: A demonstração será feita por inclução no número de execuçòes da funçào EmpurraVértice. A primeira vez que a operação EmpurraVértice é executada, os vértices inseridos em $F$ pertenceun a $R_{0}(s)$. Um vértice pode ficar com excesso positivo, durante a execução da operaçào BalanceiaVértice $(w,$.$) ou durante a execução da função$ 
EmpurraVértice $(w, .,$.$) . No primeiro caso, v \in R_{0}(w)$. No segundo caso, por indução, $w \in R_{j}(z)$, com $j$ inteiro maior que zero. Logo, $v \in R_{j+1}(z)$.

Lema 1.19 : A função EmpurraCamada é chamada no máximo $n^{2}$ vezes durante toda a execução do algoritmo.

Prova: Pelo lema 1.18, um vértice pode entrar na fila no máximo $n$ vezes. Logo, a função EmpurraCamada é chamada no máximo $n^{2}$ vezes durante toda a execução do algoritmo.

Teorema 1.7 : Cada chamada da funçào SVSP requer tempo $O\left(n^{2}\right)$.

Prova: Como na função KSP, o tempo na execuçào de todas operações EmpurraCamada é $O(1)$ por execução da operação EmpurraVértice mais $O(1)$ por aresta saturada. Pelo lema 1.19 , o resultado segue.

\subsection{O Algoritmo de Gabow}

Em 1983, Gabow [11] propôs um novo algoritmo, de 'scaling', para o problema do fluxo máximo. Ele usa o algoritmo de Dinic, como uma função interna e usa o conceito de fluxo quase ótimo que veremos a seguir.

Definição 1.23 : Seja $R=(G, s, t, c)$ uma recle e fl um fluxo em $R$. Dizemos que $f$ é um fluxo quase ótimo, se a diferença entre o valor de um fluxo maximo e o valor de $f$ é no máximo $m$.

Teorema 1.8: Seja $R=(G, s, t, c)$ uma rede onde as capacidades são inteiras. Se fornecermos um fluxo, quase ótimo $f$, como fluxo inicial para o algoritmo de $D i$, entào o algoritmo Di será executado em tempo $O(\mathrm{~nm})$.

Prova: Cada fase do algoritmo de Dinic, necessita de $O(m+a n)$, onde a é o número de aumentações. Como as capacidades sào todas inteiras, a cada aumentaçào o valor de $f$ aumenta de pelo menos uma unidade. Logo, o algoritmo Di fará no máximo m 
aumentações. Somando o tempo de todas as fases, o resultado segue.

Abaixo, segue a descrição do algoritmo proposto por Gabow. Este algoritmo utiliza a função FluxoMáximoDinic, que é o algoritmo de Dinic modificado. Esta função recebe o fluxo inicial como parâmetro, além dos parâmetros já definidos, e retorna um fluxo máximo.

função FluxoMáximoGabow (grafo induzido G; capacidade c ):

.se $\max _{a \in A}\{c(a)\} \leq \frac{m}{n}$

. então retorne FluxoMáximoDinic $((G, s, t, c), 0)$

- senão retorne FluxoMáximoDinic $\left((G, s, t, c), 2\right.$. FluxoMáximoGabow $\left.\left(G, s, t,\left\lfloor\frac{c}{2}\right\rfloor\right)\right)$;

Teorema 1.9: $\mathrm{O}$ algoritmo de Gabow tem complexidade $O(n m \lg C)$, onde $C$ é o máximo valor das capacidades.

Prova: A prova é feita por induçào em $\lg C$. Assumimos como hipótese de induçào o fato de que quando a funçào FluxoMáximoDinic é executada. o fluxo inicial é um fluxo quase ótimo e o algoritmo é correto. A base, $C \leq \frac{m}{n}$, segue diretamente do teorema 1.8. Em qualquer passo do algoritmo, por indução, FluxoMáximoGabow acha corretamente um fluxo máximo $f$ no grafo $G$ com $\left\lfloor\frac{C}{2}\right\rfloor$. Pelo teorema do fluxo-máximo, podemos inferir que o valor de $2 f$ é pelo menos a capacidade de um corte mínimo menos $m$ e portanto, $2 f$ é um fluxo quase ótimo e a função FluxoMáximoDinic será executada em $O(\mathrm{~nm})$ tempo. Como o algoritmo tem no máximo $\lg C$ chamadas recursivas, o resultado segue. 


\section{Capítulo 2}

\section{ÁRVORES ENVIESADAS}

Neste capítulo estudaremos um tipo de estrutura de dados, as chamadas árvores enviesadas que, além de serem interessantes por si só, para este trabalho sâo necessárias para a compreensão e uma análise completa da complexidade do algoritmo de Goldberg e Tarjan que será tratado no capítulo 4. Descreveremos tais estruturas de dados (cf. [3]), introduzindo o conceito de tempo amortizado e faremos a análise da complexidade amortizada de vários algoritmos.

Estamos interessados em uma estrutura de dados que facilita a realização de operações com conjuntos. Suporemos que os elementos destes conjuntos pertencem a um conjunto universo $U$ de itens totalmente ordenado. Queremos representar estes conjuntos de tal maneira que as seguintes operaçôes sejam efetuadas eficientemente:

- acesse(item i,conjunto $\left.S^{\prime}\right)$ : se o item $i$ pertence a conjunto $S$, retorna um ponteiro para o item $i$; caso contrário, retorna um ponteiro especial nulo.

- insira(item i, conjunto $S)$ : insere o item $i$ no conjunto S. É suposto que $i \notin S$.

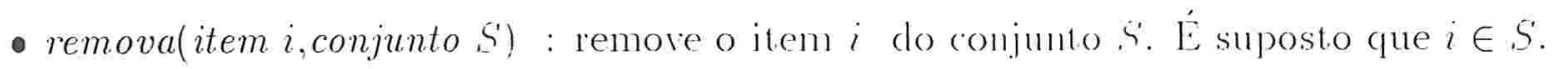

- una(conjunto $S$, conjunto $R$ ) : (una duplo) retorna o conjunto $S \cup R$ destruindo os conjuntos $R$ e $S$. É suposto que cada item de $S$ é menor que cada item de $R$.

- una(conjunto S, item i, conjunto $R$ ) : (una triplo) retorna o conjunto $S \cup\{i\} \cup R$ destruindo os conjuntos $R$ e $S$. É suposto que cada item de $S$ é menor que $i$, e cada item de $R$ é maior que $i$. 
- reparta $(S$, item i) : reparte o conjunto $S$ em três conjuntos: $P, Q$ e $R$; sendo $P$ o conjunto dos itens de $S$ menores que $i, R$ o conjunto dos itens de $S$ maiores que $i$ e $Q$ o conjunto contendo precisamente $i$, se $i \in S$, ou vazio, se $i \notin S$.

Um tipo de estrutura de dados apropriado para representar e realizar operaçóes com conjuntos ordenados é a chamada árvore de busca. Uma árvore de busca é uma árvore ordenada que contém os itens de um conjunto ordenado armazenados nas folhas e ordenados da esquerda para direita, cada folha contendo exatamente um item. As árvores de busca cujos nós possuem entre 2 e $b$ filhos, onde $b$ é um número inteiro fixo major que 2 , serão chamadas $(2, b)$-árvores.

Suporemos que cada item $i$ possui um peso conhecido $p_{i}$ que representa a freqüência com que o item $i$ é acessado. Queremos construir árvores de tal maneira que os itens mais acessados estejam mais próximos da raiz do que os itens menos acessados. Definimos tempo médio de acesso, $T_{m}$, de uma árvore de busca (de um conjunto $S$ ) como sendo:

$$
T_{m}=\sum_{i \in S} p_{i} \frac{d_{i}+1}{P}
$$

onde $d_{i}$ é a profundidade do item $i$ e $P=\sum_{i \in S} p_{i}$.

Nosso objetivo é manter o tempo médio de acesso o menor possível, sem perder com isso rapidez nas atualizaçôes da árvore. Este é o chamado problema do dicionário enviesado. Veremos aqui dois tipos de árvores de busca. chamadas localmente enviesadas e globalmente enviesadas, para resolver este problema.

Dentre os vários resultados relacionados com o problema do dicionário enviesado, o seguinte teorema [1] é um dos mais importantes. Ele oferece uma cota inferior para o tempo médio de acesso de uma árvore de busca.

Teorema: Considere uma árvore de busca para um conjunto $S$ onde cada nó possui no máximo $b$ filhos. Então:

$$
T_{m}-1=\sum_{i \in S} \frac{p_{i} d_{i}}{P} \geq \sum_{i \in S}\left(\left(\frac{p_{i}}{P}\right) \lg _{b}\left(\frac{P}{p_{i}}\right)\right)
$$


Assim, se obtivermos árvores de busca tais que $d_{i}=O\left(\lg \left(\frac{P}{p_{i}}\right)\right)$, para cada item $i$, estas árvores terão um tempo médio de acesso da mesma ordem do menor tempo médio de acesso possível. Diremos que tais árvores têm tempo ideal de acesso e chamaremos $O\left(\lg \left(\frac{P}{p_{i}}\right)\right)$ de tempo ideal de acesso do item $i$. Note que se todos os $n$ itens têm o mesmo peso, então o tempo ideal de acesso de cada item é $O(\lg n)$. Neste caso, qualquer árvore de busca balanceada tem tempo ideal de acesso.

Estamos interessados em encontrar árvores com tempo ideal de acesso, nas quais as demais operações, insira, remova, una e reparta sejam realizadas com tempo da mesma. ordem do tempo ideal de acesso.

Em muitos algoritmos, determinadas estrutura de dados são utilizadas para se fazer uma seqüência de operações e não apenas uma única operação. Não raro, na análise da complexidade de tais algoritmos, nós estamos interessados no tempo total gasto pela seqüência de operações, e nâo no tempo de cada uma das operações individuais.

Numa análise de pior caso, na qual os piores tempos de cada uma das operações individuais são somados, nós podemos estar sendo bastante pessimistas, porque estamos ignorando os efeitos co-relacionados das operaçòes na estrutura de dados. Em tal situação, se fizermos uma análise de complexidade amortizada (usando conceito de tempo amortizado) poderemos obter uma resposta mais realista. Neste caso, o tempo médio por operaçầo é calculado sobre uma seqüência de operaçôs (de pior caso).

Para tornar a análise mais concreta, usamos o conceito de crédito. Um crédito representa uma unidade de tempo de computaçào, ou seja, um crédito permite realizar $O$ (1) passos computacionais. Para cada operação nós alocamos um certo número de créditos, definido como sendo o tempo amortizado da operaçào. O nosso objetivo é realizar uma seqüência de operaçòes sem ficar sem créditos durante o processo. Se completarmos uma operação antes de gastar todos os créditos, podemos guardar os créditos extras para. usar em futuras operaçòes. Se gastarmos todos os créditos antes de completar a operaçào, podemos usar créditos que foram economizados anteriormente. Se conseguirmos provar que nunca ficamos sem créditos para completar a seqüência de operaçōes, então o tempo efetivamente gasto por qualquer parte inicial da seqüência de operaçōes é limitado pela soma dos correspondentes tempos amortizados.

O conceito de tempo amortizado pode ser formalizado usando o conceito de valores (chamados potenciais) associados a configuraçòes de estrutura de dados (cf. [20]). 
Não faremos aqui esta outra definição mais formal já que neste trabalho toda a análise será feita usando o conceito de créditos, como foi introduzido em [3]. Esperamos também que este conceito fique mais claro quando fizermos a análise amortizada dos algoritmos que serão apresentados a seguir.

Primeiramente definiremos árvores localmente enviesadas e para estas árvores descreveremos um algoritmo UNA (que realiza a operaçào una), para o qual apresentaremos uma cota superior para o tempo amortizado, bem como para o tempo no pior caso. Descreveremos também um algoritmo reparta, para o qual apresentaremos apenas uma cota superior para o tempo amortizado.

Depois definiremos árvores globalmente enviesadas e descreveremos um outro algoritmo una, para o qual apresentaremos uma cota superior para o tempo amortizado e pior caso. Além disso, provaremos uma cota superior para o tempo amortizado do mesmo algoritmo reparta aplicado em árvores globalmente enviesadas. No final deste capítulo definiremos árvores binárias localmente enviesadas e globalmente enviesadas conseguindo resultados semelhantes.

No que segue, a menos de mençào contrária, as árvores serào todas $(2, b)$-árvores de busca, cada um dos itens i nela armazenados terào peso $p_{i}$ e $P$ será a soma de todos os pesos.

\section{1 Árvores de Busca Localmente Enviesadas}

Nesta seção definiremos árvores localmente enviesadas e provaremos que estas árvores têm tempo ideal de acesso. A seguir, apresentaremos dois algoritmos: UNA e REPARTA, e faremos a análise de complexidade amortizada desses algoritmos.

Para entender melhor as definiçòes a seguir, recomendamos observar a figura 2.1.

Definição 2.1 : Para cada nó $x$ de uma árvore o posto de $x, S(x)$, é definido recursivamente por:

$$
S(x)= \begin{cases}\left\lfloor\lg p_{i}\right\rfloor & \text { se } x \text { é uma folha contendo o item } i, \\ 1+\max \{S(y) \mid y \text { é filho de } x\} & \text { se } x \text { é um nó interno. }\end{cases}
$$


Definição 2.2 : Seja $y$ um nó de uma árvore e $x$ o pai de $y$. Dizemos que $y$ é primogênito se $S(y)=S(x)-1$; e caçula se, $S(y)<S(x)-1$. Por convenção, a raiz é um nó primogênito.

Definição 2.3 : Uma árvore é localmente enviesada se qualquer irmão vizinho de um nó caçula é uma folha primogênita. Algumas vezes estas árvores serão chamadas simplesmente de l.e.

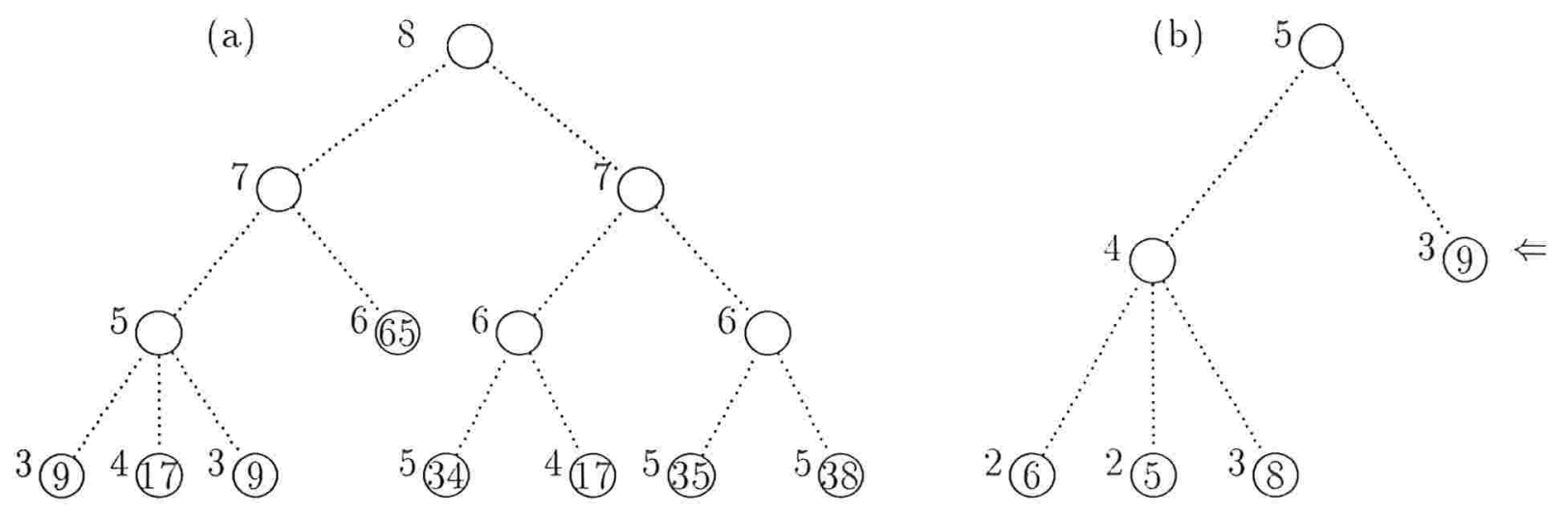

Figura 2.1 : Duas árvores de busca. Os números ao lado do nó são os postos, e os números dentro das folhas são os pesos. A árvore (a) é localmente enviesada, enquanto que a árvore (b) não é localmente enviesada, pois o nó indicado ( com uma seta ) é caçula e seu irmão vizinho é primogênito, mas não é uma folha.

Pela definiçào 2.3, uma árvore onde todas as folhas têm o mesmo peso é uma árvore balanceada (def. A.18) se e só se é localmente enviesada.

Definição 2.4 : Se $x$ é um nó de uma árvore entào o peso de $x, p(x)$, será definido como:

$$
p(x)= \begin{cases}p_{i} & \text { se } x \text { é uma folha contendo o item } i, \\ \sum\{p(y) \mid y \text { é filho de } x\} & \text { se } x \text { é um nó interno. }\end{cases}
$$


Lema 2.1 : Para cada nó ? de uma árvore l.e.

$$
2^{S(x)-1} \leq p(x)
$$

Se $x$ é uma folha,

$$
2^{S(x)} \leq p(x)<2^{S(x)+1}
$$

Prova: Faremos a demonstração por induçào no tamanho da árvore. Se $x$ é uma folha, por definição $S(x)=\lfloor\lg (p(x))\rfloor$, e portanto $2^{S(x)} \leq p(x)<2^{S(x)+1}$. Se $x$ é um nó interno com um filho caçula, $x$ tes um filho primogênito. digamos $y$, que é uma folha. Então,

$$
2^{S(x)-1}=2^{S(y)} \leq p(y) \leq p(x)
$$

Se $x$ não possui fil y caçıla, então $x$ possui pelo menos dois filhos primogênitos, digamos $y$ e $z$. Então,

$$
2^{S(x)-1}=2^{S(x)-2}-?^{S(x)-2}=2^{S(y)-1}+2^{S(z)-1} \leq p(y)+p(\tilde{z}) \leq p(x) .
$$

Lema 2.2 : Numa árvo: : l.e. se $x$ é uma folha com profundidade $d$, contendo o item $i$, então

$$
d<\lg \left(\frac{P}{p_{i}}\right)+2
$$

Prova: Seja $r$ a raiz da á." ore. Como o posto aumenta de pelo menos uma unidade de um filho para o pai, entào

$$
d \leq S(r)-S(x) .
$$

Pelo lema 2.1,

$$
\begin{gathered}
\text { ': '”) }=\lg (p(r)) \geq S(r)-1 \quad \mathrm{e} \\
\lg (p(x))<S(x)+1 .
\end{gathered}
$$

Logo,

$$
d \leq S(r)-S(x)=\lg (P)+1-\lg (p(x))+1=\lg \left(\frac{P}{p_{i}}\right)+2
$$


Teorema 2.1 : Uma (2,b)-árvore l.e. tem tempo ideal de acesso.

Prova: Segue imediatamente do lema 2.2.

Já temos uma árvore com tempo ideal de acesso. Vejamos como implementar algumas operações e como fazer a análise amortizada dessas operações ( fazendo o uso do conceito de créditos ). Antes, vamos introduzir algumas convençòes e definiçôes.

Para contabilizar os créditos economizados em operações anteriores, os créditos são armazenados nas árvores. Isto é feito para facilitar a análise da complexidade de tempo: eles não são fisicamente guardados na estrutura de dados e nem afetam a implementação dos algoritmos.

A seguinte definiçào será útil na formalizaçào das idéias.

Definição 2.5 : Uma árvore de busca localmente enviesada satisfaz invariância de créditos se cada nó caçula y com pai $x$ possui $S(x)-S(y)-1$ créditos. Quando atribuímos tal quantidade de créditos a $y$ dizemos que estamos mantendo invariância de créditos em $y$.

Note que esta definiçào é consistente com o fato de que filhos primogênitos não têm créditos.

Para proceder a análise da complexidade amortizada de uma operaçào, vamos dar a essa operação uma cota superior $T$ para o número de créditos necessários para realizá-la - neste caso dizemos que o algoritmo requer $T$ tempo amortizado - e, supondo que as árvores iniciais satisfazem invariância de créditos, vamos provar que a árvore resultante ( da operação ) satisfaz invariância de créditos. Neste caso dizemos que a operação (ou algoritmo) mantém invariáncia de créditos.

Vejamos agora o algoritmo UNA. Esse algoritmo recebe como entrada duas árvores 1.e. com raizes $x$ e $y$, que representam dois conjuntos e retorna a raiz de uma árvore l.e. que representa a uniào destes conjuntos. Logo após o algoritmo representamos esquematicamente os casos que ocorrem e qual a árvore resultante. 
função $U N A(\operatorname{raiz} x, y)$ :

raiz $z$;

nó $x_{1}, x_{2}, v, u, v_{1}, v_{2}$;

.caso 1: $S(x)=S(y)$, ou $S(x)>S(y)$ e $x$ é uma folha, ou $S(y)>S(x)$ e $y$ é uma folha.

crie um novo nó $z$ tendo $x$ e $y$ como filhos;

retorne $z$;

.caso 2: $S(x)>S(y)$ e $x$ não é uma folha.

- seja $u$ o filho mais à direita de $x$.

. $v=U N A(u, y)$;

/* Temos aqui dois (veremos que só ocorrem esses ) casos a analisar: */

subcaso $2 \mathrm{a}: S(v)<S(x)$.

faça $v$ filho direito de $x$;

retorne $x$;

subcaso $2 \mathrm{~b}: S(v)=S^{\prime}(x)$.

neste caso $v$ terá exatamente dois filhos (será demonstrado), digamos $v_{1}$ e $v_{2}$.

faça $v_{1}$ e $v_{2}$ filhos de $x$ (colocando-os à direita dos outros filhos de $x$ );

destrua $v$;

se $x$ já tinha $b$ filhos

então crie três novos nós $z, x_{1}$ e $x_{2}$;

tome os $\lceil(b+1) / 2\rceil$ filhos mais à esquerda de $x$ e faça-os filhos de $x_{1}$;

tome os $\lfloor(b+1) / 2\rfloor$ filhos mais à direita de $x$ e faça-os filhos de $x_{2}$ :

faça $x_{1}$ e $x_{2}$ filhos de $z$;

retorne $\approx$

senão retorne $x$ :

.caso 3: $S(y)>S(x)$ e $y$ nào é uma folha.

simétrico ao caso 2 . 


\section{Caso 1}<smiles>COCCOC</smiles>

Caso 2

(x) (y)

$\therefore \therefore$ ( $\left.v_{1}\right) \cdots$ (

Caso 2b

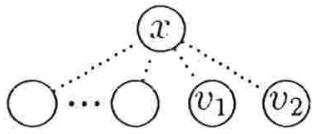

Caso $2 \mathrm{~b}$ com divisão

de filhos

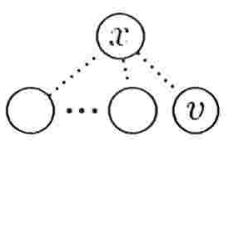

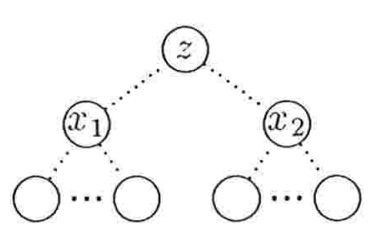

Figura 2.2 : Algoritmo una nos casos 1 e 2.

Lema 2.3 : O algoritmo UNA recebe como entrada duas árvores l.e., uma com raiz $x$ e outra com raiz y e constrói uma árvore com raiz z tal que

$$
S^{\prime}(z)=\max \left\{S^{\prime}(x), S^{\prime}(y)\right\} \text { ou } S^{\prime}(z)=\max \left\{S^{\prime}(x), S^{\prime}(y)\right\}+1 .
$$

No último caso, z possuirá exatamente dois filhos.

Prova: Será feita por induçào no tamanho da árvore construída. No caso 1 do algoritmo o nó $z$ possui exatamente dois filhos, $x$ e $y$ e portanto $S(z)=\max \{S(x), S(y)\}+1$.

No caso 2, se ocorrer o subcaso 2a temos $z=x$ e $S(z)=S(x)=\max \{S(x), S(y)\}$. Se não ocorrer o subcaso $2 \mathrm{a}$, temos $S(v) \geq S(x)$. Logo,

$$
S(v) \leq \max \{S(u), S(y)\}+1 \leq S(x), \quad \text { e portanto } S(v)=S(x)
$$

e $v$ tem exatamente dois filhos. Note que a primeira desigualdade e a última afirmaçào seguem da hipótese de induçào. Se $x$ já tinha $b$ filhos entào:

$$
S\left(x_{2}\right)=S(x)=S(z)-1
$$

e $z$ tem 2 filhos; caso contrário, $S(z)=S(x)$. 
Lema 2.4: A árvore construída pelo algoritmo UNA é l.e.

Prova: Por indução no tamanho da árvore. No caso 1 , se um dos nós ( $x$ ou $y$ ) é caçula, o outro é folha, logo a árvore resultante é l.e.

No caso 2a, temos que analisar o caso em que o irmào esquerdo de $v$ é caçula e o caso em que $v$ é caçula. Suponha que $v$ seja caçula. Então $u$ era caçula na árvore original e seu irmão esquerdo era uma folha primogênita. Logo, a nova árvore é l.e. Suponha, por outro lado, que o irmão esquerdo de $v$ seja caçula, neste caso $u$ era uma folha primogênita, o UNA $(u, y)$ recairia no caso 1 e o $U N A$ original recairia no caso $2 \mathrm{~b}$ e não $2 \mathrm{a}$.

No caso 2b, temos, novamente, dois casos a analisar: o caso em que o filho esquerdo de $v$ é caçula e o caso em que o irmão esquerdo de $u$ (na árvore original) é caçula. No primeiro caso (o filho esquerdo de $v$ é caçula), os filhos de $v$ são exatamente $u$ e $y$, e como o irmão esquerdo de $u$ (na árvore original) é uma folha primogênita, a nova árvore será l.e. Note que por hipótese de induçào a árvore com raiz v é l.e. No segundo caso (o irmão esquerdo de $u$, na árvore original, é caçula), u já era uma folha primogênita, e os filhos de $v$ são exatamente $u$ e $y, \log$ a nova árvore é l.e.

Lema 2.5 : O algoritmo UNA requer $|O(S(x)-S(y))|+1$ tempo amortizado.

Prova: Vamos supor que $S^{\prime}(x) \geq S(y)$. O caso $S(x)<S(y)$ é simétrico. No caso 1 , precisamos de 1 crédito para construir a nova árvore e mais $S(x)-S(y)$ créditos para. manter invariância de créditos em y (note que se y é caçula na nova árvore, $S(z)-S^{\prime}(y)-$ $1=S(x)-S(y))$. No total precisamos de $S(x)-S(y)+1$ créditos.

No caso 2 recebemos $S(x)-S(u)-1$ créditos de $u$ perfazendo um total de $2 . S(x)-S(y)-S(u)$ créditos. Precisamos $|S(u)-S(y)|+1$ para o UNA recursivo. No caso 2a precisamos um crédito para construir a nova árvore e $S(x)-S(v)-1$ créditos para manter invariância de créditos em $v$. Assim, o total de créditos necessários para o UNA do caso 2a é:

$$
\begin{gathered}
S(x)-S(v)-1+\max \{S(u), S(y)\}-\min \{S(u) . S(y)\}+1+1 \leq \\
2 . S(x)-\max \{S(u), S(y)\}-\min \{S(u) . S(y)\} . \quad(*)
\end{gathered}
$$

pois $S(v) \geq \max \{S(u), S(y)\}$ e $S(x)>\max \{S(u) . S(y)\}$. 
Note que, qualquer que seja a relação entre $S(u)$ e $S(y)$, a última expressão da desigualdade (*) é precisamente $2 . S(x)-S(y)-S(u)$.

No caso $2 \mathrm{~b}$ precisamos de 1 crédito para construir a nova árvore, não precisamos de nenhum crédito para armazenar nos filhos de $x$, pois os filhos de $v$ já os possuíam. A análise anterior mostra que são necessários no máximo $2 . S(x)-S(y)-S(u)$ créditos.

Teorema 2.2: $\quad$ O algoritmo $U N A(x, y)$ é correto e requer $O(|S(x)-S(y)|)$ tempo amortizado.

Prova : Imediata a partir dos lemas 2.4 e 2.5 .

Teorema 2.3 : O tempo do algoritmo UNA no pior caso é

$$
O(\max \{S(x), S(y)\}-\max \{S(u), S(v)\})=O\left(\lg \left(\frac{P}{p_{-}+p_{+}}\right)\right),
$$

onde $u$ e $v$ são as folhas mais à direita de $x$ e mais à esquerda de $y$, respectivamente, $p_{-}=p(u), p_{+}=p(v)$ e $P=p(z)$ e $z$ é a raiz da nova árvore.

Prova: Basta analisar o comportamento do algoritmo UNA em termos do caminho de $x$ até a sua folha mais à direita e do caminho de $y$ até a sua folha mais à esquerda. Veja figura 2.3 .

Não é difícil verificar que, no algoritmo, basicamente tais caminhos são percorridos paralelamente, até que se encontra uma folha em um dos caminhos ou até que dois nós com o mesmo posto sào encontrados, um em cada caminho. As partes percorridas desses caminhos são entào "juntadas", ordenando os nós em ordem decrescente de posto, e criando ou nào um novo nó para ajustar os postos. A partir da base do caminho que surgiu da junçào, indo em direçào à raiz, faz-se a divisào de nós, se necessário, para manter no máximo $b$ filhos. Esta descriçào do algoritmo justifica o resultado. 


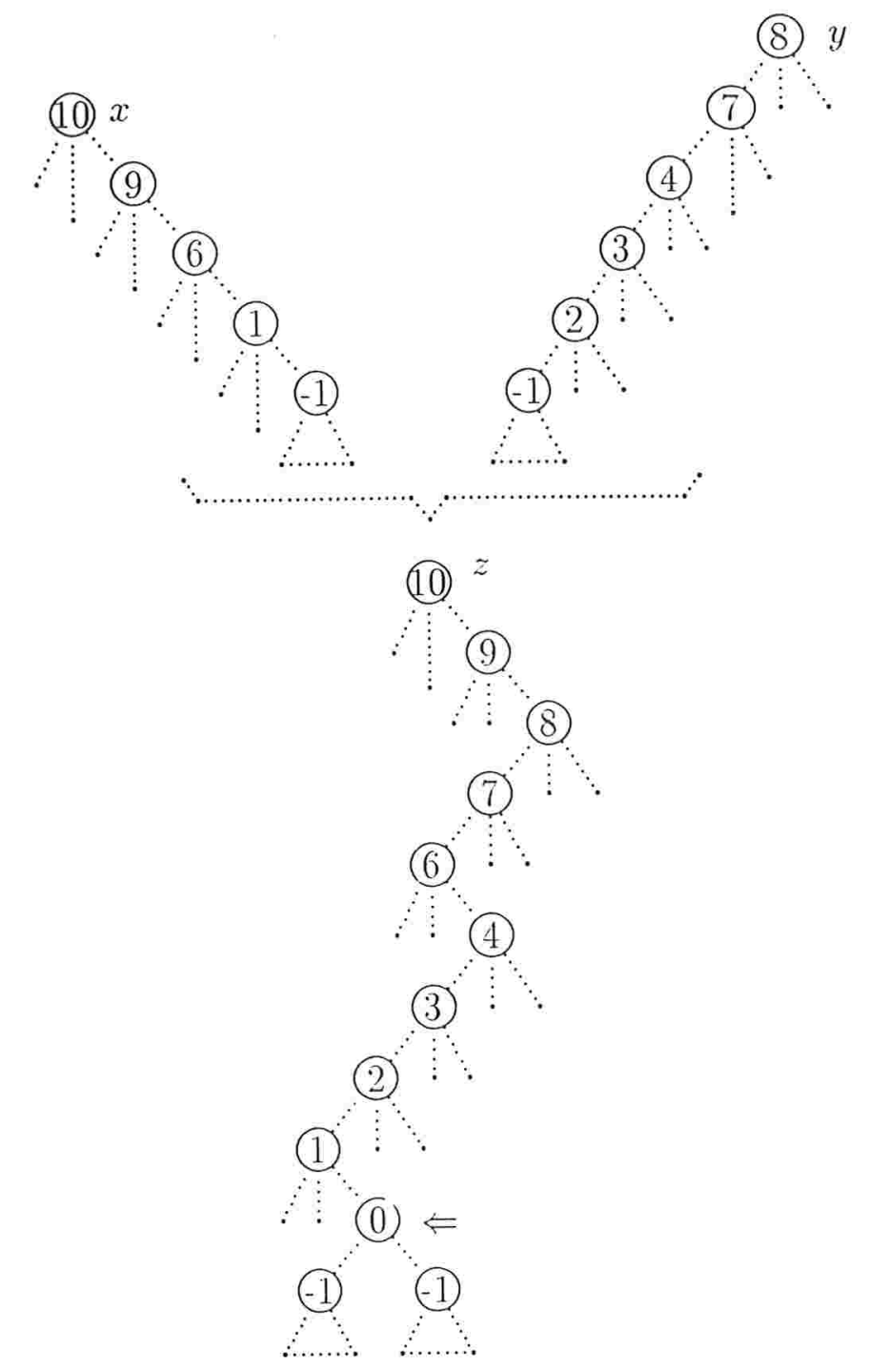

Figura 2.3 : Duas árvores onde foi aplicado o UNA. Os números dentro dos vértices são os postos. O nó indicado com uma seta foi inserido pelo UNA.

Vamos agora considerar outras operaçòes, começando pelo UNA-TRIPLO. Podemos implementar o UNA-T'RIPLO com uma seqüência de dois UNAs (duplos). Os dois teoremas anteriores fornecem o seguinte resulta.do:

Teorema 2.4: O UNA-TRIPLO requer

$$
O(\max \{S(x), S(y) . S(z)\}-\min \{S(x), S(y), S(z)\}) .
$$


tempo amortizado, e o tempo no pior caso é

$$
O\left(\max \{S(x), S(y), S(z)\}-S^{\prime}(y)\right)=O\left(\lg \left(\frac{P}{p_{i}}\right)\right),
$$

onde $x$ é a raiz da primeira árvore; $y$, raiz da segunda árvore, é uma folha; $z$ é a raiz da última árvore; $p_{i}$ é o peso do item $i$, armazenado no nó $y$, e $P$ é o peso total dos itens na nova árvore.

Uma outra maneira de formular o conceito de "alocação de créditos e manutenção de invariância de créditos é a seguinte:

Definição 2.6 : Dizemos que uma árvore com raiz $x$ é $K$-crédito invariante se ela satisfaz invariância de créditos e possui $K-S(x)$ créditos armazenados na raiz.

Com esta definição o resultado do teorema 2.2 pode ser expresso assim:

Lema 2.6 : Se duas árvores com raízes $x$ e $y$ sào $K$-crédito invariantes $\operatorname{com} K>$ $\max \{S(x), S(y)\}$ então o algoritmo UNA faz a uniào dessas duas árvores sem gastar mais créditos, produzindo uma nova árvore $K$-crédito invariante.

Prova: Imediata a partir do teorema 2.2 .

A seguir veremos como implementar o algoritmo REPARTA. Este algoritmo terá como entrada a raiz de uma árvore l.e., que representa um conjunto e um item $i$ de $U$. $O$ algoritmo retornará uma árvore l.e. que representa o conjunto dos elementos da árvore de entrada menores que o item $i$; o item $i$, se $i$ está na árvore, ou um ponteiro especial nulo, caso contrário; e uma outra árvore que representa o conjunto dos elementos da árvore de entrada maiores que $i$.

Vejamos antes uma definição que será. usada a seguir.

Definição 2.7 : Seja $i$ um item qualquer de $U$. Dizemos que um nó $y$ com filhos $f_{1} \ldots, f_{k}$ é nó base do item i na árvore se um dos casos ocorre:

caso $1: \exists l \in\{1, \ldots, k\}$ tal que $f_{l}$ é folha contendo item $i$.

caso 2: $\exists l \in\{1, \ldots, k-1\}$ tal que $l_{1} \ldots$. li sào raízes de subárvores cujas folhas contêm itens menores que $i$ e $f_{l+1} \ldots, f_{k}$ sào raizes de subárvores cujas folhas contêm elementos maiores que $i$. 
função REPARTA (raiz $r$; itemı $i)$ :

nó a, atual, próximo, e, árvore-esquerda, árvore-temporária, $Q$, árvore-direita;

se $x$ é uma folha

então se conteúdo de $x<i$

então retorne $(x$, nulo,nulo) e pare;

se conteúdo de $x=i$

então retorne (nulo,i,nulo) e pare;

se conteúdo de $x>i$

então retorne ( (ulo, nulo, $x$ ) e pare;

Procure o nó a com filhos $f_{1}, f_{2}, \ldots, f_{k}$ que é o nó base do item $i$ na árvore;

- se $x$ não tem nó base

- então se os itens de $x$ são menores que $i$

então retorne $(x$, nulo, nulo) e pare

senão retorne (nulo, nulo, $x$ ) e pare:

. se o caso 1 (da definição 2.7) ocorreu

então faça $Q=i$

se $l=1$

então faça árvore-esquerda $=$ nulo;

se $l=2$

então faça árvore esquerda = subárvore na qual $f_{1}$ é raiz;

se $l>2$

então crie um nó $\epsilon$;

faça $f_{1}, \ldots, f_{l-1}$ filhos de $\epsilon$;

faça árvore-esquerda = árvore cuja rajz é $\epsilon$;

analogamente construa a cirvore-direita:

senão /* caso 2 ocorreu */

faça $Q=$ nulo;

se $l=1$

então faça árvore-esquerda = subárvore na qual $f_{1}$ é raiz;

se $l>1$

então crie um nó $\epsilon$;

faça $f_{1}, \ldots, f_{l-1}$ filhos de $\epsilon$; 
faça árvore-esquerda = árvore na qual e é raiz;

analogamente construa árvore-direita;

- faça atual=a;

. faça próximo = pai(atual);

enquanto atual nâo é a raiz faça

- sejam $f_{1}, f_{2}, \ldots, f_{k}$ os filhos de próximo

- seja $f_{l}$ o atual

- $\quad$ se $l=1$

então faça árvore-temporária=nulo;

se $l=2$

então faça árvore-temporária=subárvore que tem $f_{1}$ como raiz;

- se $l>2$

então crie um nó $e$;

faça $f_{1}, \ldots, f_{l-1}$ filhos de $\epsilon$;

faça árvore-temporária=árvore cuja raiz é $\epsilon$;

- faça árvore-esquerda= UNA(árvore-temporária,árvore-esquerda);

analogamente produza uma nova árvore-direita:

- faça atual = próximo;

- faça próximo=pai (próximo);

- retorne árvore-esquerda, Q.árvore-direita; 

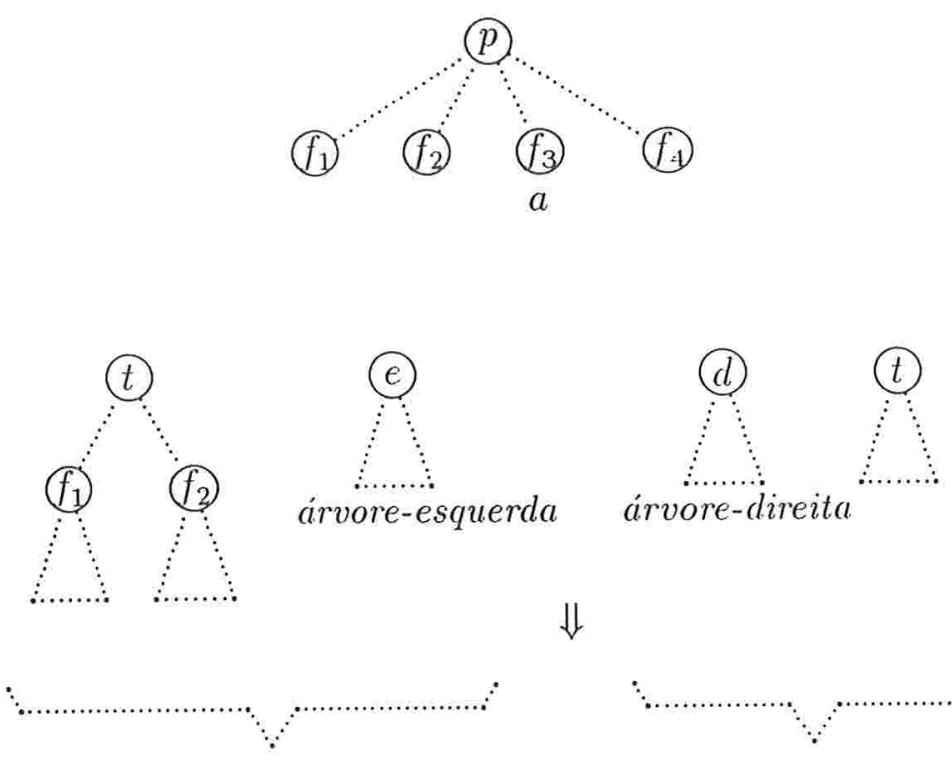

$\Downarrow$
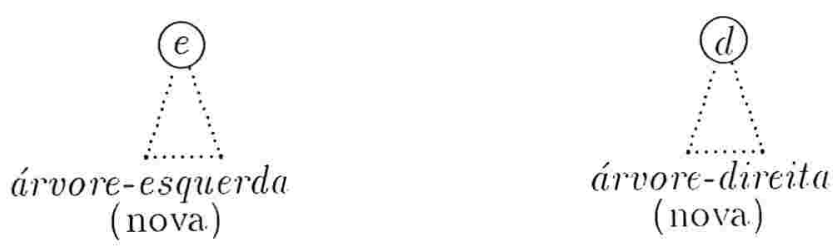

Figura 2.4 : Um passo do algoritmo REPARTA. O nó $p$ é o próximo nó, o nó a é o nó atual, as árvores de raiz $t$ são as árvores temporárias. As árvores com raízes $d$ e $e$ são as árvores direita e esquerda, sendo que as árvores mais abaixo sào as novas árvores esquerda e direita depois de serem unidas com as árvores temporárias.

Este algoritmo faz a operaçào REPARTA corretamente. Para analisar o seu tempo amortizado, vamos analisar o caso em que a árvore de entrada tem nó base. No outro caso o tempo gasto pelo algoritmo REPARTA é $O(1)$.

Chamemos de $a, p, e, e^{\prime}$ e $t$ o nó-atual,nó-próximo, raiz da árvore esquerda atual, raiz da próxima árvore esquerda e raiz da árvore temporária em cada passo do algoritmo. Na primeira iteraçào, nó-atual $=a($ clo algoritmo $)$ e nó-próximo=pai $(a)$.

Lema 2.7: $S(a) \geq S(e)$ em qualquer passo do algoritmo REPARTA.

Prova: Logo após executar o passo inicial temos que $S(\epsilon) \leq S(a)$. pois ou $\epsilon$ era um filho de $a$ na árvore original, ou é um novo nó que é pai de dois ou mais filhos de a (na árvore original). 
Num outro passo qualquer temos que $S(t) \leq S(p)$. Por indução, $S(e) \leq S(a)$ e portanto $S(e)<S(p)$. Se $S(t)<S(p)$, pelo lema 2.3 temos que $S\left(e^{\prime}\right) \leq S(p)$. Se $S(t)=S(p)$, então $S(t)>S(a)$. Logo, o UNA recairia no caso 2 e como $t$ tem menos que $b$ filhos $S\left(e^{\prime}\right)=S(t)$. Logo, $S\left(e^{\prime}\right) \leq S(p)$, onde $e^{\prime}$ e $p$ sào a raiz da árvore esquerda e o nó atual do próximo passo, respectivamente.

O lema obviamente vale para a árvore direita também.

Lema 2.8 : Em cada passo do algoritmo REPARTA necessitamos de 2. $(S(p)-S(a))+5$ créditos e as árvores esquerda e direita são $(S(a)+1)$-crédito invariantes.

Prova: No passo inicial precisamos de um crédito mais 2. $(S(p)-S(a)+1)$ créditos para colocar nas árvores esquerda e direita num total de $2 .(S(p)-S(a))+3<2(S(p)-S(a))+5$.

Num outro passo qualquer do algoritmo se colocarmos $S(p)-S(a)$ créditos em $e, e$ tornar-se-á $(S(p)+1)$-crédito invariante. Se a árvore temporária for vazia, a árvore esquerda anterior será a nova árvore esquerda. Se $t$ for um filho de $p$, então $t$ tem $S(p)-S(t)-1$ créditos (pois a árvore original satisfazia invariância de créditos); colocando mais dois créditos em $t$ a nova árvore será $(S(p)+1)$-crédito invariante. Se $t$ for pai de mais de um filho de $p$. então $S(t)=S(p)$ e colocando um crédito em $t$ ele tornar-se-á $(S(p)+1)$-crédito invariante. Logo precisamos de no máximo dois créditos para que a árvore temporária seja $(S(p)+1)$-crédito invariante. Pelo lema 2.6, a nova árvore esquerda será $(S(p)+1)$-crédito invariante. Mais $S(p)-S(a)+2$ créditos serão necessários para formar a nova árvore direita. Mais um crédito é necessário para o restante do passo do algoritmo num total de $2 .(S(p)-S(a))+5$ créditos.

Teorema 2.5 : Se $x$ é a raiz da árvore original e y é o nó base de $i$ entào, o algoritmo REPARTA requer $O(S(x)-S(y))$ tempo amortizado, gera árvores que sào $(S(x)+1)$ crédito invariantes.

Prova: Sejam $x_{1}, \ldots, x_{t}=y$ os nós atuais de todos os passos e $x_{0}=x$. Entào, pelo lema anterior, o seguinte número de créditos é suficiente:

$$
\begin{gathered}
\left(2 .\left(S\left(x_{0}\right)-S\left(x_{1}\right)\right)+5\right)+\left(2 .\left(S\left(x_{1}\right)-S\left(x_{2}\right)\right)+5\right)+\cdots+\left(2 .\left(S\left(x_{t-1}\right)-S\left(x_{t}\right)\right)+5\right)= \\
2 .\left(S\left(x_{0}\right)-S\left(x_{t}\right)\right)+5 t=2 .(S(x)-S(y))+5 t \leq 2 .(S(x)-S(y))+5 .(S(x)-S(y))= \\
7 .(S(x)-S(y))
\end{gathered}
$$


Ainda para o algoritmo REPARTA podemos observar que o tempo amortizado desse algoritmo é

$$
O(S(x)-S(y))= \begin{cases}O\left(\lg \left(\frac{P}{p_{i}}\right)\right) & \text { se } i \in S \\ O\left(\lg \left(\frac{P}{p_{i-}+p_{i+}}\right)\right) & \text { se } i \notin S\end{cases}
$$

onde no segundo caso $i^{+}$e $i^{-}$são itens em $S$ tais que $i^{-}<i<i^{+}$, e existem duas folhas consecutivas na árvore que contêm os elementos $i^{-}$e $i^{+}$.

Sabe-se que o pior tempo do algoritmo REPARTA não tem uma cota superior logarítmica ( conforme [3] ). No entanto, na próxima seçào veremos que usando árvores um pouco mais restritas pode-se obter cotas superiores boas para o pior tempo da operaçào REPARTA.

Quanto às operaçòes, insere e remove, estas podem ser obtidas combinando-se as operações UNA e REPARTA. Note que uma inserção é um REPARTA seguido de um UNA-TRIPLO; uma remoçào é um REPARTA seguido de um UNA (duplo).

Para a realizaçào da função acesse (e para encontrar o nó base na operação REPARTA) é necessário guardar em cada nó interno o maior e o menor item da sua subárvore. Note que é fácil manter estas informações nas operações UNA e REPARTA e que estas informações podem guiar a busca da folha que contém o item.

\section{2 Árvores de Busca Globalmente Enviesadas}

Nesta seção introduziremos as chamadas árvores globalmente enviesadas e provaremos o tempo, no pior caso, para o algoritmo REPARTA. usando tal estrutura de dados. Antes de definir árvores globalmente enviesadas. veremos outras definiçóes. que serào usadas para definir tais árvores. 
Definição 2.8 : Seja $x$ um nó qualquer de uma árvore. Dizemos que $y$ é o primeiro vizinho esquerdo(direito) de $x$ se o irmão direito (esquerdo) de $y$ é o primeiro ancestral de $x$ que possui $y$ como irmão esquerdo (direito). Veja figura 2.5.

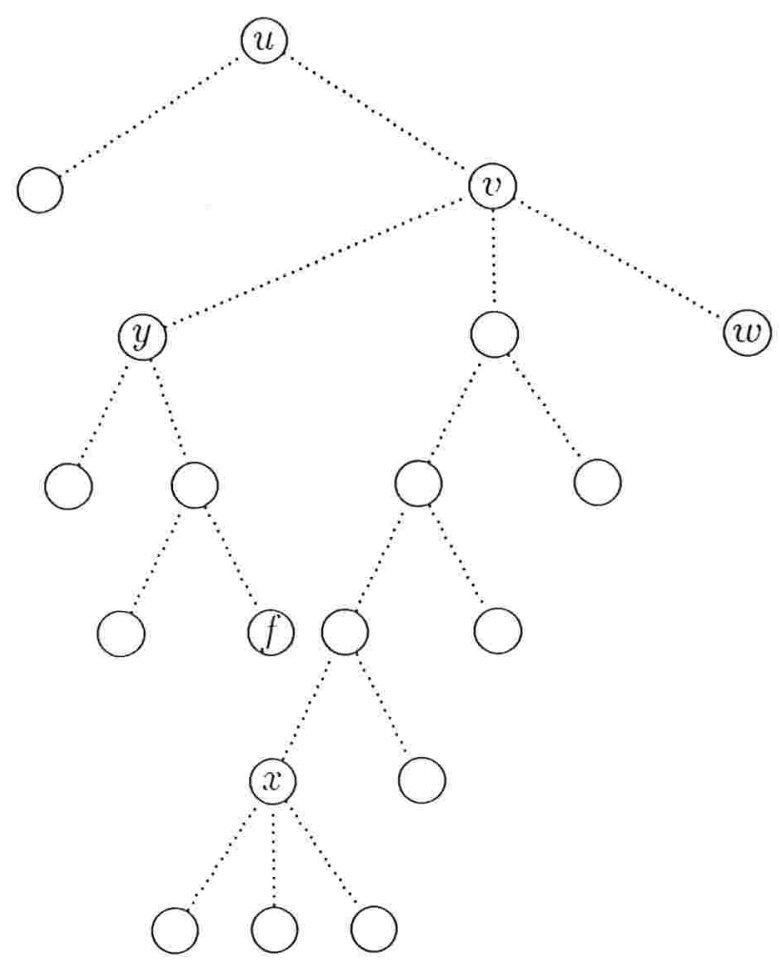

Figura 2.5: $y$ é o primeiro vizinho esquerdo de $x: f$ é a folha mais à direita de $y ; f$ é a folha vizinha esquerda de $x ;(u, v, w)$ é o caminho direito da árvore.

Definição 2.9 : Seja $x$ um nó de uma árvore. Dizemos que $y$ é a folha mais à direita (esquerda) de $x$ se $y$ é folha descendente de $x$ e todos os ancestrais a de $y$ que sào descendentes de $x, a \neq x$, sào filhos mais à direita (esquerda).

Definição 2.10 : Seja $x$ um nó de uma árvore. Definimos folha vizinha esquerda (direita) de $x$ como sendo a folha mais à direita (esquerda) do primeiro vizinho esquerdo (direito) de $x$. As folhas vizinhas direita e esquerda de $x$ sào chamadas folhas vizinhas de $x$. 
Definição 2.11 : Seja $\mathcal{A}$ uma árvore com raiz $x$. O caminho esquerdo (direito) de $\mathcal{A}$ é o caminho de $x$ até a folha mais à esquerda (direita) de $x$.

Definição 2.12 : Uma árvore é globalmente enviesada se toda folha vizinha $v$ de um nó caçula $y$ com pai $x$ é tal que $S(v) \geq S(x)-1$. Se uma árvore possui um nó $y$ com tal propriedade, dizemos que a árvore é globalmente enviesada em $y$. Para simplificar, tais árvores são denotadas simplesmente por g.e.

$A_{1}$

(6).

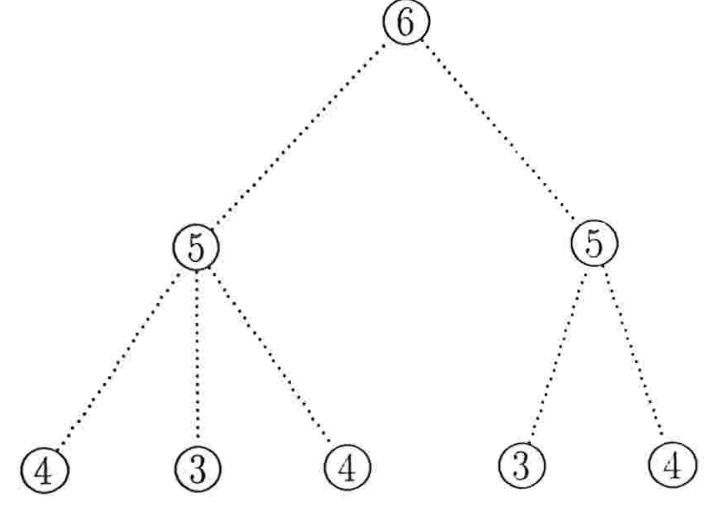

$A_{2}$

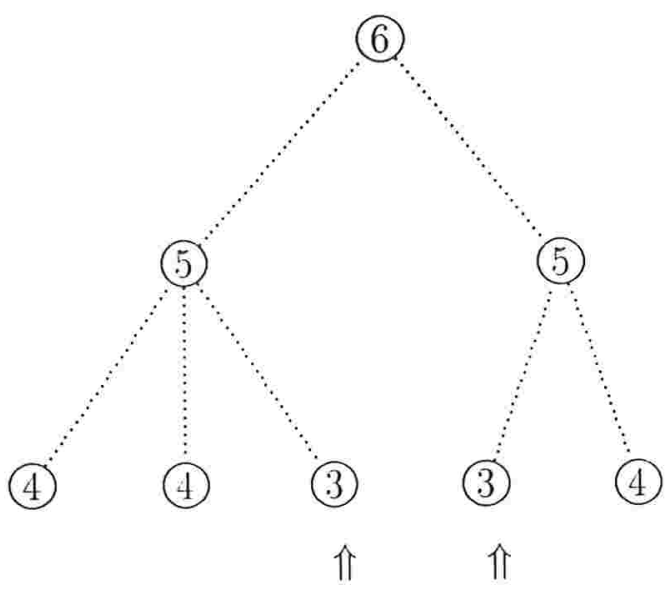

Figura 2.6 : A árvore $A_{1}$ é uma árvore g.e. A árvore $A_{2}$ é uma árvore l.e., mas não é uma árvore g.e. pois as folhas assinaladas sào folhas vizinhas caçulas que nào satisfazem a propriedade da definição 2.12 .

Como toda árvore g.e. é também l.e., segue que as árvores g.e. têm tempo ideal de acesso.

Veremos agora uma nova versão para o algoritmo UNA que chamaremos de UNAGLOBAL. Esse algoritmo receberá como entrada raizes de duas árvores g.e., que representam dois conjuntos e retornará a raiz de uma árvore g.e. que representa a uniào destes conjuntos. 
função $U N A-G L O B A L(\operatorname{raiz} x, y)$ :

raiz $z, z_{1}, z_{2}, v, e, d$;

.caso $1: S(x) \geq S(y)$ e $x$ é uma folha, ou $S(x) \leq S(y)$ e $y$ é uma folha.

- crie um novo nó $z$;

- faça $x$ e $y$ filhos de $z$;

- retorne $z$

.caso $2: S(x)>S(y)$ e $x$ não é uma folha.

- faça como no caso 2 do UNA (local);

.caso $3: S(x)<S(y)$ e y nào é uma folha.

- Simétrico ao caso 2.

.caso 4: $S(x)=S(y)$ e nem $x$ nem $y$ é uma folha.

sejam $d$ o filho mais à direita de $x$ e $\epsilon$ o filho mais à esquerda de $y$;

remova $d$ de $x$ e remova $e$ de $y$;

$v=U N A-G L O B A L(e, d)$ :

crie um nó $z$;

se $S(v)<S(x)$

então tome os filhos de $x, v$ e os filhos e $y$ e faça-os filhos de $z$

senão tome os filhos de $x$, os dois filhos de $v$ e os filhos de $y$ e faça-os filhos de $z$;

se $z$ ficar com mais de $b$ filhos

então crie dois novos nós $z_{1}$ e $z_{2}$;

divida os filhos de $z$ entre $z_{1}$ e $z_{2}$;

faça $z_{1}$ e $z_{2}$ filhos de $z$;

retorne $z$; 

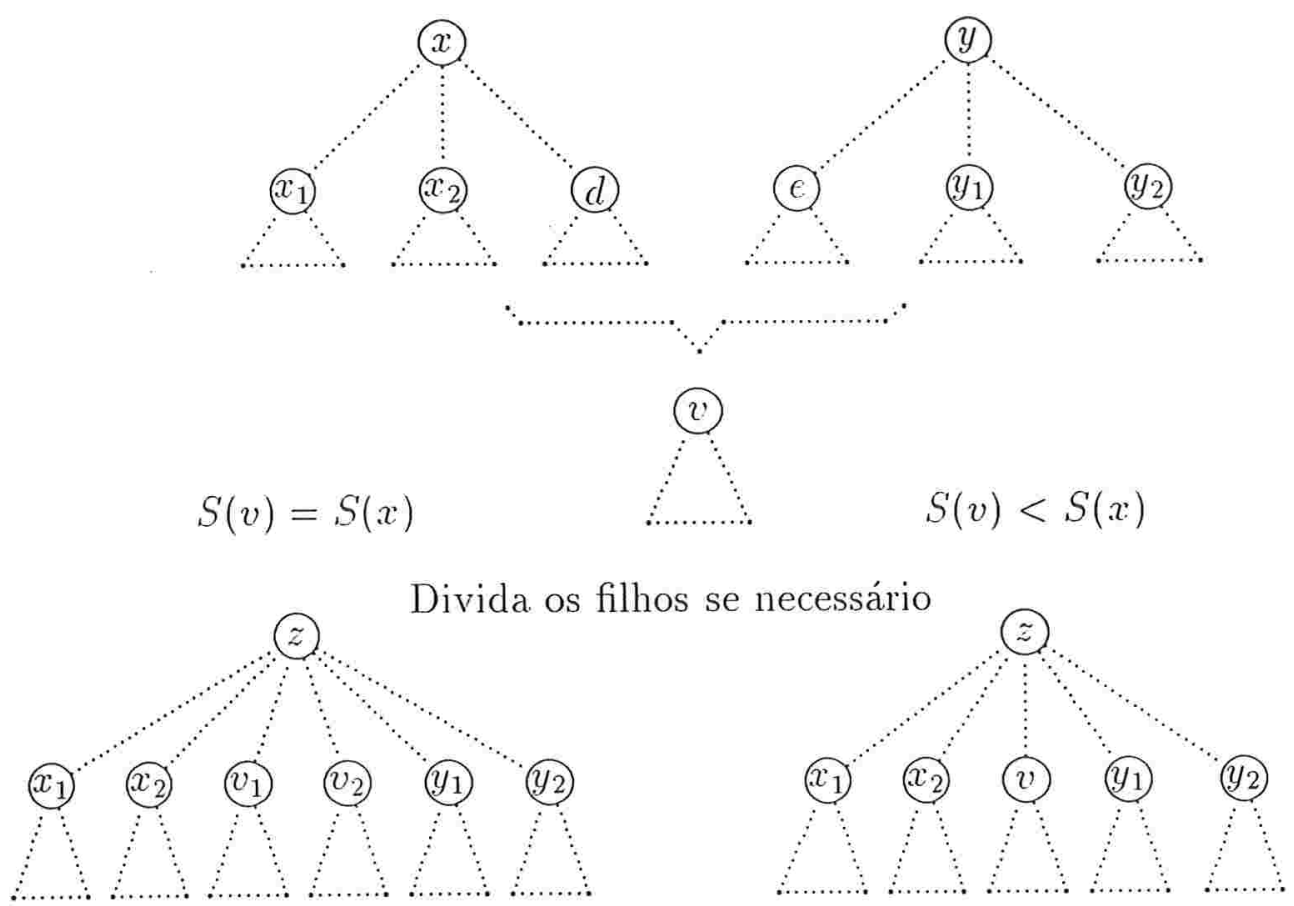

Figura 2.7 : Exemplo de um UNA-GLOBAL que recaiu no caso 4.

Observação: Na aplicaçào do UNA-GLOBAL(x,y), chamaremos de árvore-esquerda (direita) a árvore com raiz $x(y)$.

Definição 2.13 : Considere duas árvores para as quais aplicou-se o algoritmo UNAGLOBAL (sem divisão de filhos). Sejam $c d$ ( $c \epsilon$ ) o caminho direito (esquerdo) da árvore à esquerda (direita). Considere o caminho formado pelos nós raízes das árvores que resultaram da aplicaçào recursiva dos UNA-GLOBAL. chamaremos tal caminho de caminho central. Para cada nó $v$ deste caminho definimos o nó referência esquerda(direita) de $v$ como sendo o nó $g$ de $c d(c \epsilon)$, se existir, tal que $S(g) \leq S(v)<S(f)$, onde $f$ é o pai de $g$.

Lema 2.9 : Seja $v$ o nó no caminho central após a aplicação de um UNA-GLOBAL (sem divisão de filhos). Entào a folha vizinha esquerda (direita) de v é a folha vizinha. esquerda (direita) do nó referência esquerda (direita) de v' (na árvore original).

Prova: Se o nó v não possui nó referência esquerda. entào ele não tem folha vizinha esquerda. Se o nó $v$ for nó da árvore esquerda, entào $v$ é o próprio nó referência. Logo, se $v$ possuir folha vizinha esquerda na nova árvore, ela é a própria follha vizinha esquerda de $v$ na árvore original. Se $v$ nào é nó da árvore esquerda. entào v nào possui irmào direito. 
O primeiro vizinho esquerdo de $v$ será o primeiro vizinho esquerdo do nó referência direita de $v$. Logo, a folha vizinha esquerda de $v$ será a folha vizinha esquerda do nó referência esquerda de $v$.

Teorema 2.6 : O algoritmo UNA-GLOBAL é correto.

Prova: Suponha que nâo houve divisão de filhos. Os únicos nós nos quais a nova árvore pode não ser g.e. são os nós caçulas ao longo do caminho central. Seja $w$ um nó caçula no caminho central. Seja $v$ o pai de $w$. Basta analisar o caso em que $v$ possui nó referência esquerda, pois caso contrário $v$ nào possui folha vizinha esquerda e conseqüentemente a árvore é g.e. em $v$. Pelo lema 2.9 a folha vizinha esquerda $u$ de $v$ é a folha vizinha esquerda do nó referência esquerda $g$ de pai $f$ de $w$. Como $w$ é caçula, $g$ também o é. Portanto, $S(u) \geq S(f)-1$. Como $S(f) \geq S(v)$, então $S(u) \geq S(v)-1$. O mesmo raciocinio pode ser feito em relaçào à folha vizinha direita de $w$. Como as divisões de filhos preservam a propriedade de ser g.e., a nova árvore é g.e.

Teorema 2.7 : O tempo gasto pelo algoritmo UNA-GLOBAL é

$$
O\left(\lg \left(\frac{P}{p_{-}+p_{+}}\right)\right)
$$

no pior caso, onde $P$ é o peso total das duas árvores, $p_{-}$é o peso da da folha mais à direita da árvore esquerda, e $p_{+}$é o peso da folha mais à esquerda da árvore direita.

Prova: Raciocínios análogos aos desenvolvidos na demonstração do teorema 2.3 valem para o UNA-GLOBAL também.

Teorema 2.8 : O tempo gasto pelo UNA-GLOBAL-TRIPLO é

$$
O\left(\lg \left(\frac{P}{p_{i}}\right)\right)
$$

no pior caso, onde $P$ é o peso total das duas árvores e $p_{i}$ é peso do item inserido entre as duas árvores.

Prova: Imediata a partir do teorema 2.7.

Podemos usar o REPARTA definido anteriormente para repartir uma árvore g.e. produzindo duas árvores g.e.. usando UNAs (locais). 
Teorema 2.9 : O algoritmo REPARTA é correto (isto é, quando aplicado a uma árvore g.e. gera duas árvores g.e.) e leva tempo

$$
\begin{gathered}
O\left(\lg \left(\frac{P}{p_{i}}\right)\right) \text { se o item } i \text { está na árvore } \\
\text { e } \\
O\left(\lg \left(\frac{P}{p_{-}+p_{+}}\right)\right) \text {se o item } i \text { nào está na árvore. }
\end{gathered}
$$

Prova: Chamemos de $a, p, \epsilon, \epsilon^{\prime}$ e $t$ (veja figura 2.4) os nós atual, próximo, raiz da árvore esquerda anterior, raiz da próxima árvore esquerda e raiz da árvore temporária em cada passo do algoritmo. Para o passo inicial chame de nó atual o nó a(do algoritmo) e de próximo nó pai $(a)$.

Provaremos por induçào usando como hipótese de induçào que as árvores esquerda e direita são g.e. e que o caminho esquerdo da árvore esquerda e o caminho direito da árvore direita estavam (possivelmente nào as raízes) na árvore original.

Após o primeiro passo estas hipóteses estão satisfeitas. Num passo qualquer do algoritmo temos que a árvore com raiz $t$ é g.e. por construção assim como a árvore esquerda. Como $a$ não é folha. o irmão esquerdo de $a$ é um filho primogênito. Logo, $S(t)=S(p)$ ou $S(t)=S(p)-1$, e pelo lema 2.,$S(\epsilon) \leq S(a)<S(p)$, ou seja, $S(\epsilon) \leq S(t)$. Ou seja o algoritmo faz UNAs recursivos nos nós do caminho direito de $t$ até encontrar um nó $q$ tal que $S(q) \leq S(\epsilon)$. Se $S(q)=S(\epsilon)$ entào nenhum outro UNA será executado. Se $S(q)<S(e)$ entào $q$ deve ser caçula e neste caso a deve ser uma folha, pois na árvore original a folha vizinha $v$ de $q$ é a folha mais à esquerda de a (pois por induçào o caminho esquerdo da árvore esquerda estava na árvore original) e como a árvore original era g.e., $S(v) \geq S^{\prime}($ pai $(t))-1 \geq S(a)$. Logo nào serào necessários mais unas. Obviamente o caminho esquerdo de $\epsilon^{\prime}$ está todo ele (com possível exceçào de $\epsilon^{\prime}$ ) na árvore original. Os nós descendentes de $q$ que estavam no caminho direito de $t$ sào g.e., pois a follha vizinha. deles é a folha mais à esqueıda da árvore esquerda (como era na árvore original). Logo, a nova árvore esquerda é g.e. . Analogamente demonstra-se para a nova árvore direita.

Para demonstrar o tempo do pior caso chamemos de $t_{1}, t_{2}, \ldots, t_{k}$ os nós raízes das árvores temporárias $, p_{1}, p_{2} \ldots, p_{k}$ os nós próximo e $\epsilon_{1}, \epsilon_{2} \ldots, \epsilon_{k}$ os nós das árvores esquerdas após o $U N A\left(t_{i}, \epsilon_{1-1}\right)$ para $i \geq 2$ e $\epsilon_{1}=t_{1}$. Entào $S\left(t_{i}\right) \leq S\left(\epsilon_{i}\right) \leq S\left(p_{i}\right) \leq$ $S\left(p_{i+1}\right)-1 \leq S\left(t_{i+1}\right) \leq S\left(p_{i+1}\right)$ para $1<i \leq k$. Para o UNA no passo $i$. $2 \leq i \leq k-1$ precisamos de $O\left(S\left(t_{i+1}\right)-S\left(\epsilon_{i}\right)\right)$. Pelas desigualdades acima temos que $S\left(t_{i+1}\right)-S\left(e_{i}\right) \leq$ $S\left(p_{i+1}\right)-S\left(e_{i}\right)$ e $S\left(p_{i}\right)-1 \geq S\left(t_{i}\right) \geq S\left(\epsilon_{i}\right)$, ou seja, $S\left(t_{i+1}\right)-S\left(\epsilon_{i}\right) \leq S\left(p_{i+1}\right)-S\left(p_{i}\right)-1$, 
ou seja, $O\left(S\left(t_{i+1}\right)-S\left(e_{i}\right)\right)=O\left(S\left(p_{i+1}\right)-S\left(p_{i}\right)\right)$. Somando sobre todos os passos, temos o teorema.

\subsection{Usando Árvores Binárias}

Nesta seção definiremos dois tipos de árvores de busca - binárias localmente enviesadas e binárias globalmente enviesadas - conseguindo os mesmos resultados obtidos na seção anterior. Esta nova abordagem traz vantagens no aspecto de implementaçào, pois como veremos, permitem desenvolver algoritmos mais simples. Nesta seção, não demonstraremos todos os resultados.

Começaremos definindo árvores binárias l.e. que é a versão binária das árvores 1.e.

Definição 2.14 : Chamaremos de árvore binária l.e. às árvores binárias completas (todo nó interno possui exatamente dois filhos) cujos nós $x$ possuem um número inteiro $S(x)$ com as seguintes propriedades:

(i) Se $x$ é uma folha então $S(x)=\left\lfloor\lg \left(p_{i}\right)\right\rfloor$.

(ii) Se $y$ é um nó com pai $x$, então $S(y) \leq S(x)$; se $y$ é uma folha, entào $S^{\prime}(y) \leq S(x)-1$.

(iii) Se $y$ é um nó com avô $x$, então $S(y) \leq S(x)-1$.

(iv) Se $y$ é um nó caçula com pai $x$, entào se y é um filho esquerdo (direito), então o irmão de $y$ ou o filho esquerdo (direito) do irmào de $y$ é uma folha $k$ tal que $S(k)=S(x)-1$. Se, além disso, $x$ é um filho dircito e tem posto igual ao de seu pai, então o irmão de $x$ ou o filho direito do irmào de $x<$ uma folla de posto $S(x)-1$. 

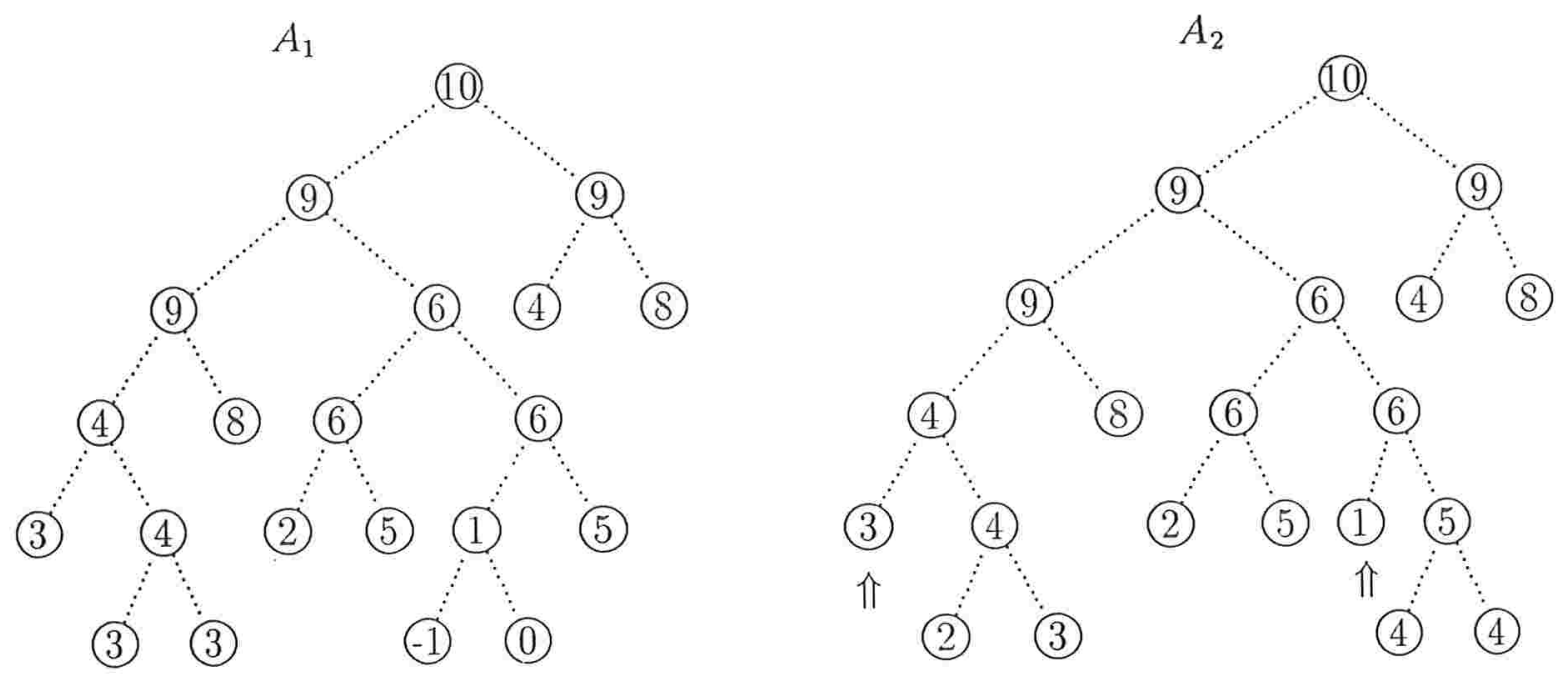

Figura 2.8 : Os números dentro dos vértices são os postos. A árvore $A_{1}$ é uma árvore binária l.e., enquanto que a árvore $A_{2}$ nâo é binária l.e., pois os nós assinalados (com seta) não satisfazem a propriedade (iv) da definiçào 2.14 .

Árvores binárias enviesadas constituem uma versào binária de (2,4)-árvores enviesadas como mostra a figura 2.9 . 

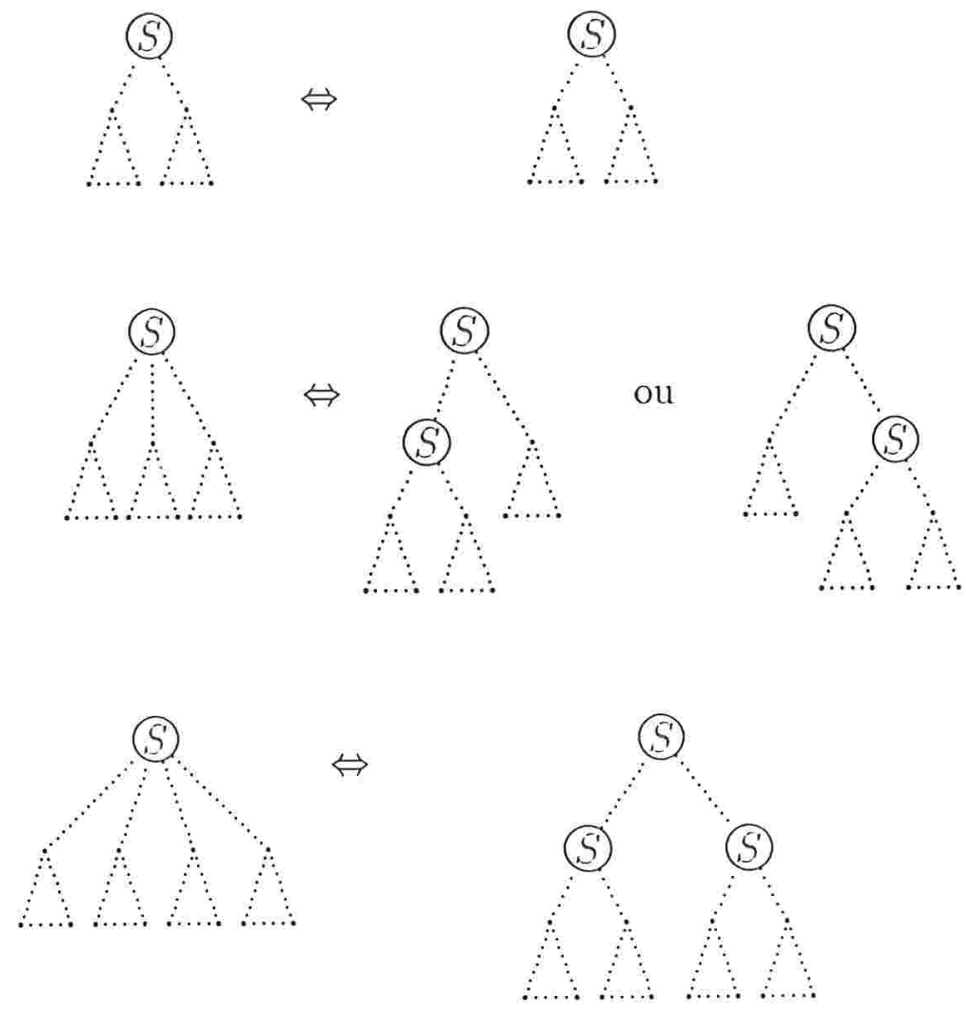

Figura 2.9 : Correspondência entre $(2,4)$-árvores e árvores binárias.

Todos os teoremas da seçào anterior para $(2, \mathrm{~b})$ árvores enviesadas valem para árvores binárias. Em particular. uma árvore binária possui tempo ideal de acesso. Mostraremos uma versào dos algoritmos UNA, UNA-GLOBAL e REPARTA para árvores binárias enviesa.das.

Primeiramente, definiremos duas operaçòes básicas que serào usadas no UNABINÁRIO.

rotaçâo-esquerda(x): Sejam $x_{1}$ e $x_{2}$ os filhos esquerdo e direito de $x$. Se $S(x)=S\left(x_{1}\right)=$ $S\left(x_{2}\right)$, faça $S(x)=S(x)+1$ e retorne $x$. Se $S\left(x_{1}\right)<S(x)=S\left(x_{2}\right)$, entào sejam $x_{21}$ e $x_{22}$ os filhos esquerdo e direito de $x_{2}$. Faça $x$ e $x_{22}$ filhos esquerdo e direito de $x_{2}$ e, faça $x_{1}$ e $x_{21}$ filho esquerdo e direito de $x_{1}$ e retorne $x_{2}$ ( veja figura 2.10 ). Nos demais casos retorne $x$.

rotaçâo-direita $(x)$ : Simétrica à rotaçâo-esquerdal $(x)$. 

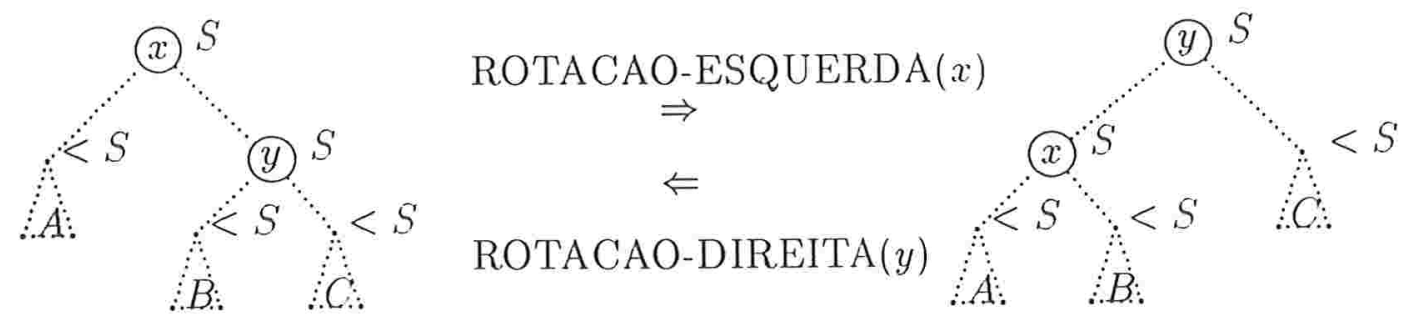

Figura 2.10 : Uma rotaçào em torno do nó $x$ e outra em torno do nó $y$.

Note que após uma rotação as folhas das árvores original e resultante estão na mesma ordem, e se a árvore original é binária l.e. a resultante também o é.

Veremos agora o UNA-BINÁRIO que é a versào do UNA para árvores binárias l.e. Esse algoritmo receberá como entrada a raiz de duas árvores binárias l.e., que representam dois conjuntos e retornará a raiz de uma árvore binária l.e. que representa a união destes conjuntos.

função UNA-BINÁRIO (raiz $x, y)$ :

nó $z, z_{1}, z_{2}$;

.caso 1: $S(x)=S(y)$, ou $S(x)>S(y)$ e $x$ é folha, ou $S(x)>S(y)$ e $y$ é folha.

crie um nó $z$;

- faça $x$ e $y$ filhos esquerdo e direito de $z$;

- $S(z)=\max \{S(x), S(y)\}+1$ :

retorne $z$;

caso 2: $S(x)>S(y)$ e $x$ nào é folha.

$z=\operatorname{rotaçâo-esquerda(~} x)$

$z_{1}=$ filho direito de $z ;$

. $z_{2}=U N A-B I N A ́ R I O\left(z_{1}, y\right)$;

- faça $z_{2}$ filho direito de $z$ :

retorne $z$;

.caso 3: $S(x)<S(y)$ e y nào é folha.

Simétrico ao caso 2. 
a)

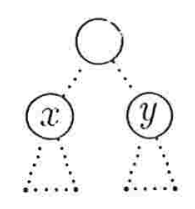

b)

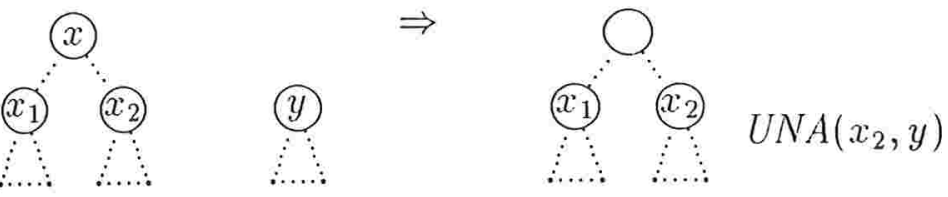

c)

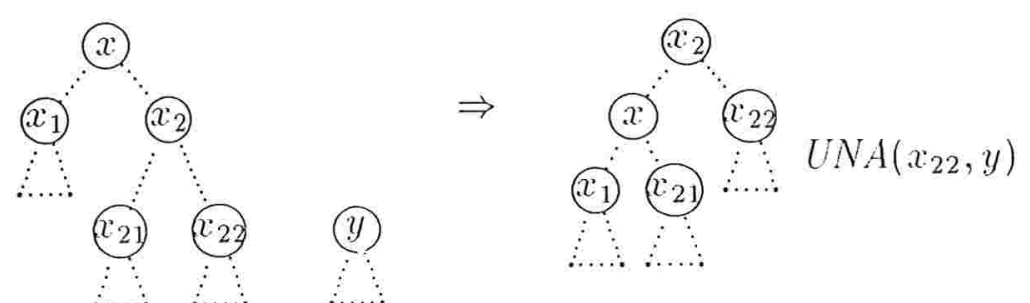

Figura 2.11 : Exemplo de $U N A-B I N A ́ R I O$. a) Caso 1. b) Caso 2 quando a rolaçào não ocorreu efetivamente. c) Caso 2 quando a rotaçào ocorreu efetivamente.

Lema 2.10 : Seja z a raiz de uma árvore resultante do UNA-BINÁRIO(x,y) entào $S(z)=\max \{S(x), S(y)\}$ ou $S(z)=\max \{S(x), S(y)\}+1$ e no último caso se os filhos de $z$ são $z_{1}$ e $z_{2}, S(z)>S\left(z_{1}\right)$ e $S(z)>S\left(z_{2}\right)$.

Prova: No caso 1 temos que $S^{\prime}(z)=\max \left\{S(x), S^{\prime}(y)\right\}+1, S(z)>S\left(z_{1}\right)$ e $S^{\prime}(z)>S\left(z_{2}\right)$. No caso 2 , se $S(x)$ nào se alterou entào $S(z)=\max \{S(x), S(y)\}$. Por outro lado. ainda no caso 2 , se $S(x)$ foi incrementado, entâo se $x_{2}$ era o filho direito de $x, x_{2}$ nào era folha (pois $S(x)=S\left(x_{2}\right)$ ) e $S\left(x_{2}\right)>S(y)$. Portanto, o caso 2 foi aplicado novamente. Pela propriedade (iii) das árvores binárias l.e., $S\left(x_{21}\right)<S\left(x_{2}\right)$ e $S\left(x_{22}\right)<S\left(x_{2}\right)$. onde $x_{21}$ e $x_{22}$ são os filhos de $x_{2}$. Portanto. se $z_{2}$ é a raiz do UNA-BINÁRIO recursivo, temos que $S\left(z_{2}\right)=S\left(x_{2}\right)$. Portanto, $S(z)>S\left(z_{1}\right)$ e $S(z)>S\left(z_{2}\right)$. O caso 3 é simétrico.

Teorema 2.10 : O algoritmo UNA-BINÁRIO é correto. 
Prova: No caso 1 é óbvio. No caso 2 temos 3 subcasos a analisar:

Caso 2a: após a rotação-esquerda $S(x)$ foi incrementado.

Caso 2b: após a rotação-esquerda não houve nenhuma alteração na árvore.

Caso 2c: após a rotação-esquerda houve alteraçào na estrutura da árvore.

No caso $2 \mathrm{a}$, como vimos no lema $2.10, S\left(z_{2}\right)<S(z)$. Portanto, as propriedades (i), (ii), e (iii) continuam válidas e neste caso, $x_{1}$ e $x_{2}$ não podiam ser caçulas. Logo, a propriedade $(i v)$ também continua válida.

No caso $2 \mathrm{~b}$, pelo lema $2.10, S\left(z_{2}\right) \leq \max \left\{S\left(x_{2}\right), S(y)\right\}+1$ e portanto $S\left(z_{2}\right) \leq$ $S(z)$, satisfazendo a propriedade (ii). Se $S\left(z_{2}\right)=S(z)$, pelo lema $2.10, S\left(z_{2}\right)>S\left(z_{21}\right)$ e $S\left(z_{2}\right)>S\left(z_{22}\right)$ satisfazendo a propriedade (iii). Se $x_{1}$ for caçula, então $x_{2}$ ou $x_{21}$ (o filho esquerdo de $x_{2}$ ) é folha primogênita. Logo, $z_{21}=x_{21}$, o que verifica a validade da propriedade $(i v)$.

No caso 2 c, $S\left(x_{22}\right)<S\left(x_{2}\right)$ ( $x_{2}$ ficou sendo a nova rajz da árvore). Pelo lema 2.10 , $S\left(z_{2}\right) \leq \max \left\{S\left(x_{2}\right), S(y)\right\}+1$ e portanto $S\left(z_{2}\right) \leq S\left(x_{22}\right)$. o que verifica a propriedade (ii); se $S\left(z_{2}\right)=S\left(x_{22}\right)$, pelo lema $2.10, S\left(z_{2}\right)>S\left(z_{21}\right)$ e $S\left(z_{2}\right)>S\left(z_{22}\right)$ o que verifica a propriedade (iii). Como $x$ nào é caçula a propriedade (iv) continua valendo.

Os resultados obtidos nos teoremas 2.2. 2.3 e 2.4, podem ser demonstrados para a versão binária do $U N A$.

O algoritmo REPART A apresentado na seçào anterior pode ser usado com uma redução no número de casos e os resultados apresentados no teorema 2.5 podem ser demonstrados. O tempo, no pior caso, do algoritmo REPARTA pode ser obtido para árvores binárias g.e.

Definição 2.15 : Chamaremos de árvore binária globalmente enviesadas às árvores binárias completas cujos nós possuam as propriedades (i), (ii). e (iii) das árvores binárias l.e. e a seguinte propriedade $\left(i v^{\prime}\right)$ :

$\left(i v^{\prime}\right)$ Se $y$ é um filho caçula com pai $x$, entào para qualquer folha v vizinha de $y$ temos que $S(v) \geq S(x)-1$.

Precisamos novamente modificar o algoritmo (NA-BINÁRIO para unir árvores g.e. Chamaremos de $d(x)$ e $e(x)$ os filhos direito e esquerdo de um nó $x$. Esse algoritmo receberá como entrada raízes de duas árvores binárias g.e., que representam dois conjuntos e retornará a raiz de uma árvore binária g.e. que representa a uniào destes conjuntos. 
função UNA-GLOBAL-BINÁRIO (raiz $x, y)$ :

nó $z, z_{1}, z_{2}, u, v$;

.caso $1: S(x) \geq S(y)$ e $x$ é uma folha, ou $S(y) \geq S(x)$ e $y$ é uma folha.

- crie um nó $z$;

- faça $x$ e $y$ filhos de $z$;

- retorne $z$;

.caso 2: $S(x)>S(y)$ e $x$ não é folha.

. $z=$ rotação-esquerda $(\mathrm{x})$;

- $z_{1}=$ filho direito de $z$;

. $z_{2}=U N A-G L O B A L-B I N A ́ R I O\left(z_{1}, y\right)$

- faça $z_{2}$ filho direito de $z$;

retorne $z$;

.caso 3: $S(x)<S(y)$ e $y$ não é folha.

. Simétrico ao caso2;

.caso 4: $S(x)=S(y)$ e nem $x$ nem $y$ é uma folha.

se $S(d(x))<S(x)$

então $u=x$

senão $u=d(x)$;

se $S(e(y))<S(y)$

então $v=y$

senão $v=e(y)$;

$z=U N A-G L O B A L-B I N A ́ R I O(d(u), e(v))$;

$I^{*}$ Observe que em qualquer um dos casos temos que $S(u)=S(x)$ e $S(d(u))<S(x)$, ocorrendo o mesmo entre $y$ e $v . * /$

caso4a: $S(z)=S(x)$.

$d(u)=e(z)$

$e(v)=d(z)$

$e(z)=x$;

$d(z)=y$;

$S(z)=S(x)+1 ;$

retorne $z$; 
. caso4b: $S(z)<S(x) . /^{*}$ Temos aqui 5 subcasos: */

$$
\begin{aligned}
& \operatorname{caso} 4 \mathrm{~b}(\mathrm{i}): u=d(x) . \\
& d(x)=e(u) \\
& e(v)=z ; \\
& e(u)=x ; \\
& d(u)=y ; \\
& S(u)=\max \{S(x), S(y)\}+1 ;
\end{aligned}
$$

retorne $u$;

$$
\operatorname{caso} 4 \mathrm{~b}(\mathrm{ii}): v=e(y) \text {. }
$$

$e(y)=d(v)$

$d(u)=z$

$e(v)=x ;$

$d(v)=y$

$S(v)=\max \{S(x), S(y)\}+1$;

retorne $v$;

caso4b(iii): $u=x$ e $S(x)=S(\epsilon(x))$.

$e(v)=z ;$

$d(x)=y$

$S(x)=S(x)+1$

retorne $x$;

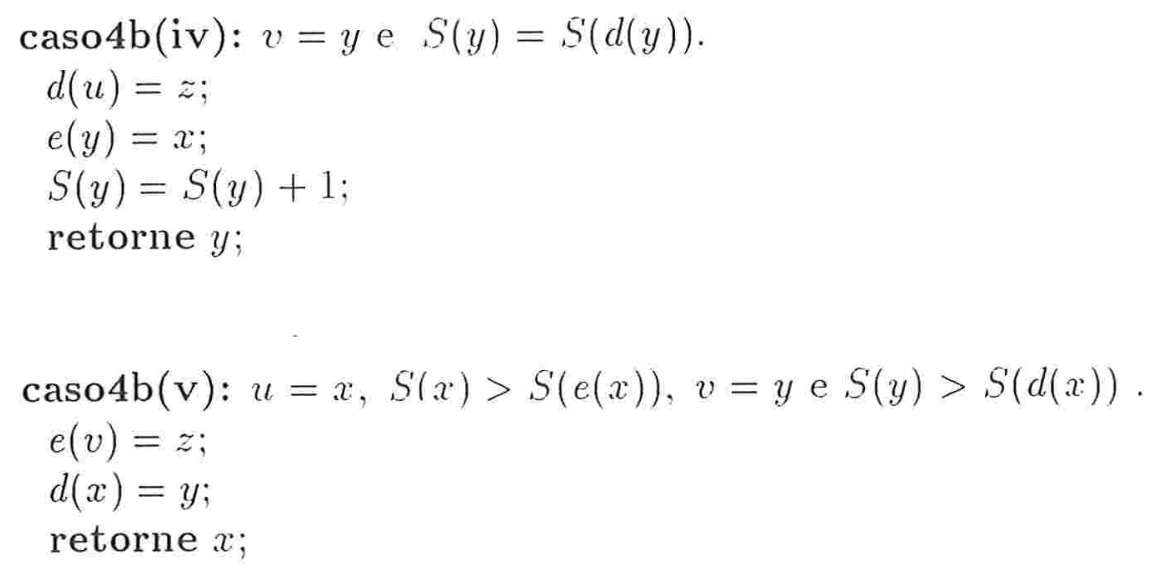

Observação: Os casos 4b(i) e (ii) assim como os casos 4b(iii) e 4b(iv) nào sào disjuntos. Quando dois casos sào possíveis a escolha pode ser arbitrária. 

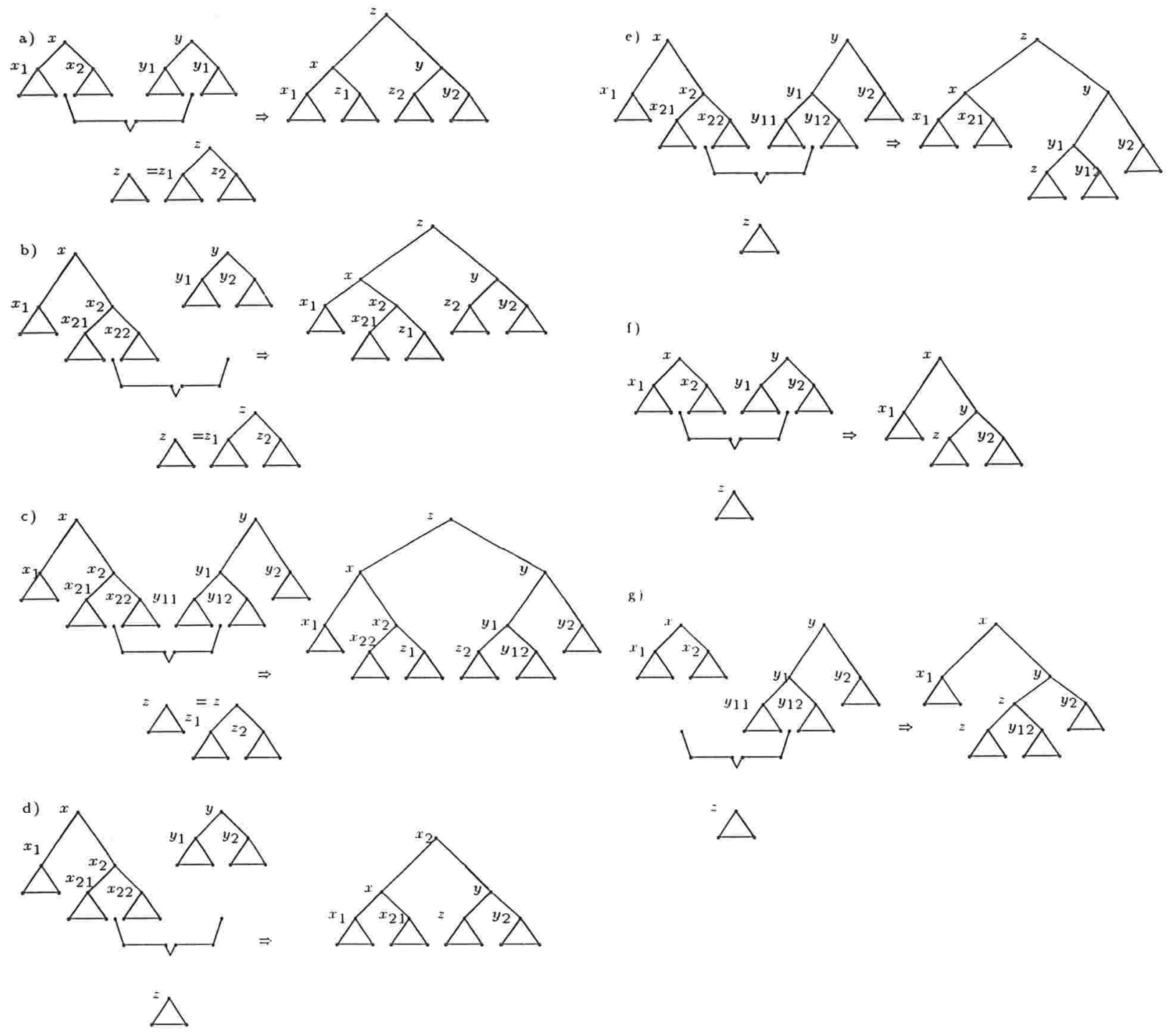

$\triangle$

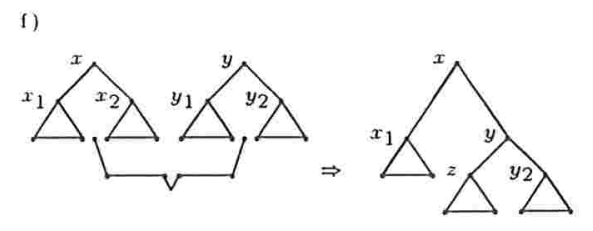

$\triangle$

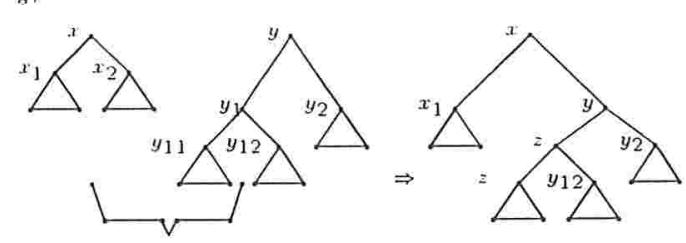

$\triangle$

Figura 2.12 : Caso 4 do UNA-GLOBAL-BINÁRIO.

a) Caso 4 a $(S(z)=S(x))$ com $u=x, v=y$.

b) Caso 4 a com $u=d(x), v=y$. Caso 4 a com $u=x, v=e(v)$ é simétrico.

c) Caso 4 a $\operatorname{com} u=d(x), v=e(y)$.

d) Caso $4 \mathrm{~b}$ (i) $\operatorname{com} v=y$. Caso $4 \mathrm{~b}$ (ii) $\operatorname{com} u=x$ é simétrico.

e) Caso 4 b(i) $\operatorname{com} v=\epsilon(y)$. Caso 4 b(ii) com $u=d(x)$ é simétrico.

f) Caso $4 \mathrm{~b}$ (iii) $\operatorname{com} v=y$ e caso $4 \mathrm{~b}$ (v). (Caso $4 \mathrm{~b}$ (iv) $\operatorname{com} u=x$ é simétrico.

g) Caso $4 \mathrm{~b}($ iii) $\operatorname{com} v=e(y)$. Caso $4 \mathrm{~b}$ (iv) $\operatorname{com} u=d(x)$ é simétrico.

A verificaçào de que o algoritmo é correto pode ser feita através de uma simples, porém longa, verificaçào de todos os casos. Deixaremos isto a cargo do leitor. 
Da mesma maneira que ocorre com (2,b)-árvores g.e., o REPARTA-BINÁRIO usado para repartir árvores binárias l.e., pode ser usado para repartir árvores binárias g.e. e obter árvores binárias g.e. . Além disso, o teorema 2.9 que fornece o tempo no pior caso do REPARTA, vale também para árvores binárias g.e.

Além da aplicação no problema das árvores clinâmicas - que será visto no próximo capítulo - tais estruturas de dados podem ser aplicadas no tratamento de vários problemas computacionais, como por exemplo no problema do dicionário com pesos de acesso e no problema das árvores de busca multidimensionais. Maiores detalhes podem ser encontrados em [3]. 


\section{Capítulo 3}

\section{ÁRVORES DINÂMICAS}

Vários algoritmos de otimizaçào em redes requerem uma estrutura de dados para representar uma coleção de árvores disjuntas, nas quais deseja-se realizar operaçôes que podem ou não alterar suas estruturas. Neste capítulo veremos que, usando árvores (de busca) enviesadas, podemos desenvolver uma estrutura de dados para tais árvores dinâmicas, nas quais várias operaçòes de interesse podem ser realizadas em tempo $O(\lg n)$, onde $n$ é o número de vértices da coleção. A estrutura de dados que apresentaremos aqui será. utilizada na implementaçào de um algoritmo bastante eficiente para o problema do fluxo máximo, tópico este a ser abordado no próximo capítulo. Faremos aqui uma descrição similar a feita por Sleator e Tarjan [18], com algumas modificaçòes.

\subsection{O Problema das Árvores Dinâmicas}

Considere o seguinte problema: Dada uma floresta de árvores disjuntas (com raiz), onde cada uma das arestas possui um custo, desejamos representar essas árvores por uma estrutura de dados que nos permita executar eficientemente as seguintes operaçòes:

- pai(vértice v): Retorna o pai do vértice $v$. Se v nào possui pai (é a raiz de uma árvore), então retorna um valor especial nulo.

- raiz(vértice $v)$ : Retorna a raiz da árvore que contém $v$.

- customin (vértice $v)$ : Retorna um vértice $w$ tal que a aresta $(w, p a i(w))$ seja a aresta de menor custo no caminho de v até raiz(v). Esta operaçào supòe que v nào é uma raiz.

- custo(vértice v): Retorna o custo da aresta (vpai(v)). Esta operaçào supòe que v nào 
é uma raiz.

- tamanho(vértice $v)$ : Retorna o tamanho da árvore a que $v$ pertence.

- atualiza(vértice $v$, real $x)$ : Soma $x$ no custo de cada uma das arestas do caminho de $v$ até $\operatorname{raiz}(v)$.

- enxerta(vértice $v, w$; real $x)$ : Junta as árvores que contêm os vértices $v$ e $w$ adicionando a aresta $(v, w)$ com custo $x$ e fazendo $w$ pai de $v$. Esta operação considera que $v$ e $w$ estão em árvores diferentes e que $v$ é a raiz de uma árvore.

- poda(vértice $v)$ : Divide a árvore contendo o vértice $v$ em duas árvores, obtidas eliminandose a $\operatorname{aresta}(v, p a i(v))$; retorna o custo desta aresta. Esta operação supõe que $v$ não é raiz.

- reverte(vértice $v$ ): Modifica a árvore que contém $v$, fazendo $v$ tornar-se raiz da árvore.

As operações pai, raiz, customin, custo, tamanho só extraem informações da floresta sem alterá-la; a operação atualiza altera os custos das arestas, mas não altera a estrutura da floresta. As operaçòes enxerta, podı e reverte alteram a estrutura da floresta.

Nas análises que faremos, suporemos que a floresta inicial é uma coleçào de $n$ vértices isolados, $n \geq 2$, e denotaremos por $m$ o número total de operaçòes (dos tipos acima).

Antes de apresentarmos uma soluçào mais sofisticada, consideremos a solução óbvia, que seria cada vértice v guardar um ponteiro para o seu pai e o custo da aresta. $(v, p a i(v))$. Com esta representaçào poderíamos realizar cada uma das operaçòes pai, custo, enxerta e poda em tempo $O(1)$. O tempo para cada uma das demais operações seria o comprimento do caminho de $v$ até raiz $(v)$, que é $O(n)$ no pior caso.

Usando uma outra representação - que veremos a seguir - podemos realizar as operaçôes raiz, customin, atualiza e reverte em tempo $O(\lg (n))$, com prejuízo das demais operaçoes que passam a ser realizadas em tempo $O(\lg (n))$ também.

\subsection{Representando Árvores como Conjunto de Ca- minhos}

Para resolver o problema das árvores dinâmicas que descrevemos na seçào anterior, vamos representar cada árvore por uma coleçào de caminhos disjuntos, e vamos realizar cada uma 
das operações na árvore por meio de uma ou mais operações sobre caminhos. Nesta seção veremos uma maneira simıles de representar árvores como conjunto de caminhos.

Dada uma árvore, particionando as suas arestas em dois grupos, sólidas e frágeis - com a propriedade de que no máximo uma aresta sólida entra em um vértice (def. A.14) - , podemos particionar tal árvore em conjuntos de caminhos disjuntos. As arestas sólidas definem uma coleção de caminhos sólidos. Un vértice no qual não incide nenhuma aresta sólida é também um caminho (de comprimento nulo) que será considerado sólido. Assim, cada vértice da árvore pertence a exatamente um caminho sólido. Os caminhos sólidos serão chamados simplesmente de caminhos.

Cada caminho tem um nó cabeça, que é o nó mais distante da raiz, e um nó cauda, que é o nó mais próximo da raiz. A cabeça é o início do caminho, e a cauda é o fim do caminho. Além dos caminhos precisamos representar as arestas frágeis. Estas ficam representadas da seguinte forma: Cada nó cauda v, guarda a informaçào dpai(v), que é o pai de $v$ na árvore (via aresta frágil) e a informaçào dcusto, que é o custo da aresta $(v, \operatorname{pai}(v))$. Se $v$ é a raiz da árvore então $\operatorname{dpai}(v)=n u l o$ e dcusto $(v)$ fica indefinido.

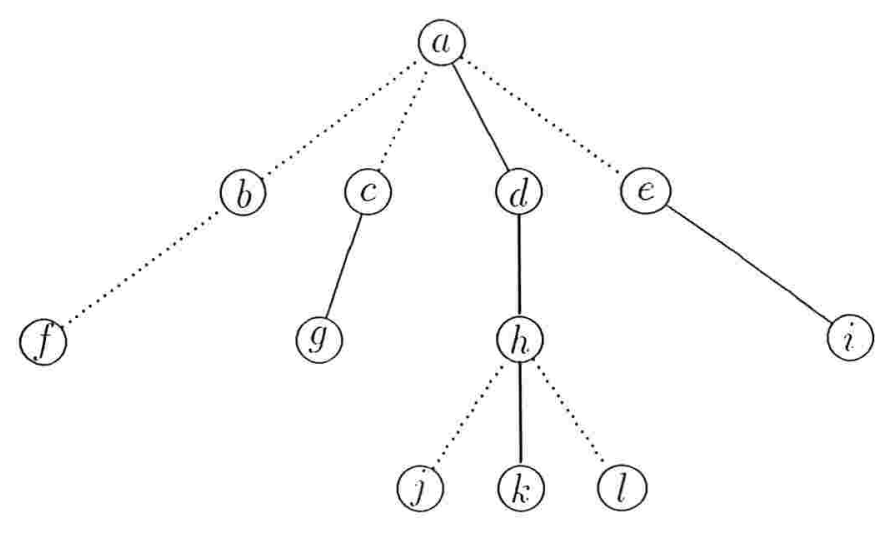

Figura 3.1 : Exemplo de uma árvore particionacla em caminhos. (k.h.d.a) é um caminho onde $k$ é a cabeça e $a$ a cauda.

A seguir definiremos várias operaçòes sobre caminhos:

- caminho(vértice v): Retorna o caminho ao qual o vértice $v$ pertence.

- cabeça( caminho $c)$ : Retorna a cabeça do caminho c.

- cauda (caminho c): Retorna a cauda do caminho c. 
- anterior(vértice $v$ ): Retorna o vértice anterior a $v$ no caminho(v). Se $v$ é a cabeça do caminho, retorna um valor especial nulo.

- posterior (vértice $v$ ): Retorna o vértice posterior a $v$ no caminho(v). Se $v$ é a cauda do caminho, retorna um valor especial nulo.

- ccusto(vértice $v)$ : Retorna o custo da aresta $(v$, posterior $(v))$. Esta operação supõe que $v$ não é a cauda do cuminho(v).

- ccustomin( caminho $c)$ : Retorna o vértice $v$ no caminho $c$ tal que a aresta $(v$, posterior $(v))$ seja a aresta de menor custo no caminho $c$.

- catualiza(caminho $c$; real $x)$ : Adiciona $x$ ao custo de cada uma das arestas do caminho $c$.

- inverte (caminho c): Inverte a direçào do caminho $c$ fazendo com que a cabeça se torne cauda e vice-versa.

- concatena (caminho $p, q$ : real $x$ ): Concatena os caminhos $p$ e $q$ adicionando a aresta. $(\operatorname{cauda}(p)$, cabeça $(q))$ com custo $x$, retornando o novo caminho formado.

- quebra(vértice v): Divicle o caminho $p$ em até três caminhos removendo as arestas incidentes a $v$. Retorna a lista $\left\{c_{1}, c_{2}, x_{1}, x_{2}\right\}$ onde:

- $c_{1}$ é o caminho de cabeşa( caminho(v)) até anterior(v):

- $c_{2}$ é o caminho de caudal caminho(v)) até postcrior(v):

- $x_{1}$ é o custo da aresta removida (anterior( $\left.(v), v^{v}\right)$ :

- $x_{2}$ é o custo da aresta removida $(v$, posterior(v)).

Se $v$ é originalmente a cabeça do caminho(v) entào $c_{1}$ é nulo e $x_{1}$ indefinido. Por outro lado, se $v$ é originalmente a cauda do caminho(v) entào $c_{2}$ é nulo e $x_{2}$ indefinido.

- emenda (caminho c): Estende o caminho $c$, convertendo a aresta frágil incidente à cauda(c) em sólida e a aresta sólida entrando em pai(cauda $(p))$, se existir, em frágil. Retorna este caminho. Veja figura 3.2 (i). Esta operaçào supòe que cauda(c) nào é uma. raiz.

- estende(vértice v): Cria un caminho com cabeça v e cauda raiz(v) convertendo as arestas frágeis entre v e raiz(v) em sólidas e convertendo as arestas sólidas incidentes a. este caminho em frágeis. Retorna este novo caminho formado. Veja figura 3.2 (ii). 
- ctamanho(caminho c): Retorna o tamanho da subárvore que tem como raiz cauda(c).

i)<smiles>CCCCOc1ccccc1OCCO</smiles>

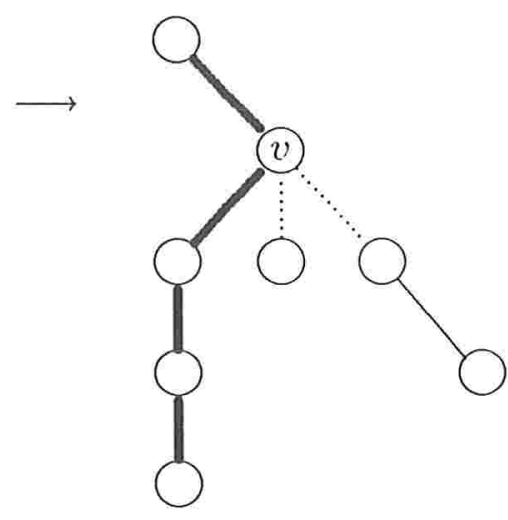

ii)
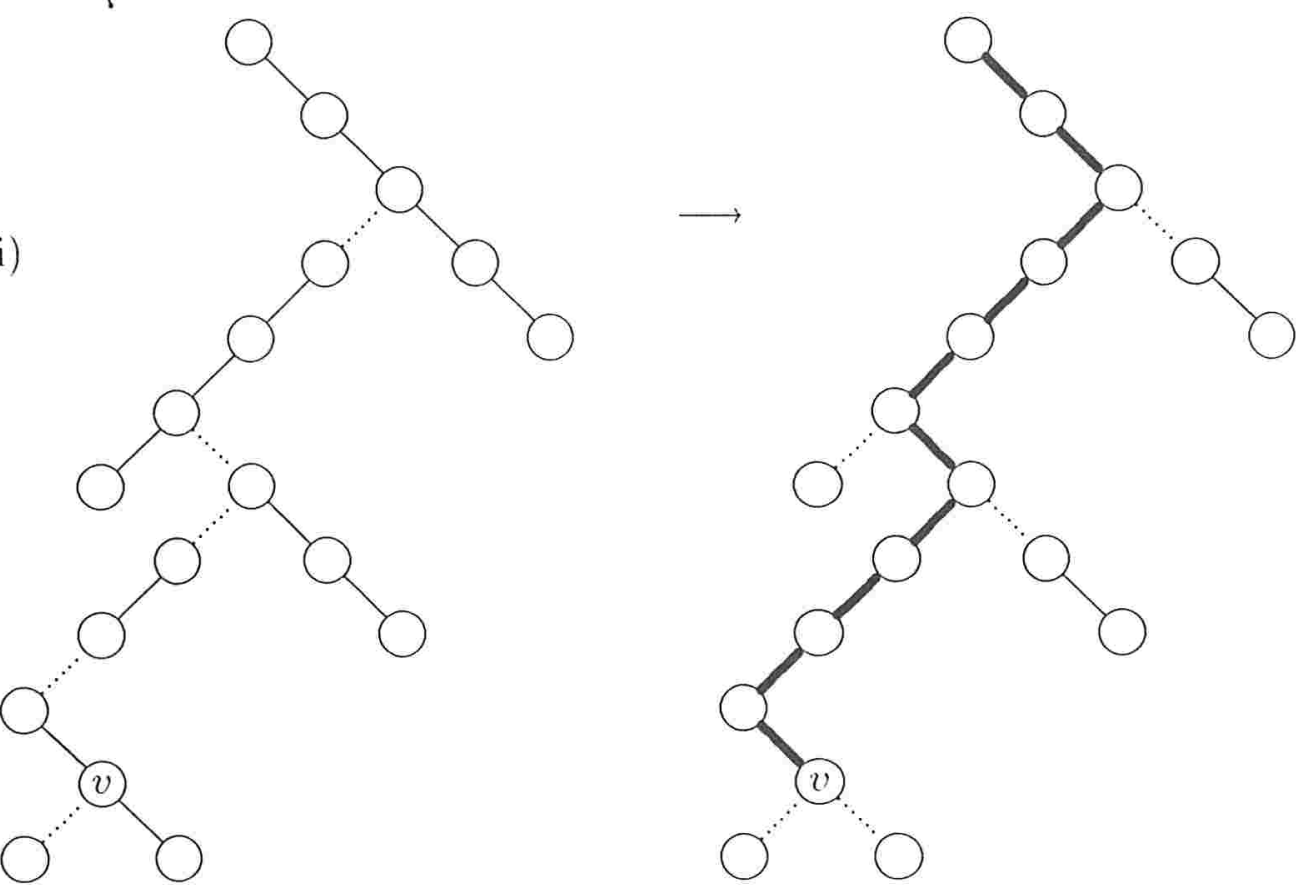

Figura 3.2 : Exemplo de emenda e estende: i) emenda(c), ii) estende(v).

Veremos agora como implementar emenda, estende, e as operaçòes sobre as árvores com base nas operaçòes sobre caminhos. 
função emenda( caminho $c)$ :

vértice $v$;

caminho $c_{1}, c_{2}$;

real $x_{1}, x_{2}$;

$. v=\operatorname{dpai}(\operatorname{cauda}(c))$;

$. c_{1}, c_{2}, x_{1}, x_{2}=q u e b r a(v)$;

.se $c_{1} \neq$ nulo

então dpai( $\left.\operatorname{cauda}\left(c_{1}\right)\right)=v$;

dcusto $\left(\operatorname{cauda}\left(c_{1}\right)\right)=x_{1}$;

$. c=$ concatena $(c$, caminho $(v)$, dcusto $($ cauda $(c))$;

.se $c_{2}=$ nulo

- então retorna $c$

- senão retorna concaten $a_{(}\left(c_{,} c_{2}, x_{2}\right)$ :

função estende(vértice v):

caminho $c, c_{1}, c_{2}$;

real $x_{1}, x_{2}$

$. c_{1}, c_{2}, x_{1}, x_{2}=$ quebra $(v)$

.se $c_{1} \neq$ nulo

- então dpai $\left(\operatorname{cauda}\left(c_{1}\right)\right)=v$;

dcusto $\left(\right.$ cauda $\left.\left(c_{1}\right)\right)=x_{1}$;

.se $c_{2}=$ nulo

- então $c=\operatorname{caminh} o(v)$

- senão $c=$ concatena $\left(\right.$ caminho(v), $\left.c_{2}, x_{2}\right)$;

.enquanto dpai( cauda $(c)) \neq$ nulo faça

. $c=$ emenda $a(c)$;

retorna $c$;

função pai(vértice v):

.se $v=\operatorname{cauda}(\operatorname{caminh} o(v))$

- então retorna $\operatorname{dpai}(v)$

- senão retorna posterior(v) : 
função raiz(vértice v):

.retorna cauda( estende $(v))$ :

função custo(vértice v):

.se $v=\operatorname{cauda}(\operatorname{caminh} o(v))$

- então retorna dcusto $(v)$

- senão retorna ccusto( $(v)$;

função customin(vértice v):

.retorna ccustomin (estende $(v))$;

função atualiza(vértice v:real $x$ ):

.catualiza(estende(v), x);

função enxerta(vértice v, w:real $x)$ :

.concatena $($ caminho(v), estende $(w), x)$;

função poda(vértice v):

caminho $c_{1}, c_{2}$;

real $x_{1}, x_{2}$;

.estende $(v)$;

. $c_{1}, c_{2}, x_{1}, x_{2}=$ quebra $(v)$;

.dpai $(v)=$ nulo:

retorna $x_{2}$; 
função reverte(vértice $v$ ):

.inverte $($ estende $(v))$;

$. d p a i(v)=$ nulo

função tamanho(vértice v):

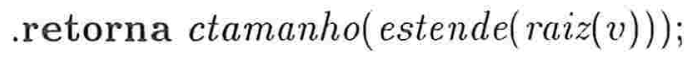

$\mathrm{Na}$ análise das operaçòes acima, a única tarefa não trivial é calcular o número de operações emenda realizadas por estende. Contaremos o número de operações emenda realizadas após uma seqüência de $m$ operações sobre árvores.

Definição 3.1 : Definimos grandeza de um vértice $v$, denotada por grandeza(v), como sendo o número de descendentes de $v$ contando ele próprio.

Definição 3.2 : Dizemos que uma aresta $(v, p a i(v))$ é pesada se 2.grandeza(v) > grandeza(pai $(v))$; e leve, caso contrário.

Lema 3.1 : Seja $v$ um vértice qualquer de uma floresta $\operatorname{com} n$ vértices. Entào existe no máximo uma aresta pesada entrando em $v$ e no máximo $\lfloor\lg (n)\rfloor$ arestas leves no caminho de $v$ até $\operatorname{raiz}(v)$.

Prova: Suponha por absurdo que $\left(w_{1}, v\right)$ e $\left(w_{2}, v\right)$ sejam duas arestas pesadas entrando em $v$. Então 2.grande $z a\left(w_{1}\right)>\operatorname{grande} z a(v)$ e 2.grande $z a\left(w_{2}\right)>\operatorname{grande} z a(v)$.

Logo, 2. $\left(\right.$ grande $\left.z a\left(w_{1}\right)+\operatorname{grande} z a\left(w_{2}\right)\right)>2$.grande $z a(v)$. Absurdo, pois $\left(\right.$ grande $z a\left(w_{1}\right)+$ grande $\left.z a\left(w_{2}\right)\right)<$ grandeza $(v)$.

Veremos agora, porque existem no máximo $\lfloor\lg (k)\rfloor$ arestas leves no caminho de $v$ até $\operatorname{raiz}(v)$. A prova será por indução em $k$, onde $k$ é o número de vértices da árvore que contém $v$.

Denotaremos por leves $(v, w)$ o número de arestas leves no caminho de $v$ até $w$.

Se $k=1$, nào há arestas e portanto nào há arestas leves.

Suponha $k \geq 2$. Suponha que $r$ é a raiz da árvore e $\left(r^{\prime}, r\right)$ é a última aresta no caminho de $v$ até $r$. Se $\left(r, r^{\prime}\right)$ é pesada nào há nada a demonstrar. Suponha que $\left(r, r^{\prime}\right)$ 
seja leve. Seja $k^{\prime}$ o número de vértices da subárvore com raiz $r^{\prime}$. Então $2 . g r a n d e z a\left(r^{\prime}\right) \leq$ grande.za $(r)$, isto é, $2 . k^{\prime} \leq k$. Por induçào, leves $\left(v, r^{\prime}\right) \leq\left\lfloor\lg \left(k^{\prime}\right)\right\rfloor$. Logo, leves $(v, r)=\operatorname{leves}\left(v, r^{\prime}\right)+1 \leq\left\lfloor\lg \left(k^{\prime}\right)\right\rfloor+1$, e portanto

$$
\operatorname{leves}(v, r) \leq\left\lfloor\lg \left(\frac{k}{2}\right)\right\rfloor+1=\lfloor\lg (k)\rfloor
$$

Considerando as características leves, pesadas, sólidas e frágeis podemos dividir as arestas em quatro grupos: pesadas sólidas, pesadas frágeis, leves sólidas e leves frágeis. Com base no efeito que as cperaçōes sobre árvores causam no tamanho destes grupos de arestas daremos um limite para o total de emenda. Chamamos uma operação emenda(c) de especial se pai(cauda $(c))$ é a cabeça de um caminho; e normal, caso contrário. Uma operação emenda especial aumenta o número de arestas sólidas de um, enquanto que uma operação emenda normal deixa o número de arestas sólidas inalterado.

Teorema 3.1 : Em uma seqüência de $m$ operaçòes sobre árvores sào executadas no máximo $m$ operações emenda especiais.

Prova: Sejam | sólidas |, | estende |, | especiais |,| enxerta | e | poda | o número de arestas sólidas, operaçôes estende. emendas especiais, operaçòes enxerta e operaçòes poda, respectivamente. O número total de arestas é: $\mid$ enxerta $|-|$ poda $\mid$. Logo,

$$
\mid \text { sólidas }|\leq| \text { enxerta }|-| \text { poda } \mid \text {. }
$$

Os primeiros comandos da funçào estende decrementam | sólidas | de no máximo 1; o último comando desta função (enquanto) incrementa $\mid$ sólidas $\mid$ de pelo menos 1 por emenda especial. Fora da operaçào estende. a operaçào enxerta incrementa | sólid.lus | de 1, e a operaçào poda decrementa | sólidas | de no máximo 1. Logo, podemos escrever a seguinte desigualdade:

$\mid$ sólidas $|\geq|$ especiais $|+|$ enxerta $|-|$ estende $|-|$ poda $\mid$. Dessa desigualdade resulta que $\mid$ especiais $|\leq|$ estende $|+|$ sólidas $|-|$ enxerta $|+|$ poda $\mid$. E como $\mid$ sólidas $|-|$ enxerta $|+|$ poda $\mid \leq 0$. segue que

$$
\mid \text { especiais }|\leq| \text { estende } \mid \leq m \text {. }
$$

Teorema 3.2 : Em uma seqüência de $m$ operaçòes sobre árvores dinâmicas. são executadas no máximo $m(3 \cdot\lfloor\lg (n)\rfloor+1)$ operaçòes emenda. 
Prova: Dizemos que uma operação emenda (c) é leve quando a aresta ( cauda(c),pai( cauda(c)) é leve; e pesada, caso contrário. Para calcular o número total de operaçōes emenda, vamos calcular o número de emendas leves, | emendas leves $\mid$ e o número de operaóes emenda pesadas,

| emendas pesadas|. Durante uma operação estende são realizadas no máximo $\lfloor\lg (n)\rfloor$ emendas leves. Então $\mid$ emendas leves $|\leq\lfloor\lg (n)\rfloor|$ estende $\mid$. Para obter um limite no número de operaçôes emendas pesadas vamos denotar por ps o número de arestas pesadas e sólidas. Durante uma operaçào estende. cada operação emenda pesa.da incrementa ps de 1, cada operaçâo emenda leve decrementa ps de no máximo 1, e as duas primeiras linhas do estende decrementa ps de no máximo 1.

Na operação enxerta $(v, w, x)$, temos que quantificar o decremento de $p s$ ocorrido após a operação estende, já que o decremento de ps causado pela operaçào estende será contado à parte. Após a operaçào estende temos que todas as arestas do caminho de $w$ até $\operatorname{raiz}(w)$ se tornam sólidas, logo depois de adicionar a aresta $(v, w)$ possivelmente algumas arestas deste caminho se tornam pesadas. Já as arestas incidentes a este caminho eram frágeis e continuam assim. Logo, o ps não decresce.

A operaçào poda decrementa a grandeza de todos os vértices, exceto $v$, de $v$, até raiz $(v)$ no caminho da árvore original. No máximo $\lfloor\lg (n)\rfloor$ arestas deste caminho tornamse leves. Logo, a operaçào poda decrementa o ps de no máximo $\lfloor\lg (n)+1\rfloor$, contando a. aresta removida.

$\mathrm{Na}$ operaçào reverte $(v)$, novamente, temos que quantificar o decremento de $p s$ ocorrido após a operaçào estende. A operação reverte(v) altera a grandeza de todos os vértices no caminho de $v$ até raiz(v) na árvore original. No máximo $\lfloor\lg (n)\rfloor$ arestas deste caminho tornam-se leves. Logo. a operaçào reverle decrementa ps de no máximo $\lfloor\lg (n)\rfloor$.

A partir clas afirmasòes acima podemos in lerir que:

$$
\mid \text { cnxerta }|-| \text { poda } \mid \geq p . s \geq
$$

$\geq \mid$ emendas pesadas $|-|$ emendas leves $|-|$ estende $\mid-(\lfloor\lg (n)\rfloor+1)$. $\mid$ poda $\mid-\lfloor\lg (n)\rfloor$. $\mid$ reverte $\mid$.

Logo,

$$
\text { | emendas pesadas } \mid \leq
$$

$\leq \mid$ enxerta $|-|$ poda $|+|$ emendas leves $|+|$ estende $\mid+(\lfloor\lg (n)\rfloor+1)$. $\mid$ poda $|+\lfloor\lg (n)\rfloor \cdot|$ reverte $\mid=$ $=\mid$ enxerta $|+|$ emendas leves $|+|$ estende $\mid+(\lfloor\lg (n)\rfloor) \cdot(\mid$ poda $|+|$ reverte $\mid) \leq$ $(\lfloor\lg (n)\rfloor+1) . \mid$ estende $\mid+\lfloor\lg (n)\rfloor \cdot(\mid$ enxerta $|+|$ poda $|+|$ reverte $\mid) \leq m \cdot(2 \cdot\lfloor\lg (n)\rfloor+1)$. e portanto,

$$
\mid \text { emendas leves }|+| \text { emendas pesadas } \mid \leq \text { m.(3. }\lfloor\lg (n)\rfloor+1) \text {. }
$$


Teorema 3.3 : Em uma seqüência de $m$ operaçòes sobre árvores dinâmicas são realizadas no máximo $O(m\lfloor\lg (n)\rfloor)$ operações sobre caminhos.

Prova: Imediata a partir do teorema 3.2.

\subsection{Como Implementar as Operações Sobre Cami- nhos}

Para completar a solução do nosso problema, precisamos de uma maneira de representar os caminhos. A solução que a.presentaremos é representar estes caminhos por árvores binárias, onde cada nó folha, da esquerda para direita, é um nó do caminho, nesta ordem, isto é, o nó mais à esquerda é a cabeça do caminho, e o nó mais à direita a cauda. Cada nó interno representará um subcaminho dos nós que sào seus descendentes. Cada nó interno representa também uma aresta que é a aresta que liga o descendente mais à direita, de seu filho esquerdo com o descendente mais à esquerda, de seu filho direito.

Para cada nó interno $v$ da árvore definimos dois valores:

- custobruto(v): Que é o custo da aresta que o nó v representa.

- menorcusto(v): Que é o menor custo entre as arestas do subcaminho que o nó $v$ representa. 
Para facilitar a implementaçào das várias operaçòes com caminhos, armazenamos em cada nó interno $v$ as seguintes informaçòes:

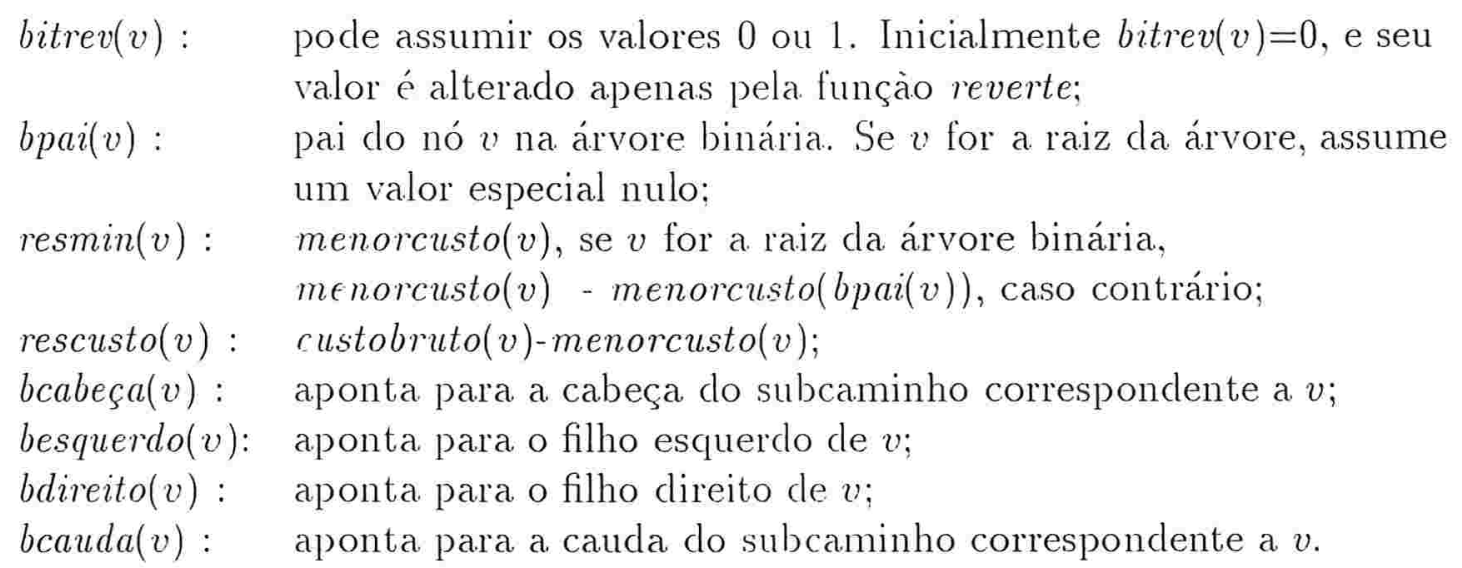

Definição 3.3 : Definimos recursivamente, estado reverso de um vértice $v$ como:

Se $v$ é raiz da árvore binária, entào estado reverso de $v$ é bitrev(v). Se $v$ nào é raiz, entào estado reverso de $v$ é bitrev(v) ou (exclusivo) estado reverso de (bpai $(v))$.

O estado reverso de um vértice indica se seus filhos estào trocados, isto é, se seu filho direito é, na realidade. seu filho esquerdo, e vice-versa. Este conceito será usado nas operações anterior e posterior.

a)

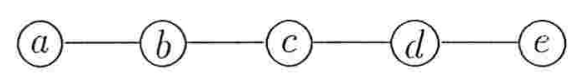

b)

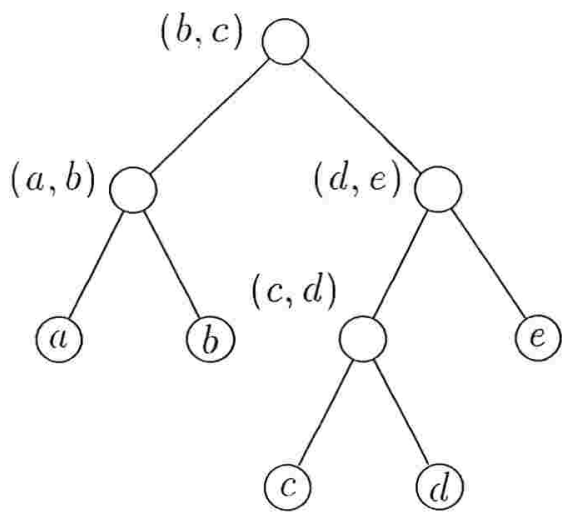

Figura 3.3 : $\operatorname{Em}(\mathrm{a})$, temos um caminho e em (b) a representaçào do mesmo em uma árvore binária (as folhas sảo os nós do caminho e os nós internos as arestas).

Com esta representaçào podemos implementar facilmente as operações sobre caminhos da maneira como segue. Note que se $c$ é um caminho, entào podemos nos referir 
a $c$ como sendo a raiz da árvore que representa tal caminho.

- $\operatorname{caminho}($ vértice $v)$ : Procura o ancestral de $w$ de $v$ tal que bpai. $(w)=$ nulo. Esta operaçào toma tempo proporcional à profundidade de $v$.

- cabeça $($ caminho $c)$ : Se bitrev $(c)=0$ retorna bcabeça(c); caso contrário, retorna bcauda(c).

Esta operaçào leva tempo $O(1)$.

- cauda (caminho c): Simétrico a cabeça(c).

- anterior(vértice v): Percorra os vértices de $v$ até caminho(v) na árvore binária. Retorne neste caminho computando o estado reverso de cada nó. Procure o ancestral $w$ mais próximo de $v$ que é um filho direito. Seja $u$ o irmào esquerdo de $w$. Retorne bcauda(u) se estado reverso $(u)=0$; e bcabeça(u), caso contrário. Esta operaçào leva tempo proporcional à profundidade de $v$ na árvore.

- posterior(vértice v): Simétrico a anterior.

- ccusto(vértice $v$ ): Procura o ancestral $w$ mais próximo de $v$ que é um filho esquerdo. Seja $\left(\operatorname{bpai}(w)=v_{0}, v_{1}, \ldots, v_{k}=(\operatorname{caminho}(v))\right.$ os vértices do caminho de $v$ até caminho(v) na árvore binária. Retorne rescusto(bpai(w) ) + menorcusto $($ bpai $(w))=$ rescusto $\left(v_{0}\right)+\sum_{i=0}^{k}\left(\right.$ resmın $\left.\left(v_{i}\right)\right)$. Esta operação leva tempo proporcional à profundidade de $v$ na árvore.

- ccustomin(caminho c): Comece $\operatorname{com} u=c$ e repita o seguinte passo enquanto um dos filhos de $u$ nào é folha e possui rescusto positivo: se o filho direito de u é um nó interno e tem rescusto nulo, substitua u pelo seu filho direito: caso contrário, substitua u pelo seu filho esquerdo. Uma vez computado $u$, retorne o descendente (folha) mais à direita de seu filho esquerdo ( o estado reverso deve ser levado em conta). Esta operaçào leva tempo proporcional à profundidade de $u$.

- catualiza(caminho $c$, real $x)$ : Adiciona $x$ ao resmin.c). Esta operaçào leva tempo $O(1)$.

- inverte (caminho c): Nega o bitrev(c). Esta operaçào leva tempo $O(1)$.

As operaçòes acima independem da classe de árvores que escolhemos para representar os caminhos, pois elas nào alteram a estrutura das mesmas, mas apenas extraem e alteram informaçòes das mesmas. A operaçào ctamanho. poderia ser implementada independentemente do tipo de árvore, no entanto faremos isto assim que escolhermos o tipo de árvore mais adequada para tal. No caso das operaçòes quebra e concatena, precisamos explicitar a classe de árvores que estamos trabalhando, pois elas vão alterar a estrutura das árvores. Uma boa classe de árvores, pode ser a classe das árvores balanceadas. Com árvores balanceadas, todas as operaçóes que levam tempo proporcional à 
altura das árvores seriam executadas em tempo $O(\lg n)$. As operaçòes quebra e concatena também poderiam ser executadas em tempo $O(\lg n)$. A operação ctamanho, poderia ser executada em tempo constante, mas veremos como implementá-la mais adiante. Além disso, uma operaçào emenda pode ser executada em tempo $O(\lg n)$ pois ele chama uma vez a operaçào quebra e uma ou duas vezes a operaçào concatena. O teorema 3.3, nos fornece uma cota superior para o tempo necessário para realizar m operaçòes sobre árvores, apresentada no seguinte teorema:

Teorema 3.4: Representado-se os caminhos por árvores binárias balanceadas, uma seqüência de $m$ operaçòes sobre árvores dinâmicas necessitam tempo $O\left(m(\lg n)^{2}\right)$.

Um resultado melhor que o teorema anterior pode ser obtido como veremos, representando-se os caminhos por árvores binárias l.e. Consegue-se neste caso, uma melhora de um fator igual a $\lg n$. Para usar esta classe de árvores precisamos definir o peso das folhas, que será definido como segue:

$$
\operatorname{peso}(v)= \begin{cases}\operatorname{grande} z a(v) . & \text { se nào entra nenhuma aresta sólida em } v ; \\ \operatorname{grande} z a(v)-\operatorname{grande} z a(w), & \text { se a aresta sólida }(v, v) \text { entra em } v\end{cases}
$$

Note que se c é um caminho entào peso(c) denota o peso da raiz da árvore que representa. $c$.

No capítulo 2, definimos peso de um nó interno (definiçào 2.4), mas esta informaçào nào era armazenada nos nós internos das árvores enviesadas. Para a implementaçào das árvores dinâmicas. é importante armazenar esta informaçào, porém isto não acarreta alteraçào no tempo de execuçào das operaçòes sobre árvores enviesadas. Observe que com esta informaçào, a funçào ctamanho pode ser implementada de maneira. muito simples:

função ctamanho( caminho c):

retorne peso(c);

Relembramos aqui que $S(v)$ denota o posto de $v$. conforme definimos no capítulo anterior.

Lema 3.2 : Representando caminhos por árvores binárias l.e. a operaçào concatena $\left(c_{1}, c_{2}, x\right)$ requer $O\left(\left|S\left(c_{1}\right)-S\left(c_{2}\right)\right|\right)$ tempo amortizado e a raiz da nova árvore possuirá posto $\max \left\{S\left(c_{1}\right), S\left(c_{2}\right)\right\}$ ou $\max \left\{S\left(c_{1}\right), S\left(c_{2}\right)\right\}+1$. 
Prova: Segue do lema 2.3 e do teorema 2.2.

Lema 3.3 : Representando caminhos por árvores binárias l.e. a operaçàao quebra $(v)$, requer $O(S(c)-S(v))$ tempo amortizado, onde $c$ é o caminho ao qual v pertencia antes da operaçào quebra ser aplicada. Se a lista retornada for $\left(c_{1}, c_{2}, x, y\right)$, entào se $c_{1} \neq$ nulo entào $S\left(c_{1}\right) \leq S(c)+1$, se $c_{2} \neq$ nulo entào $S\left(c_{1}\right) \leq S(c)+1$. Além disso, se $c_{1} \neq$ nulo entào $c_{1}$ é $\left(S\left(c_{1}\right)-S(c)+1\right)$-crédito invariante e se $c_{2} \neq$ nulo entào $c_{2}$ é $\left(S\left(c_{2}\right)-S(c)+1\right)$-crédito invariante

Prova: Segue do teorema 2.5.

Observe que a operaçào REPARTA deve ser modificada., pois nào definimos qual é o item de cada folha, mas esta informaçào é necessária apenas para encontrar o nó base, este pode ser encontrado facilmente. já que temos a folha da árvore enviesada que estamos repartindo.

Lema 3.4 : Para qualquer nó interno v de uma árore binária l.e. que representa um caminho tem-se que $1 \leq p e s o(v) \leq n$, onde $n$ é o número total de vértices da árvore. Isto significa que $0 \leq S(v) \leq 1+\lg n$.

Prova: Seja $c$ a raiz de uma árvore binária l.e. que representa o caminho $\left(\right.$ cabeça $(c)=v_{0}, v_{1}, \ldots, v_{k}=$ ctudula $\left.(c)\right)$ e $v$ um vértice qualquer deste caminho. Pela definição de peso temos que:

$$
\begin{gathered}
1 \leq \operatorname{peso}(v) \leq \operatorname{peso}(c)=\sum_{i=0}^{k} \operatorname{peso}\left(v_{i}\right)= \\
\operatorname{grande} z a\left(v_{0}\right)+\sum_{i=1}^{k}\left(\operatorname{grande} a\left(v_{i}\right)-\operatorname{grande} \sim a\left(v_{i-1}\right)\right)= \\
\operatorname{grande} \approx a\left(v_{k}\right)=\operatorname{grande} \sim a(\operatorname{cauda}(c)) \leq n .
\end{gathered}
$$

As operaçòes emenda e estende precisam ser modificadas para atualizar os pesos dos vértices. Abaixo reescrevemos as operaçòes indicando com setas as modificaçòes necessárias. 
função emenda( caminho $c)$ :

vértice $v$;

caminho $c_{1}, c_{2}$

real $x_{1}, x_{2}$;

$. v=\operatorname{dpai}(\operatorname{cauda}(c))$;

. $c_{1}, c_{2}, x_{1}, x_{2}=$ quebra $(v)$;

.peso $(v)=\operatorname{peso}(v)-\operatorname{peso}(c) ; \quad \Leftarrow$

. se $c_{1} \neq$ nulo

. então dpai $\left.\operatorname{cauda}\left(c_{1}\right)\right)=v$;

. $\quad$ dcusto $\left(\right.$ cauda $\left.\left(c_{1}\right)\right)=x_{1}$;

$\operatorname{peso}(v)=\operatorname{peso}(v)+\operatorname{peso}\left(c_{1}\right) ; \quad \Leftarrow$

$. c=$ concatena $(c$, caminho(v). dcusto $(\operatorname{cauda}(c))$ )

.se $c_{2}=$ nulo

- então retorna $c$

- senão retorna concatena $\left(c, c_{2}, x_{2}\right)$;

função estende(vértice v):

caminho $c, c_{1}, c_{2}$;

real $x_{1}, x_{2}$;

$. c_{1}, c_{2}, x_{1}, x_{2}=q u e b r a(v)$;

se $c_{1} \neq$ nulo

- então dpail cauda $\left.\left(c_{1}\right)\right)=v$ :

dcusto $\left(\right.$ cauda $\left.\left(c_{1}\right)\right)=x_{1}$;

$\operatorname{peso}(v)=\operatorname{peso}(v)+p_{i} \operatorname{eso}\left(c_{1}\right) ; \quad \Leftarrow$

se $c_{2}=$ nulo

então $c=$ caminho(v)

senão $c=$ concatena $($ caminho( $\left.v), c_{2}, x_{2}\right)$;

.enquanto dpai( cauda $(c)) \neq$ nulo faça

- $c=$ emenda(c);

retorna $c$;

Lema 3.5 : Seja $(w, v)$ uma aresta sólida de uma árvore. Se $u$ é irmào de $w$ e é cauda de um caminho $c$. então $\operatorname{peso}(v) \geq \operatorname{peso}(c)$ e $S(v) \geq S(c)-1$.

Prova: $\quad \operatorname{peso}(v)=\operatorname{grande} z a(v)-\operatorname{grande} z a(w) \geq \operatorname{grande} z a(u)=\operatorname{peso}(c)$. 
Logo,

$$
S(v)=\lfloor\lg p e s o(v)\rfloor \geq\lfloor\lg p \epsilon s o(c)\rfloor \geq S(c)-1 .
$$

onde a última desigualdade segue do lema 2.1 .
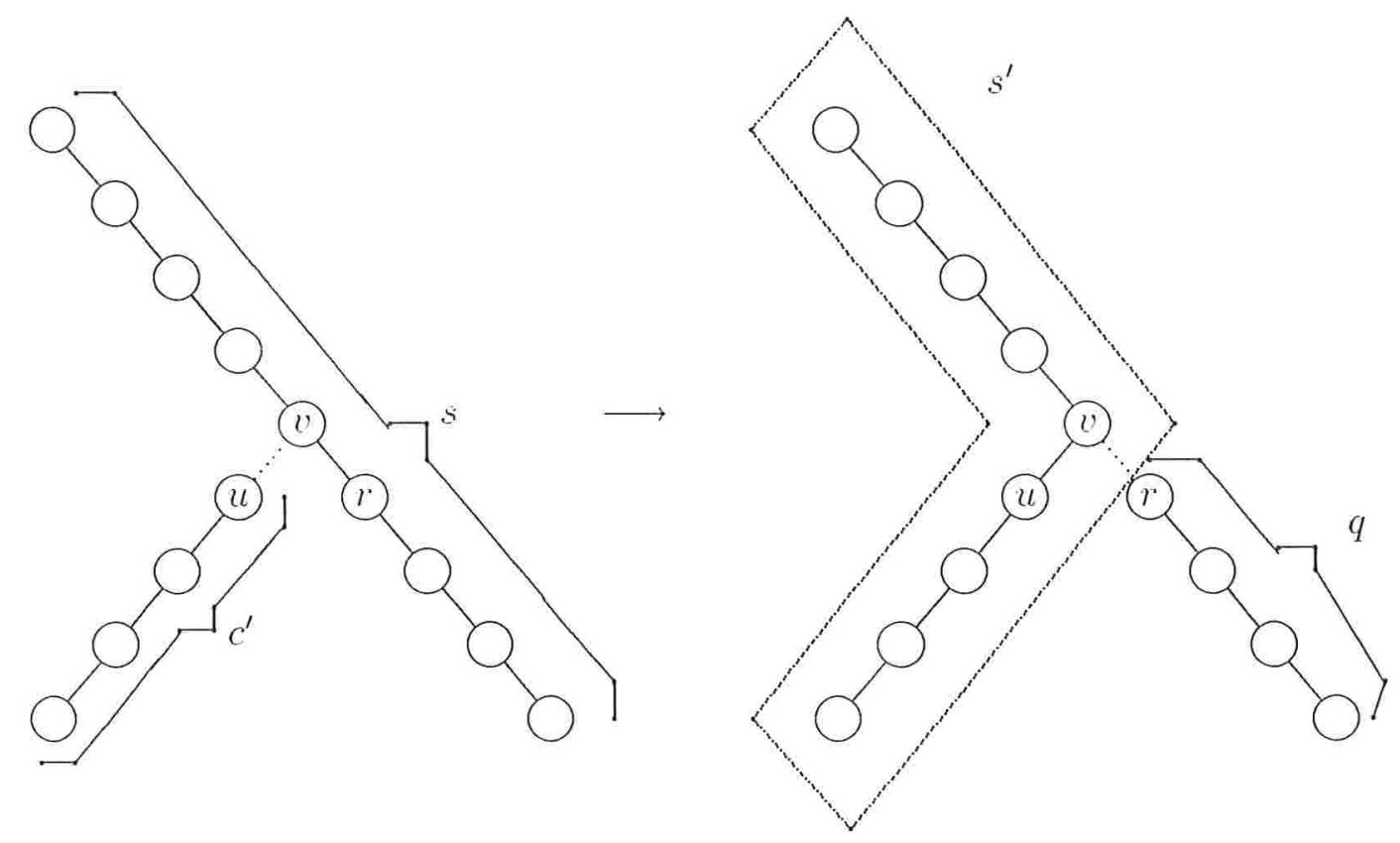

Figura 3.4 : Exemplo de una emenda normal.

Teorema 3.5: Usando árvores binárias l.e. e fazendo a implementaçào descrita, o tempo necessário para realizar uma seqüência de $m$ operaçòes sobre árvores dinâmicas é $O(m \lg n)$.

Prova: Os lemas 3.2, 3.3 e 3.4 implicam que as operaçòes concatena e quebra necessitam $O(\lg n)$ tempo amortizado e as demais operaçòes sobre caminhos necessitam de $O(\lg n)$ tempo no pior caso. A operaçào emenda necessita de $O(\lg n)$ tempo amortizado. Isto significa que, pelos teoremas 3.1 e 3.2 o tempo necessário para realizar $m$ operaçǒes é $O(m \lg n)$ mais o tempo necessário para as $O(m \cdot \lg n)$ operaçòes emenda normais que são realizadas durante as operaçòes estende.

Para obter um limite para o tempo gasto em operaçòes emenda normais considere a i-ésima operação emenda normal que ocorre dentro de uma iteraçào de uma operação estende (veja figura 3.4). Seja $u$ a cauda do caminho que está sendo estendido, c o caminho 
contém $u$ antes da primera operaçào emenda e $c^{\prime}$ o caminho contendo $u$ antes da i-ésima operaçào emenda. Seja v o pai de $u$ s o caminho contendo " antes da primeira operaçào emenda. e $s^{\prime}$ o caminho contendo $v$ após a i-ésima operaçào cmenda. Seja ainda w o filho de $v$ que está no caminho $s$. Provaremos em primeiro lugar que cada emenda normal necessita de $O\left(S(s)-S^{\prime}(c)+S^{\prime}\left(s^{\prime}\right)-S\left(c^{\prime}\right)\right)$ tempo amortizado.

Sejam peso $(v)$ e $\operatorname{peso}^{\prime}(v)$, os pesos de $v$ antes e depois da i-ésima operação emenda, respectivamente, e $S^{\prime}(v)$ e $S^{\prime \prime}(v)$ o posto de $v$ antes e depois da i-ésima operação emenda.

Como a operaçào emenda é normal, entào $S(s) \geq S(v)+1$.

Pelo lema 3.5 temos que $S(v)+1 \geq S(c)$ e $S(v)+1 \geq S\left(c^{\prime}\right)$

Logo,

$S(s) \geq S(c)$ e $S(s) \geq S\left(c^{\prime}\right)$.

Pelo lema 3.5 temos que

$$
S(s)-S(v) \leq S(s)-S(c)-1
$$

Pelo lema 3.5 temos que $S\left(s^{\prime}\right) \leq S^{\prime}(v)+1=S^{\prime}(q)$. Logo.

$S\left(s^{\prime}\right) \leq S(q)$.

Para a operaçào quebra necessitamos de $O(S(s)$ - S(v)) créditos. Logo, de (2) segue que $O(S(s)-S(c))$ créditos sào suficientes para realizar esta operaçào.

Na primeira concatenaçào da operaçào emenda precisamos de $\left|S^{\prime}\left(c^{\prime}\right)-S^{\prime}(v)\right|+1$ créditos. Se $S\left(c^{\prime}\right)-S^{\prime}(v) \geq 0$, então:

$$
\left|S\left(c^{\prime}\right)-S^{\prime}(v)\right|+1=S^{\prime}\left(c^{\prime}\right)-S^{\prime \prime}(v)+1 \leq S^{\prime}\left(s^{\prime}\right)-S^{\prime}\left(c^{\prime}\right)+S^{\prime}\left(s^{\prime}\right)-S^{\prime \prime}(v)+1 .
$$

Pois, pelo lema $3.2, S\left(c^{\prime}\right) \leq S\left(s^{\prime}\right)$ e $S^{\prime}\left(s^{\prime}\right)-S^{\prime}\left(c^{\prime}\right) \geq 0$. Por outro lado se $S^{\prime}\left(c^{\prime}\right)-S^{\prime}(v) \leq 0$, então

$$
\left|S\left(c^{\prime}\right)-S^{\prime}(v)\right|+1=S^{\prime}(v)-S^{\prime}\left(c^{\prime}\right)+1 \leq S\left(s^{\prime}\right)-S^{\prime}\left(c^{\prime}\right)+S^{\prime}\left(s^{\prime}\right)-S^{\prime}(v)+1 .
$$

Pois, pela definiça de posto. $S^{\prime}(v) \leq S^{\prime}\left(s^{\prime}\right)$ e $S^{\prime}\left(s^{\prime}\right)-S^{\prime \prime}(v) \geq 0$.

Logo, de (3) temos que

$$
\left|S\left(c^{\prime}\right)-S^{\prime}(v)\right|+1 \leq S\left(s^{\prime}\right)-S\left(c^{\prime}\right)+S\left(s^{\prime}\right)-S^{\prime}(v)+1 \leq
$$




$$
\leq S^{\prime}\left(s^{\prime}\right)-S\left(c^{\prime}\right)+S^{\prime}\left(s^{\prime}\right)-S^{\prime \prime}(q)+2
$$

Pois, do lema 3.5 temos que $S^{\prime}(v) \geq S(q)-1$. Como a operaçào quebra deixa. $S(s)-S(q)+1$ créditos temos que esta concatena.çào necessita de mais $S\left(s^{\prime}\right)-S(c)+$ $S\left(s^{\prime}\right)-S(s)+1 \leq 2\left(S^{\prime}\left(s^{\prime}\right)-S^{\prime}\left(c^{\prime}\right)\right)+1$ créditos.

Sejam $c^{\prime \prime}$ e $c^{\prime \prime \prime}$ os caminhos da segunda concatenação da operação emenda. A segunda concatena.çào necessita de mais $\left|S\left(c^{\prime \prime}\right)-S\left(c^{\prime \prime \prime}\right)\right|+1$. Com um raciocínio semelhante a.o aplicado para obter o resultado anterior e usando (3) obtemos:

$$
\left|S\left(c^{\prime \prime}\right)-S^{\prime}\left(c^{\prime \prime \prime}\right)\right|+1 \leq S^{\prime}\left(s^{\prime}\right)-S^{\prime}\left(c^{\prime \prime}\right)+S^{\prime}\left(s^{\prime}\right)-S\left(c^{\prime \prime \prime}\right)+1 .
$$

Como $S^{\prime}\left(c^{\prime \prime}\right) \geq S^{\prime}\left(c^{\prime}\right)$. entào, pelo lema 3.2

$$
S^{\prime}\left(s^{\prime}\right)-S\left(c^{\prime \prime}\right)+S^{\prime}\left(s^{\prime}\right)-S^{\prime}\left(c^{\prime \prime \prime}\right)+1 \leq 2 . S^{\prime}\left(s^{\prime}\right)-S\left(c^{\prime}\right)-S^{\prime}\left(c^{\prime \prime \prime}\right)+1
$$

Como a operaçào quebra deixa mais $S(s)-S^{\prime}\left(c^{\prime \prime \prime}\right)+1$ créditos e

$$
2 . S^{\prime}\left(s^{\prime}\right)-S^{\prime}\left(c^{\prime}\right)-S^{\prime}(s) \leq 2 \cdot\left(S^{\prime}\left(s^{\prime}\right)-S^{\prime}\left(c^{\prime}\right)\right) \text {. }
$$

uma operação emenda gastará $O\left(S(s)-S^{\prime}(c)+S\left(s^{\prime}\right)-S^{\prime}\left(c^{\prime}\right)\right)$ créditos. Somando o tempo gasto em operaçòes emendas normais de uma operaçào estende temos um limite de $O(k+$ $\lg n$ ) onde $k$ é o número de operaçòes emendas normais. Com este resultado e o do teorema 3.2 temos que o tempo total gasto em uma seqüência de $m$ operaçòes sobre árvores dinâmicas é no pior caso $O(m \lg n)$.

\subsection{Uma Implementação Mais Sofisticada}

Nesta seçào veremos uma implementaçào mais sofisticada para o problema das árvores dinâmicas, objetivando encontrar um limite superior para o pior tempo de execuçào de uma operaçào particular sobre árvores dinâmicas.

Faremos algumas modificaçòes nos algoritmos da seçào anterior, que resultará em algoritmos que necessitam de tempo $O(\lg n)$ no pior caso. Vale aqui ressaltar que a. modificação que introduziremos torna a estrutura mais complicada. sendo portanto muito provável que a implementaçào já vista tenha um desempenho melhor na prática. Assim, a nova estrutura que veremos é mais de interesse teórico do que prático. 
A nova implementaçào manterá uma aresta sólida se e somente se ela for pesada ( $2 \operatorname{grandeza}(v)>\operatorname{grande} z a(p a i(v))$. Como a operaçào estende pode transformar arestas leves em sólidas, e pesadas țm frágeis, necessitamos uma uma nova operaçào que recoloca a estrutura de dados na situaçào desejada. Com este propósito usaremos a seguinte operaçào:

- abafa(caminho c): Converte todas as arestas leves deste caminho em frágeis; e toda aresta pesada incidente a este caminho em sólida.

A seguir reescrevemos cada operaçào com as devidas alteraçòes:

função pai(vértice v):

(a mesma da seçào anterior)

função raiz(vértice v):

caminho c;

$. c=\operatorname{estende}(v) ;$

$. v=\operatorname{cauda}(c)$;

. abafa(c) ;

retorna $v$;

função custo(vértice v):

(a mesma da seçào anterior)

função customin(vértice v):

caminho c;

real $x$ :

$. c=\operatorname{estende}(v)$;

$. x=$ ccustomin $(c)$;

. abafa(c) ;

retorna $x$; 
função tamanho(vértice v):

inteiro $t$

raiz r;

$. \mathrm{r}=\operatorname{raiz}(v)$;

$. t=$ ctamanho( estende $(\mathrm{r}))$;

abafa(r);

retorna $t$;

função atualiza(vértice v:real $x)$ :

caminho c;

$c=$ estende $(v)$;

.catualiza $(c, x)$ :

. abafalc) ;

função enxerta(vértice $v$, u: real $x)$ :

-abafa( concatena (caminho(v). estende $(w), x))$;

função poda(vértice v):

caminho $c_{1}, c_{2}, c$;

real $x_{1}, x_{2}$

$. c=$ estende $(v)$;

$. c_{1}, c_{2}, x_{1}, x_{2}=$ quebra $(v)$;

dpai $(v)=$ nulo:

- abafa $a\left(c_{2}\right)$;

- abafa(caminho(v));

retorna $x_{2}$; 
função reverte(vértice $v$ ):

caminho $c$;

$. c=$ estende $(v)$ :

inverte $(c)$;

dpai $(v)=$ nulo :

. abafa $(c)$;

Para implementar a operação abafa faremos três modificaçòes na estrutura de dados. A primeira modificaçào consiste em acrescentar dois campos nos nós internos da. árvore binária. Antes definiremos dois conceitos que determinarào o conteúdo dos campos.

Definição 3.4 : Seja u um nó interno de uma árvore binária que corresponde à aresta $(v, w)$. Definimos tendesquerdo $(u)$ como sendo a soma dos pesos dos vértices do subcaminho de $v$ até cabeça $(v)$ menos peso $(v)$. Definimos minesquerdo $(u)$ como sendo:

$$
\min \{\text { tendesquerdo }(t) \mid t \text { é descendente de } u\} \text {. }
$$

Definição 3.5 : Seja u um nó interno de uma árvore binária que corresponde à aresta $(v, w)$. Definimos tendedireito $(u)$ como sendo a soma dos pesos dos vértices do subcaminho de $w$ até $\operatorname{cauda}(w)$ menos peso(v). Definimos mindireito(u) como sendo:

$$
\min \{\text { tendedireito }(t) \mid t \text { é descendente de } u\} \text {. }
$$

Lema 3.6 : Seja u um nó interno de uma árore binária (jue corresponde à aresta $(v, w)$ do caminho $c$. Entào $(v, w)$ é pesada se e somentec se Ir udr sque rido(u) $>0$.

Prova: Sejam $v_{0}=$ cabeça $(c), v_{1}, \ldots, v_{k}=w$, os vértices do subcaminho de cabeça(c) até w. Entào:

$$
\text { tendesquerdo }(u)=\sum_{i=0}^{k-1} \operatorname{peso}\left(v_{i}\right)-\operatorname{peso}(u)=
$$

$\operatorname{grande} z a\left(v_{0}\right)+\sum_{i=1}^{k-1}\left(\operatorname{grande} z a\left(v_{i}\right)-\operatorname{grande} z a\left(v_{i-1}\right)\right)-(\operatorname{grande} z a(w)-\operatorname{grande} z a(v))=$ 
$\operatorname{grande} z a(v)+\operatorname{grand} z a(v)-\operatorname{grande} z a(w)=2 \cdot \operatorname{grande} z a(v)-\operatorname{grande} z a(w)$,

ou seja, $(v, w)$ é pesada se e somente se tendesqur rdo $(u)>0$.

Precisamos agora de mais uma operaçào sobre caminhos:

- leve (caminho $c$ ): Retorna o vértice $v$ mais próximo da cauda(c) tal que (anterior $(v), v)$ seja leve; ou nulo, se nào existir tal vértice.

A implementaçào da função acima é semelhante à implementaçào do ccustomin. Começando da raiz da árvore binária, desce-se nos nós calculando minesquerdo e tendesquerdo ( mindireito e tendedireito também ), procurando o nó w mais à esquerda tal que tendesquerdo $<0$ (ou tendedireito $<0$, dependendo do estado reverso). Devolva o descendente mais à direita do filho esquerdo de $w$. Esta operaçào leva tempo proporcional à profundidade de $w$.

Outra modificaçào é a utilizaçào de árvores g.e. em lugar de l.e. Com esta modificação, conseguimos um limite superior para o tempo de execuçào das operações concatena e quebra.

Lema 3.7 : Se representarmos caminhos por árores binária g.c.. podemos realizar a operaçào concatena $\left(c_{1}, c_{2}, x\right)$ em tempo $O\left(\max \left\{\left(S_{S}\left(c_{1}\right) ., c_{2}\left(c_{2}\right)\right\}\right.\right.$ - max $\{(S(v), S(w)\})$, onde

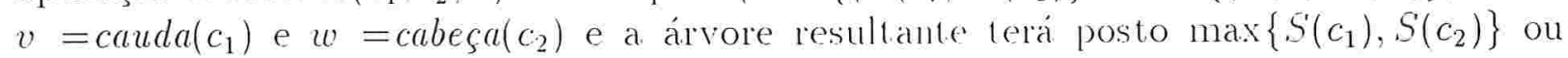
$\max \left\{S\left(c_{1}\right), S\left(c_{2}\right)\right\}+1$.

Prova: Imediata a partir do lema 2.3 e do teorema 2.7 .

Lema 3.8 : Se representarmos caminhos por árvores binária g.e., podemos realizar a operaçào quebra $(v)$, retornando a lista $\left(c_{1}, c_{2}, x, y\right)$ em tempo $O(S(c)-S(v))$, onde $c$ é o caminho ao qual $v$ pertencia antes da operaçào quebra ser aplicada.

Prova: Imediata a partir do teorema 2.9.

A última modificacào será a manutençào. para carla vértice $v$, de um conjunto de todos caminhos $c$ tais que (caudal $(c), v)$ é leve. Estes conjuntos serào manipulados por três operaçǒes: 
- pesomax(vértice $v$ ) : Devolve o caminho de maior peso no conjunto de caminhos de $v$. Se o conjunto de caminhos de $v$ é vazio devolve nulo.

- insere(caminho $c$, vértice $v$ ): Insere o caminho $c$ no conjunto de caminhos de $v$.

- remove( caminho $c$, vértice $v$ ): Remove o caminho $c$ no conjunto de caminhos de $v$.

Para representar estes conjuntos de caminhos, utilizaremos árvores binárias g.e.. O peso de cada caminho é utilizado como posto. Além disso manteremos, para cada nó interno, um apontador para seu descendente mais à esquerda. Com esta representação podemos executar a operaçào pesomax em tempo $O(1)$ e as operaçòes insere $(c, v)$ e remove $(c, v)$ em $O\left(\lg \left(\frac{P}{\text { peso(c) }}\right)\right)$, onde $P$ é a soma dos pesos de todos os caminhos no conjunto de caminhos de $v$.

As operaçòes emenda e estende precisam ser modificadas para manter os conjuntos de caminhos. Abaixo temos as operaçòes reescritas com as modificaçòes necessárias.

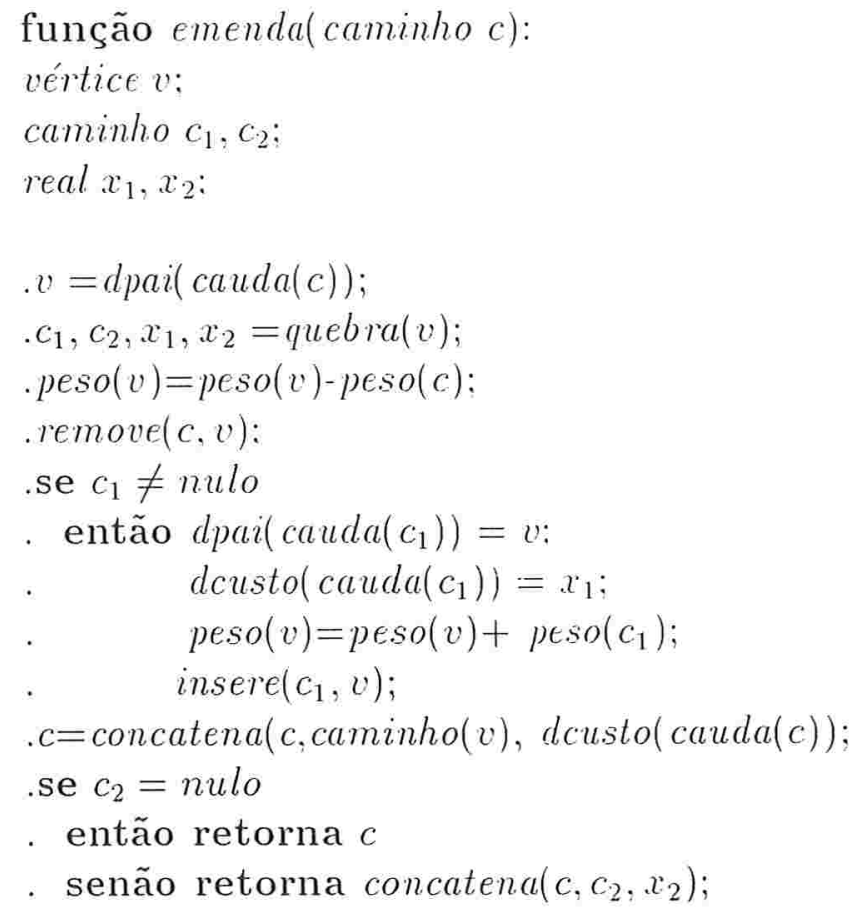




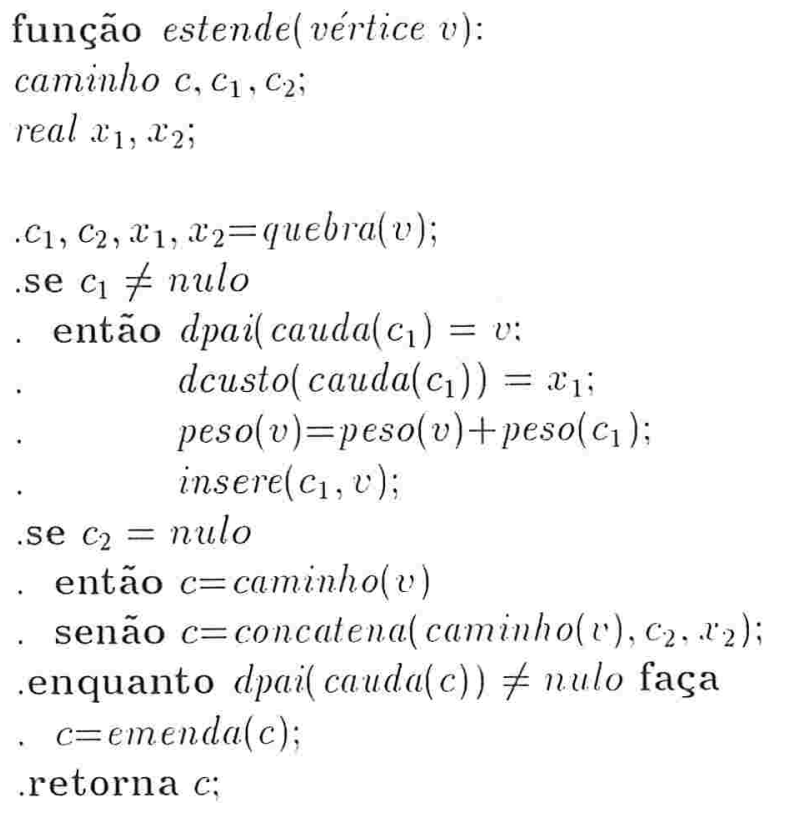

Teorema 3.6 : A operaçào estende, na última versào, necessita de tempo $O(\lg n)$, no pior caso.

Prova: A demonstraçào é muito semelhante à feita para o teorema 3.5. O tempo de uma operaçào estende é $O(\lg n)$ mais o tempo gasto nas $O(\lg n)$ operaçòes emenda. Considere a i-ésima operaçào emenda de uma operaçào estende (veja figura 3.4). Seja u a cauda do caminho que está sendo estendido pela operaçào emenda. seja c o caminho que continha u antes do início da operaçào tstendt. e $c^{\prime}$ o caminho contendo $u$ antes da i-ésima operaçào emenda. Seja $v$ o pai de $u$, seja s o caminho contendo $v$ antes da i-ésima operaçào emenda, e $s^{\prime}$ o caminho contendo $v$ após a i-ésima operaçào emenda. Seja ainda $w$ o filho de $v$ que está no caminho $s$.

Pelo lema 3.8 necessitamos de $O(S(s)-S(v))$ tempo para executar a operação quebra em uma operaçào emenda. Pelo lema 3.5. $S\left(c^{\prime}\right) \leq 1+\zeta(v)$. Logo, necessitamos de tempo $O(S(s)-S(c))$ em cada quebra. ou seja, o tempo tolal gasto nas operaçòes quebra é $O(\lg n)$.

A operaçào remove necessita de tempo $O\left(\lg \left(\frac{p \operatorname{cso}(v)}{p \operatorname{cso}\left(c^{\prime}\right)}\right)\right)$ para ser executada. Como peso $(v) \leq \operatorname{peso}(s), O\left(\lg \left(\frac{p \in s o(s)}{p e s o\left(c^{\prime}\right)}\right)\right)$ tempo é suficiente para realizar um remove. Somando sobre todos as opera.çòes emenda. temos um tempo total de $O(\lg n)$ gasto em todas as operaçòes remove.

A operaçào insere necessita de tempo $O\left(\lg \left(\frac{p e s o(v)}{p e s o(q)}\right)\right)$, onde q é o caminho inserido. Como $(\operatorname{caud} a(q), v)$ é pesada: 2.grandeza $(\operatorname{cauda}(q))>\operatorname{grande} z a(v)$, ou seja, $\frac{\operatorname{peso}(v)}{\text { peso(q) }}=$ $\frac{\text { grandeza(v)-grandeza(cauda }(q))}{\text { grandeza(cauda(q)) }} \leq 1$. Logo, a operaçào insere necessita de tempo $O(1)$. 
Pelo lema 3.7, a primeira operação concatena necessita tempo $O\left(\max \left\{S\left(c^{\prime}\right), S^{\prime}(v)\right\}-\right.$ $\left.\max \left\{S\left(\operatorname{cauda}\left(c^{\prime}\right)\right), S^{\prime}(v)\right\}\right)=O\left(S\left(s^{\prime}\right)-S^{\prime}(v)\right)$. Analogamente, a segunda operação concatena necessita de tempo $O\left(S\left(s^{\prime}\right)-S^{\prime}(v)\right)$. Como $(u, v)$ é leve,

$$
\begin{aligned}
& \text { 2.grande } a(u) \leq \operatorname{grande} z a(v), \text { ou seja, } \\
& \text { grande } z a(u) \leq \operatorname{grande} \sim a(v)-\operatorname{grande} \sim a(u) .
\end{aligned}
$$

Portanto, é suficiente tempo $O\left(S^{\prime}\left(s^{\prime}\right)-S\left(c^{\prime}\right)\right)$ para realizar as cluas operaçòes concatena de cada operaçào emenda. Somando sobre todas as operaçòes emenda, temos um tempo total de $O(\lg n)$ para todas as operações concatena. Logo, para realizar a operação estende é necessário tempo $O(\lg n)$.

A operaçào abafa é praticamente a operaçào estende de trás para frente. Ela recebe um caminho, que tem a raiz como cauda, vai subindo, da cabeça em direçào à raiz, realizando, uma operaçào inversa à operaçào emenda, a qual chamaremos de corta. A operação corta está descrita abaixo.

- corta (caminho $c)$ : Converte a aresta leve(c) em frágil, dividindo o caminho $c$ em dois caminhos $q$ e $r$. Se existir alguma aresta pesada entrando em $r$, torna-a sólida. Retorna o caminho q. Esta operação supõe que existe pelo menos uma aresta leve em $c$. Veja figura 3.5 .

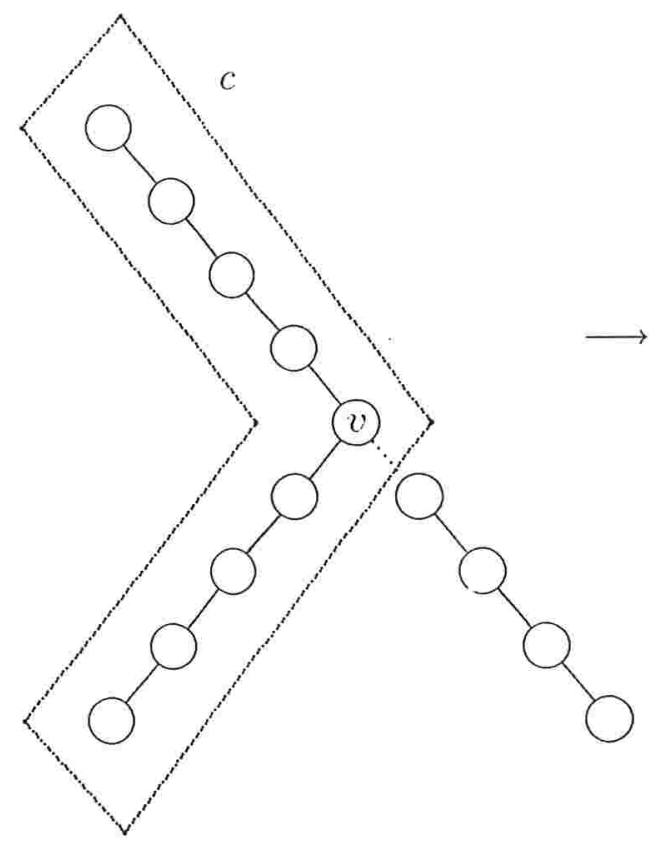

Figura 3.5 : Exemplo de um corta.

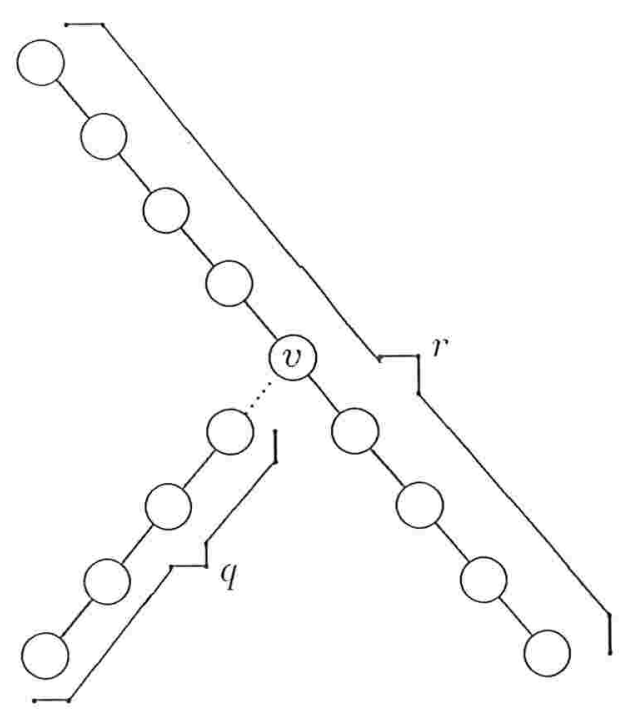


A seguir. temos a implementaçào das lunçòes corla e abafa:

função corta(caminho $\mathrm{c})$ :

vértice $v$;

caminho $q, r, s$;

real $x, y$;

$. v=l e v e(c)$

$. c, r, x, y=q u e b r a(v)$ :

se $r=$ nulo inverte $(c)$

. então $s=\operatorname{caminho}(v)$

- senão $s=$ concaten $a(\operatorname{caminh} o(v), r, y)$;

.dpai $($ cauda $(c)) . d$ custocauda(c) $)=v \cdot x$;

.peso $(v)=\operatorname{peso}(v)+\operatorname{peso}(c)$;

$. q=\operatorname{pesomax}(v)$;

.se 2 .peso $(q) \geq \operatorname{peso}(v)$

- então peso(v)=peso(v)-peso(q) :

remove $(q \cdot v)$

concatena(q, s, dcusto(cauda(q))) :

insere $(c, v)$;

retorna $c$;

procedimento abaja(caminho c):

vértice $v$;

caminho q,r,s:

real $x, y$;

enquanto leve $(c) \neq$ nulo faça

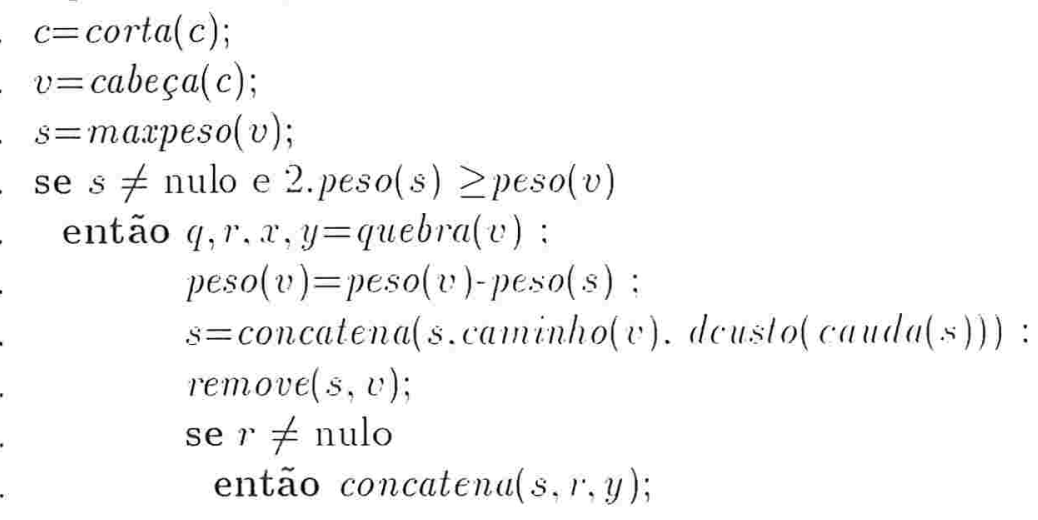


Teorema 3.7 : A operaçào abaf́a requer de tempo $O(\lg n)$, no pior caso.

Prova: A demonstraçào deste teorema é muito semelhante à do teorema anterior. A operaçào abafa requer tempo $O(\lg n)$, mais o tempo necessário das operaçòes corta. Considere uma operaçào corta típica. Seja $c$ o caminho a ser cortado, v=leve $(c), c^{\prime}$ o caminho contendo $v$ após a operaçào corta, s o caminho retornado pela operaçào corta e $s^{\prime}$ o caminho contendo cauda(s) após o término da operaçào abafa. (Na figura 3.5, $c^{\prime}$ é o caminho $r$, e s é o caminho q).

As operaçòes leve e quebra necessitam tempo $O(S(c)-S(v))$. Como (cauda(s),v) é leve, 2.grandeza $(\operatorname{cauda}(s)) \leq \operatorname{grandeza}(v)$. Ou seja, peso(s)=grandeza $($ cauda $(s)) \leq$ grandeza(v)-grandeza $($ cauda $(s))=$ peso $(v)$. Logo, em cada corta, as operaçǒes leve e quebra necessitam tempo $O(S(c)-S(s))$, ou seja, o tempo total gasto em todas operaçòes leve e corta em um abafá é $O(\lg n)$.

A operação remove necessita tempo $O\left(\lg \left(\frac{p(s o(\cdot)}{\mu(s)(q)}\right)\right)$ onde q é o caminho removido. Como a aresta (cauda(q),v) é pesada, entào grandeza(v) $<2$ grandeza( cauda $(q))$, e portanto, $\lg \left(\frac{p e s o(v)}{p e s o(g)}\right)=O(1)$. Logo. o tempo total gasto em todas as operações remove de um abafa é $O(\lg n)$.

As duas operaçòes concatena necessitam tempo $O\left(S^{\prime}\left(c^{\prime}\right)-S^{\prime \prime}(v)\right)$. Como $S^{\prime}\left(s^{\prime}\right) \leq$ $1+\lfloor\lg$ peso(s) $\rfloor \leq 1+\left\lfloor\lg p e s o^{\prime}(v)\right\rfloor=1+S(v)$, as operaçào concutena de cada cortu necessitam tempo $O\left(S\left(c^{\prime}\right)-S\left(s^{\prime}\right)\right)$, e $O(\lg n)$ em toda operaçăo abafa.

A operaçào insere necessita tempo $O\left(\lg \frac{p e s o^{\prime}(v)}{p e s o(s)}\right)$ onde peso' $(v)$ é o peso de $v$ depois da operaçào corta. Como peso(s)=peso( $\left.s^{\prime}\right)$ e peso $(c) \leq p e s o\left(c^{\prime}\right)$, a operaçào insere em uma operaçào corta necessita tempo $O\left(\lg \frac{p e s o\left(c^{\prime}\right)}{\text { peso(s })}\right)$. Logo, para todas as operaçōes insere de uma operaçào abafa, é necessário tempo $O(\lg n)$.

Logo, é necessário tempo $O(\lg n)$ para realizar a operaçào abafia.

Teorema 3.8 : Com a nova implementaçào. podemos realizar cada uma das operaçòes sobre árvores dinâmicas em tempo $O(\lg n)$.

Prova: Imediata a partir dos teoremas 3.6 e 3.7 .

Além da aplicaçào em algoritmos para o problema do fluxo máximo, tais estruturas de dados podem ser aplicadas ao problema da construçào de árvores geradoras mínimas e ao algoritmo simplex para redes, entre outros. Maiores detalhes podem ser encontrados em [18]. 


\section{Capítulo 4}

\section{O ALGORITMO DE GOLDBERG-TARJAN}

Em 1986, Goldberg desenvolveu um algoritmo (cf. [5]) de complexidade $O\left(n^{3}\right)$, utilizando a idéia de pré-fluxo introduzida por Karzanor. A partir desse algoritmo, Goldberg e Tarjan desenvolveram uma rersào mais simples com a mesma complexidade. Fazendo uso de árvores dinâmicas, os autores melhoraram este algoritmo, obtendo um, de complexidade $O\left(n m \log \left(\frac{n^{2}}{m}\right)\right)$. Neste capítulo veremos detalhadamente estes dois últimos algoritmos.

Primeiramente, redefiniremos o conceito de fluxo e pré-fluxo, de maneira similar à feita no capítulo 1. e introduziremos duas operaçoess básicas. A seguir. descreveremos um algoritmo básico, que consiste fundamentalmente lla aplicaçào indiscriminada destas operaçòes. Veremos entào. um critério de escolla destas operacòs. obtendo um algoritmo de complexidade $O\left(n^{3}\right)$. Finalmente, veremos a forma mais solisticada deste algoritmo que utiliza árvores dinâmicas.

$\mathrm{Na}$ última seção, selecionaremos todas as idéias deste algoritmo que surgiram nos algoritmos descritos no capítulo 1 .

\subsection{Um Algoritmo Básico}

Nesta seçào apresentaremos um algoritmo básico. que será refinado nas próximas seções. Para isso, faremos algumas definiçòes e convencionaremos uma notaçào similar à exibida no capítulo 1:

Seja $G=(V, A)$ um grafo orientado, $X, Y \subseteq V . v \in V$. e g uma funçào 
$g: V \times V \rightarrow \Re$. Entào $g[X . Y]$ denota a seguinte soma:

$$
g\left[X . Y^{*}\right]=\sum_{(x, y) \in X \times Y} g((x, y)) .
$$

Além disso,

$$
g[v, X]=g[\{v\}, X] \text { e } g[X, v]=g[X,\{v\}] .
$$

Note que. neste capítulo, trataremos de funçòes definidas sobre $V \times V$.

Definição 4.1 : Uma rede GT é uma quádrupla $(G, s, t, c)$, onde $G=(V, A)$ é um grafo orientado, s e $t$ são vértices distintos de $V$ e $c$ é uma função, $c: V \times V \rightarrow \Re$, tal que:

$c(v, w)=0$ se $(v, w) \in\left(V \times I^{\prime}\right)-A \mathrm{e}$

$c(v, w)>0$ se $(v, w) \in A$.

Chamaremos s de vértice origem, $t$ de vértice destino e $c$ de função capacidade.

Definição 4.2 : Um GT-fluxo numa rede Cil' (Ci.s.l.c) c definido como uma funçào $f: V \times V \rightarrow \Re$ tal que:

1) $f(v, w) \leq c(v, w)$ para todo $(v, w) \in V \times V$

2) $f(v, w)=-f(w, v)$ para todo $(v, w) \in V \times V$

3) $f[V, v]=0$ para todo $v \in V-\{s, t\}$ (restriçào de capacidade); (restriçào de antissimetria); (restriçào de conservaçào).

Além disso, definimos o valor do GT-fluxo $f$ como sendo: $f[V, t]$. Dizemos também que um GT-fluxo é máximo se ff tem valor máximo.

A restriçào de antissimetria elimina a possibilidade de existir fluxo positivo em ambas as arestas de um par reverso $(v, w)$ e $(w, v)$, eliminando assim certas dificuldades técnicas. Além disso, com esta restriçào (antissimetria), é possivel formular a restriçào de conservação de forma mais simples do que a feita no capítulo 1, pois, note que para todo $v \in V-\{s, t\}$

$$
\sum_{(u, v) \in A} f(u, v)-\sum_{(v, z) \in A} f(v, z)=\sum_{(u, v) \in A} f(u \cdot v)+\sum_{(v, z) \in \cdot 1} f(z \cdot v)=f[V, v] .
$$

Assim, é fácil ver que dada uma rede $R$ e um fluxo $f$ em $R$, como definidos no capítulo 1, o problema de encontrar um fluxo máximo em $R$ pode ser reduzido ao problema 
de encontrar um $G T$-fluxo máximo numa rede $G T$. Note que, se $G=(V, A)$ é o grafo da rede $R=(G, s, t, c)$, entào basta estender para todo $(v, w) \in V \times V$ a função capacidade $c$ definida apenas para as arestas de $G$, definindo $c(v, w)=0$ para todo $(v, w) \notin A$. Obtemos assim uma rede GT , e, claramente, um GT-fluxo máximo $f^{\prime}$ nessa rede define um fluxo máximo $f$ em $R$. Tal $f$ é obtido tomando-se $f(v, w)=f^{\prime}(v, w)$ se $f^{\prime}(v, w)>0$. e $f(v, w)=0$ se $f^{\prime}(v, w) \leq 0$.

Nota importante: Neste capítulo só trataremos de GT-fluxos em redes GT. Para simplificar a notaçăo, deste ponto em diante nos referiremos aos CiT-fluxos simplesmente por fluxos, e às redes $G T$, simplesmente por redes.

O algoritmo que descreveremos, para resolver o problema do fluxo máximo, utilizará uma funçào menos restrita que a funçào fluxo. e quando esta funçào satisfizer todas as condiçòes de fluxo, ela será a soluçào do problema. Tal funçào receberá o nome de pré-fluxo e está definida a seguir.

Definição 4.3 : Seja $R=(G, s, t, c)$ uma reck. lma lunçào $l: V \times V \rightarrow \Re$ é um pré-fluxo em $R$ se satisfizer as condiçòes 1) e 2) de fluxo (definiçào 4.2 ) e a seguinte condiçào $\left.3^{\prime}\right)$ :

$$
\left.3^{\prime}\right) f[V, v] \geq 0 . \quad \text { para todo } v \in V-\{s, t\} \quad \text { (restriçào de nào negatividade). }
$$

Para quantificarmos o que falta para um pré-fluxo ser um fluxo. definiremos excesso de (fluxo em) um vértice.

Definição 4.4 : Seja $R=(G, s, t, c)$ uma rede e $f$ um pré-fluxo em $R$. Para cada vértice $v$, definimos excesso de (fluxo $\mathrm{em}) v, \epsilon(v)$, da seguinte maneira:

$$
\epsilon(v)=f[l \cdot v] .
$$

Observação: No capítulo 1, para descrevermos o algoritmo de Rarzanov, definimos pré-fluxo e excesso de fluxo em um vértice. As definiçòes que apresentaremos aqui sào diferentes, devendo ficar claro que neste capítulo, estamos nos referindo às definições aqui feitas, segundo Goldberg e Tarjan.

A idéia do algoritmo consiste em 'empurrar' fluxo de um vértice $v$ com excesso positivo até outro que esteja 'mais próximo' de $t$. Para podermos descrever este processo apresentaremos antes algumas definições. 
Definição 4.5 : Seja $R=(G, s, t, c)$ uma rede e $f$ um pré-fluxo em $R$. Para cada par $(v, w)$, em $V \times V$. define-se capacidade residual de $(v, w)$, denotada por $r_{f}(v, w)$, da seguinte maneira:

$$
r_{f}(v, w)=c(v, w)-f(v, w) .
$$

Definição 4.6 : Seja $R=(G . s, t, c)$ uma rede e $f$ um pré-fluxo em $R$. Definimos grafo residual de $f$ como sendo o grafo $G_{f}=\left(V_{f}, A_{f}\right)$, onde:

$$
\begin{aligned}
& V_{f}=V \mathrm{e} \\
& A_{f}=\left\{(v, w) \in V \times V \mid r_{f}\left(v, w^{\prime}\right)>0\right\} .
\end{aligned}
$$

Com o objetivo de estimar a distância de um vértice qualquer ao vértice $t$ ou $s$, definiremos rotulaçào válidá.

Definição 4.7: Seja $R=(G, s, t, c)$ uma rede e $f$ um pré-fluxo em $R$. Uma $f$ rotulação válida em $R$ é definida como sendo uma funçào $d: V \rightarrow \mathcal{Z}^{+} \cup\{\infty\}$ tal que:

$d(s)=n$;

$. d(t)=0$

$. d(v) \leq d(w)+1$ para todo $(v, w) \in A_{f}$.

Chamaremos de rótulo de um vértice $v$, ao valor de $d(v)$. Para nào sobrecarregarmos a notaçào, chamaremos simplesmente de rotulação válida, devendo ficar claro no contexto qual é o pré-fluxo a que estamos nos referindo.

Note que se $d$ é uma rotulaçào válida, se $d(v)<n$ entào $d(v)$ é uma cota inferior para a distância de $v$ a $t$ no gralo residual $i_{f}$. Vormos fur durante o desenrolar do algoritmo, se $d(v) \geq n$ entào $d(v)-n e ́$ uma cola inlorior para a distância de $v$ a $s$ no grafo residual.

A seguir, definiremos vértice ativo, que utilizaremos na descriçào do algoritmo.

Definição 4.8 : Seja $R=(G . s, t, c)$ uma rede, $f$ um pré-fluxo em $R$ e $d$ uma rotulaçào válida em $R$. Um vértice ativo é um vértice $v$ tal que

$v \in V-\{s, t\}$

$. d(v)<\infty$

$. e(v)>0$.

O algoritmo consistirá de duas operações básicas: empurra e rerrotula. A operação empurra, enviará fluxo de um vértice ativo para um outro, enquanto que a operação rerrotula aumentará o rótulo de um vértice ativo, passível de aumentação. 
procedimento empurra( vértice $v, w)$ :

real $\delta$;

/*É aplicável quando: */

${ }^{*} v$ é ativo,

${ }^{*} r_{f}(v, w)>0 \mathrm{e}$

$* /$

$/^{*} d(v)=d(w)+1$.

$* /$

$l^{*} f$ é o pré-fluxo corrente $* /$

$\delta=\min \left(e(v), r_{f}(v, w)\right)$

$f(v, w)=f(v, w)+\delta$;

$f(w, v)=f(w, v)-\delta$ :

$e(v)=\epsilon(v)-\delta$;

$. e(w)=e(w)+\delta$ :

Definição 4.9 : Seja $R=(G, s, t, c)$ uma rede e $f$ um pré-fluxo em $R$. Se uma operação empurra é aplicada de $v$ a $w$, dizemos que $(v, w)$ fica saturada, se após esta operação obtemos $f(v, w)=c(v, w)$. Além disso, um empurra aplicado de $v$ a $w$ é dito saturador se ele satura $(v, w)$; e não saturador, caso contrário.

procedimento rerrotula(rérlice e):

vértice w;

/*É aplicável quando: */

${ }^{*} v$ é ativo e*/

$l^{*} \forall w \in V,(v, w) \in A_{f} \Rightarrow d(v)<d(w)+1^{*} /$

/* f́é o pré-fluxo corrente */

$. d(v)=\min _{(v, w) \in A_{f}}(d(w)+1) ;$

Lema 4.1 : Seja $R=(G, s, t, c)$ uma rede, $f$ um pré-fluxo em $R$ e $d$ uma rotulaçào válida. Se $v$ é um vértice ativo. entào ou um empurra ou um rerrotula pode ser aplicado a $v$.

Prova: No caso em que nào podemos aplicar o rmpurra ao vértice ativo v, temos que $\left\{w \in V \mid r_{f}(v, w)>0\right.$ e $\left.d(v)=d(w)+1\right\}=\emptyset$. ('omo d c uma rotulaço válida. entào $\forall w \in V,(v, w) \in A_{f} \Rightarrow d(v)<d(w)+1$. C'omo v's ativo. rrrolula é aplicável a $v$. 
A seguir descreveremos o algoritmo FLUXO-MAXIMO-BASICO. Este algoritmo recebe como entrada uma rede e devolve um fluxo máximo nesta rede. Este fluxo máximo será obtido a partir de um pré-fluxo que será alterado dinamicamente pelo algoritmo até se tornar um fluxo máximo.

algoritmo FLUXO-MÁXIMO-BÁSICO $\operatorname{rede}(G, s, t, c))$ :

pré-fluxo f;

vértice $v, w$;

/* Inicializaçào do pré-fluxo */

.para todo $(v, w) \in(V-s) \times(V-s)$ faça

. $f(v, w)=f(w, v)=0$;

.para todo vértice $w \in V$ faça

- $f(s, w)=c(s, w)$

$f(w, s)=-f(s, w)$

/* Inicializaçào dos rótulos */

$. d(s)=n$;

.para todo $v \in V-$ s faça

$d(v)=0$;

/* iteraçào */

.enquanto $\exists$ uma operaçào básica aplicável faça

- selecione uma operaçào básica e aplique-a;

retorne $f$;

A seguir, faremos a análise da a complexidade do algoritmo e provaremos que o mesmo é correto.

Lema 4.2 : Durante a execuçào do algoritmo. para cada virtice l. o seu rótulo d(v) nunca decresce. Uma operaçào rerrolula aplicada a r aumonta d(r).

Prova: Segue imediatamente observando a condiçào para que a operaçào rerrotula possa ser aplicada a $v$, e a atualização que á feita no rótulo de $v$.

Lema 4.3 : O algoritmo mantém a rotulaçào válicla. 
Prova: Suponha que uma operaçào rerrotula seja aplicada a $v$. Seja $d$ a rotulação antes da chamada do rerrotula e $d^{\prime}$ a rotulaçào após a chamada do mesmo. Como $d^{\prime}(v)=$ $\min _{(v, w) \in A_{f}}(d(w)+1)$ : e $d^{\prime}(w)=d(w)$ para todo $w \in V-\{v\}$, temos que

$d^{\prime}(v) \leq d(w)+1=d^{\prime}(w)+1 \quad \forall w \in V$ tal que $(v, w) \in A_{f}$. Como

$d(w) \leq d(v)+1 \quad \forall w \in V$ tal que $(w, v) \in A_{f}$, usando o lema 4.2. concluimos que:

$d^{\prime}(w)=d(w) \leq d(v)+1<d^{\prime}(v)+1$.

Suponha agora que uma operaçào empurra seja aplicada de $v$ a $w$. Se após esta operação, $(v, w)$ fica saturada. esta deixa de pertencer a $A_{f}$, o que nào invalicla a rotulaçào. Se após a operaçào empurra. (w.v) passa a pertencer ao novo $A_{f}, \operatorname{como} d(v)=d(w)+1$, entào $d(w) \leq d(v)+1$. Como a rotulaçào inicial é válicla. segue que a rotulação feita pelo algoritmo permanece válida.

Teorema 4.1 : Seja $R=(G, s, t, c)$ uma rede e $f$ um fluxo em $R$. Entào, $f$ é máximo se e somente se nào existe caminho orientado de s a $t$ em $G_{f}$.

Prova: Imediata a partir do corolário do teorema do fluxo máximo, visto no capítulo 1 , observando ạ equivalência entre a existência de $u m$ caminho orientado de $s$ a $t$ em $G_{f}$ e a existência de um caminho aumentador de $s$ a $t$ em $G$.

Lema 4.4 : Se $(G, s, t, c)$ é uma rede. flé um pré-fluxo e dé uma rotulaçào válida, então nào existe caminho orientado de $s$ a $t$ em $G_{f}$.

Prova: Suponha que existam $s=v_{0}, v_{1}, \cdots, v_{k}=1$ tais que $\left(v_{i}, v_{i+1}\right) \in A_{f}$, para $i=$ $0,1, \ldots, k-1$. Como dé uma rotulaçào válida. $d\left(c_{i}\right) \leq d\left(c_{i+1}\right)+1 . \operatorname{Logo} . d(s) \leq d(t)+k$. Como $d(s)=n$ e $d(t)=0$. entào $k \geq n$. àlssurclo.

Teorema 4.2: Suponha que o algoritmo termine $\operatorname{com} d(v)<\infty, \forall v \in V$. Então o pré-fluxo $f$ é um fluxo máximo.

Prova: Se o algoritmo pára. entào nào existe operaçào básica aplicável. Logo, pelo lema 4.1, não existe vértice ativo. Como $d(v)<\infty, \forall v \in V$, temos pela definição de vértice ativo que $e(v)=0, \forall v \in V-\{s, t\}$, ou seja, f é um fluxo.

Pelo lema 4.2, o algoritmo mantém a rotulaçào válida: e pelo lema 4.4, temos que não existe caminho orientado de $s$ até $t$ em $G_{f}$. Portanto, pelo teorema 4.1 , temos que $f$ 
é um fluxo máximo.

Lema 4.5 : Se $f$ é um pré-fluxo em uma rede (G.s.l.c) e v' é um vértice com excesso positivo, entào existe um caminho orientado de $r$ atés $s \mathrm{em} C_{\text {f }}$.

Prova: Seja $v$ um vértice $\operatorname{com} \epsilon(v)>0$,

$S=\left\{i \in V \mid \exists\right.$ caminho orientado em $G_{f}$ de $v$ a $\left.i\right\}$ e $\bar{S}=V-S$.

Suponha por absurdo que s $\notin S$. Então

$$
\sum_{i \in S} \epsilon(i)=\sum_{i \in S} f[V, i]=f[V, S]=f[S, S]+f[\bar{S}, S]=f[\bar{S}, S]
$$

Seja $(i, w) \in(S, \bar{S})$. Pela definição de $S$, temos que $(i, w) \notin A_{f}$, ou seja $r_{f}(i, w)=0$. e portanto. $c(i, w)=f(i, w)$. Logo. $f(i, w) \geq 0$. Como $f(w, i)=-f(i, w)$, temos que $f(w, i) \leq 0$. Portanto, $\sum_{i \in S} e(i) \leq 0$. Como $\epsilon(i) \geq 0, \forall i \in S$ e, $v \in S$, temos que $e(v)=0$. Absurdo.

Lema 4.6 : Em qualquer passo da execuçào do algoritmo tem-se que, $d(v) \leq 2 n-1$ para todo $v$ em $V$.

Prova: Como d só se altera na operaçào m molula e esta ci aplicada a véplices ativos, basta.

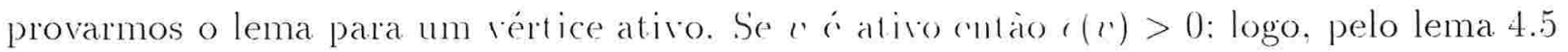
existe um caminho orientado $\left(v=v_{0}, v_{1} \ldots . v_{k}=s\right) \mathrm{cm}\left(i_{f}\right.$. Como $d$ é uma rotulaçào válida, $d(v) \leq d(s)+k$. Logo, $d(v) \leq n+n-1$.

Lema 4.7 : O número máximo de operaçòes rerrotula é $2 n-1$ por vértice e $(2 n-1)(n-2)$ em toda a execução do algoritmo.

Prova: Pelo lema 4.6, o rótulo de um vértice vé no máximo $2 n-1$, em qualquer passo da execuçào do algoritmo. Como a operaçào rerrotula incrementa o rótulo de um vértice $v$ de pelo menos 1 , e o rótulo inicial de $v$ é zero (pois $v \neq s$ ), podemos aplicar a operaçào rerrotula $(v)$ no máximo $2 n-1$ vezes. Como a $s$ e a $t$ nào se aplica rerrotula, temos que o número máximo de operaçòes rerrotula é $(n-2)(2 n-1) \leq 2 n^{2}$.

Lema 4.8 : O número máximo de empurras saturadores é 2 mn durante toda a execuçào do algoritmo. 
Prova: Considere dois vértices l' e $u$. Vamos contar o numero de empurras saturadores entre $v$ e $w$ (isto é, de $v$ a $w$ ou de $w$ a $v$ ). Note que se tais operaçòes ocorrem entào $(v, w) \in A$ ou $(w, v) \in A$. Suponha que num determinado passo do algoritmo, $(v, w)$ fica saturada pela operaçào empurra. Logo, $d(v)=d(w)+1$. Para ocorrer uma nova saturação entre $v$ e $w$, é necessário que uma operaçào empurra tenha sido aplicada de $v$ a $w$. Se chamarmos de $d^{\prime}$ a rotulaçào durante a aplicaçào deste último empurra, temos que $d^{\prime}(w)=d^{\prime}(v)+1$. Pelo lema $4.2, d^{\prime}(v) \geq d(v)$. Portanto, $d(w)=d(v)-1 \leq d^{\prime}(v)-1=$ $d^{\prime}(w)-2$. Isto significa que, para ocorrer uma nova saturaçào entre $v$ e $w$, o rótulo de $w$ deve ser incrementado de pelo menos 2 .

Analogamente, se $(w, v)$ fica saturada pela operaçào empurra, podemos concluir que para ocorrer uma nova saturaçào entre $v$ e $w$. o rótulo de $v$ deve ser incrementado de pelo menos 2 .

Portanto. entre dois empurras saturadores ocorridos entre $v$ e $w, d(v)+d(w)$ deve ser incrementado de pelo menos 2 .

No primeiro empurra aplicado entre $u^{\circ} u$ temos $d(u)+d(u) \geq 1$. Pelo lema 4.6 e pelas condiçòes de aplicabilidade do rmpurr. tomos (gur no último cmpurra aplicado entre $v$ e $w . d(v)+d(w) \leq t n-3$. Entào. o múncro máximo de cmpuras saturadores entre $v$ e $w$ é $2 n-1$.

Logo, temos $(2 n-1) m \leq 2 n m$ empurras saturadores durante toda a execuçào do algoritmo.

Lema 4.9 : O número máximo de empurras nào saturadores é $4 n^{2} m$ durante toda a execuçào do algoritmo.

Prova: Seja.

$$
\phi=\sum_{\{v \mid v \text { é ativo }\}} d(v) .
$$

Analisemos o efeito de cada operaçào básica sobre a funçào 0 .

Em primeiro lugar. vejamos o efeito de um r mpurr nà saturador sobre $\phi$. Su-

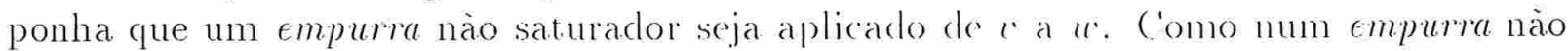
saturador $\min \left\{\epsilon(v), r_{f}(v \cdot u)\right\}=\epsilon(v)$. temos que após a aplicaçào desta operaçào $v$ deixa de ser um vértice ativo, $\operatorname{logo} d(v)$ deixará de fazer parte da somatória. Por outro lado, após a aplicação desta operaçào, caso $w$ nào seja nem s nem $t, d(w)$ fará parte da somatória, sendo $d(w)=d(v)-1$. Ou seja, $\phi$ decresce de 1 ou de $d(v)$. Portanto, após a aplicação de um empurra nào saturador, $\phi$ decresce de pelo menos 1 . 
Vejamos agora o efeito de todos os empurras saturadores sobre $\phi$. Se um empurra saturador for aplicado de $v$ a $v$, entào $\min \left\{e(v), r_{f}(v, w)\right\}=r_{f}(v, w)$, portanto $v$ pode continuar ativo e caso $w$ nào seja nem $s$ nem $t, d(w)$ fará parte da somatória. Como $d(v) \leq 2 n-1$, temos que o pode aumentar de no máximo $2 n-1$ unidades. Portanto, o total de acréscimos a $\phi$ causados pelos empurras saturadores é no máximo $2 m n(2 n-1)$.

Vejamos entào, o efeito das operaçòes rerrotula. Como toda vez que é aplicado um rerrotula a $v, v$ deve ser um vértice ativo, $d(v) \leq 2 n-1$, entào o total de acréscimos causados por rerrotulas é no máximo $(n-2)(2 n-1)$. já que nào se aplica rerrotula nem a. $s$ nem a $t$.

No início do algoritmo $\Theta=0$ e no decorrer do mesmo $\odot \geq 0$. Como cada empurra nào saturador decrementa o de pelo menos 1 . o número de empurrs nào saturadores nào pode ser maior que o total de acréscimos que o solreu pelos rerrotulas e empurras saturadores. Ou seja, o número máximo de fmpurus nào saturadores é:

$$
T=2 m n(2 n-1)+(n-2)(2 n-1) .
$$

Como $m \geq n-1$. temos:

$$
\begin{gathered}
T \leq 4 n^{2} m-2 m n+2 n^{2}-5 n+2 \leq \\
4 n^{2} m-2(n-1) n+2 n^{2}-5 n+2= \\
4 n^{2} m-2 n^{2}+2 n+2 n^{2}-5 n+2 \leq 4 n^{2} m .
\end{gathered}
$$

Teorema 4.3 : O algoritmo FLEXO-MAXIMO-BASICO é correto e realiza $O\left(n^{2} m\right)$ operaçòes básicas para encontrar o fluxo máximo.

Prova: Imediata, a partir do teorema 1.2 e dos lomas 1.6. 1.7. 1.s e 1.9.

\subsection{Uma Primeira Implementação}

Note que no algoritmo básico, o comando "selecione uma operaçào básica" pode ser implementado de várias maneiras. Para selecionar uma operaçào básica, necessitamos fazer duas seleçòes: a de um vértice ativo e a operaçào em si. Nesta seção, veremos uma. maneira de selecionar um vértice ativo e a operaçào básica, obtendo um algoritmo de complexidade $O\left(n^{3}\right)$. 
Precisamos incluir algumas novas informaçòes na estrutura de dados. Em primeiro lugar, chamemos um par nào ordenado $\{v, v\}$ de aresta real se $(v, v) \in A$ ou $(w, v) \in A$. A cada aresta real $\{v, w\}$ associaremos 3 valores: $c(v, v), c(v, v)$ e $f(v, w)(=$ - $f(v, v))$. Cada vértice $v$ possuirá uma lista de arestas reais $\{v, w\}$, incidentes a ele. Desta maneira, cada aresta real $\{v, w\}$ aparecerá em duas listas, na lista de $v$ e na lista de w. Além disso, cada lista possuirá um ponteiro para o candiclato - chamado corrente - a realizar um empurra; este ponteiro, no início. estará apontando para o primeiro elemento da lista. Tal lista tem uma ordenaçào arbitrária. mas lixa.

A seguir, temos a descrição da operaçào empurra-rerrotula (aplicada a $v$ ), que combina as duas operaçōes (resolvendo o problema de selecionar a operação a ser aplicada a $v$, quando este está selecionado), retornando o vértice $w$ tal que $\{v, w\}$ é aresta real corrente da lista de $v$ no início da aplicaçào da operaçào. O vértice $w$ será utilizado num procedimento posterior.

função empurra-rerrotula(vértice v):

vértice w;

/* É aplicável quando $v$ é um vértice ativo */

$l^{*} f$ é o pré-fluxo corrente */

.tome a aresta corrente $\{v, w\}$. da lista de arestas reais de $v$;

. se $d(v)=d(v)+1$ e $r_{f}(v, w)>0$

então empurra(v,w) /* empurra é aplicável */

senão se $\{v, w\}$ nào é a última aresta da lista de arestas de v

então troque aresta corrente corrente $\{r \cdot u\}$ pola próxima aresta da lista de $v$ senão faça a primeira aresta da lista do 10 a aresta corrente de $v$;

rerrotula $(v)$ :

.retorne $w$;

Precisamos mostrar que a operaçào empurra-rerrotula usa corretamente a operação rerrotula.

Lema 4.10 : A operação empurra-rerrotula chama a operaçăo rerrotula somente quando ela é realmente aplicável.

Prova: Para aplicarmos a operaçào rerrotula a um vértice $v$ é necessário que $v$ seja ativo e que para cada aresta $\{v, w\}$ da lista de $v$, tenhamos ou $d(v)<d(w)+1$ ou $r_{f}(v, w)=0$. A primeira condiçâo é satisfeita pois o empurra-rerrotula só é aplicado a vértices ativos. Vejamos agora porque a segunda condição é satisfeita.

No momento em que é feita a troca da aresta corrente $\{v, v\}$ pela próxima aresta 
da lista de $v$, ou $d(v)<d(w)+1$ ou $r_{f}(v, w)=0$, pois o empurra nâo pôde ser aplicado. Se o empurra nâo pôde ser aplicado porque $d(v)<d(w)+1$, como $d(w)$ nunca cresce, enquanto o rerrotula não for aplicado a $v$, esta condiçào será mantida. Por outro lado, se o empurra não pôde ser aplicado porque $r_{f}(v, w)=0$, e esta condiçâo não se mantiver até a aplicação do rerrotula a $v$, então um empurra foi aplicado de $w$ a $v$ e neste caso, $d(w)=d(v)+1$ ou seja, $d(v)<d(w)+1$. Portanto, a partir do momento da troca, em qualquer passo antes do rerrotula ser aplicado ao vértice $v$, ou $d(v)<d(w)+1$ ou $r_{f}(v, w)=0$, ocorre.

Como imediatamente antes da aplicação da operação rerrotula ao vértice $v$, o ponteiro da lista de arestas de $v$ já percorreu toda a lista, com exceção da última aresta (mas nesta aresta, como o empurra não pode ser aplicado, esta aresta também satisfaz as condições acima), para cada vértice $w$ tal que $\{v, w\}$ está na lista de $v$, ou $d(v)<d(w)+i$ ou $r_{f}(v, w)=0$, e portanto, a operação rerrotula é aplicável a $v$.

Finalmente, resta-nos descrever como fazer a seleçào de um vértice ativo. Para isto, necessitamos de mais uma estrutura de dados. Esta estrutura de dados é uma fila, $F$, que contém todos os vértices ativos. e será manipulada pelo procedimento descarta. Este procedimento remove um vértice da fila e aplica a opcraça rmpurra-rerrotula até que o vértice deixe de ser ativo ou o seu rótulo aumentc. No inicio. $F=\{w \in V-\{s, t\} \mid c(s, w)>$ $0\}$. O algoritmo chama o procedimento descarta até a fila $F$ se tornar vazia. A seguir, temos a descrição do procedimento descarta.

procedimento descarta( fila $F)$ :

vértice $v, w$;

${ }^{*}$ É aplicável quando $F \neq \emptyset * /$

.remova o vértice $v$ de $F ; \quad / *$ v deve ser ativo */

repita

. $w=$ empurra-rerrotula $(v)$;

se $w$ tornou-se ativo durante a operaçào empurra-rerrotula(v)

então insira $w$ em $F$;

. até que $e(v)=0$ ou $d(v)$ aumenta;

. se $v$ ainda é ativo

então insira $v$ em $F$;

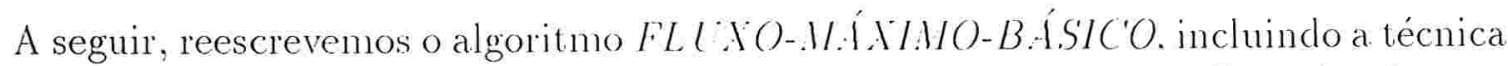
de seleção das operaçòes básicas e dos vértices ativos. descritas nesta seçào. Este algoritmo recebe o nome de FLUXO-MÁXIMOI. 
algoritmo FLUXO-MÁXIMO1(rede $(G, s, t, c))$ :

pré-fluxo $f$;

vértice $v, w$;

/ Inicializaçào do pré-fluxo */

.para toda aresta $(v, w) \in(V-s) \times(V-s)$ faça

. $f(v, w)=f(w, v)=0$

-para todo vértice $w \in V$ faça

$f(s, w)=c(s, w)$

- $f(w, s)=-f(s, w)$;

/* Inicialização dos rótulos */

$. d(s)=n$;

-para todo $v \in V-s$ faça

$\cdot d(v)=0$;

/* Inicializaçào da fila $F$ cle vértices ativos */

$. F=\{w \in V-\{s, t\} \mid c(s, w)>0\}$

/* iteração */

.enquanto $F \neq \emptyset$ faça

- descarta $(F) ; \quad / *$ chama u procedimento empurra-rerrotula*/

.retorne $f$;

Lema 4.11 : O tempo que o algoritmo FLUXO-MAXIMOI necessita é $O(m n)$ mais $O(1)$ por empurra nào saturador.

Prova: Chamemos a lista de arestas reais de um vértice e de $L_{2}$. Após cada rerrotula. a lista do vértice $v$ foi percorrida duas vezes. una antes de aplicar o rerotula e outra durante o rerrotula. Pelo lema t.T. o rerrotula $\therefore$ aplicado no máximo $2 n-1$ vezes por vértice. Portanto o tempo gasto em operaçoes rrrolulu. inclunindo os tempos de percorrer as listas é

$$
(2 n-1) \sum_{v \in V^{\prime}-\{s, t\}} 2\left|L_{v}\right| \leq(2 n-1) 4 m .
$$

ou seja, $O(m n)$. Logo, o tempo gasto pelo algoritmo é $O(m n)$ mais $O(1)$ por empurra. Aplicando o lema 4.8, o resultado segue.

Teorema 4.4: A complexidade do algoritmo FLUXO-MÁXIMOI é O $\left(n^{2} m\right)$. 
Prova: Imediata, a partir dos lemas 4.11 e 4.9.

Na verdade, a complexidade do algoritmo FLUXO-MÁXIMO1 é $O\left(n^{3}\right)$, pois não são necessários mais que $O\left(n^{3}\right)$ empurras não saturadores. Para demonstrar esta afirmaçâo é necessário analisar o comportamento da fila $F$ (lembrando que numa fila, o primeiro que entra é o primeiro que sai). Faremos isto a seguir.

Definição 4.10 : Define-se passagem sobre uma fila indutivamente, da seguinte maneira: Passagem 1 é a aplicação da operaçào descarta sobre todos os vértices da fila inicial. Dado que a passagem $i$ está definida, a passagem $i+1$ é a aplicação da operação descarta sobre todos os vértices inseridos na fila durante a passagem $i$.

Lema 4.12 : O número máximo de passagens sobre a fila $F$ é $4 n^{2}$.

Prova: Seja $\Phi=\max \{d(v) \mid v$ é ativo $\}$. Para obter o número máximo de passagens sobre a fila $F$, contaremos o número de passagens em que $\Phi$ aumenta, se mantém inalterado e diminui. Se após uma passagem sobre a fila, $\Phi$ nào se alterou, entào é necessário que para todo $v$ na fila tal que $d(v)=\Phi$. $v$ tenha deixado de ser ativo: além disso, deve existir algum vértice $v$ na fila tal que $d(v)<\Phi$ e em $v$ tenha-se aplicado um rerrotula de tal maneira que $d^{\prime}(v)=\Phi$, após o rerrotula. Portanto, neste caso pelo menos uma operação rerrotula deve ter sido aplicada. Por outro lado, se $\Phi$ aumentou, entào o rótulo de algum vértice $v$, deve ter sido incrementado pelo menos na mesma quantidade que $\Phi$ aumentou, ou seja, novamente temos que pelo menos um rerrolula deve ter sido aplicado. Portanto, o número total de passagens sobre a fila tal que $\Phi$ nào se altera ou aumenta é no máximo o número de operaçòes rêrotula que é no máximo $2 n^{2}$. pelo lema $4 . \bar{t}$.

Cada vértice pode provocar acréscimos à funçào $\Phi$ de no máximo $(2 n-1)$. Como temos $(n-2)$ vértices que podem causar acréscimos a $\Phi$. temos que o total de acréscimos a $\Phi$ é no máximo $(n-2)(2 n-1) \leq 2 n^{2}$. Como no inicio $\phi=0$. e $\Phi \geq 0$ durante a execuçào do algoritmo, o número total de passagens em que $\Phi$ diminui é no máximo $2 n^{2}$. Logo. o número máximo de passagens sobre a fila é $4 n^{2}$.

Teorema 4.5 : A complexidade do algoritmo FLUXO-MAXIMOL é O $\left(n^{3}\right)$.

Prova: Em uma passagem sobre a fila $F$ são executados no máximo $n$ empurras nào saturadores, pois o tamanho máximo da fila é $n$ e quando um empurra nào saturador é aplicado a um vértice $v$, o excesso de $v$ se anula e portanto nào se aplica mais nenhum 
empurra-rerrotula a $v$, até o final desta passagem sobre a fila. Portanto, pelo lema 4.12, temos que o número máximo de empurras não saturadores é no máximo $4 n^{3}$. Pelo lema 4.11, segue o resultado.

\subsection{Usando Árvores Dinâmicas}

Nesta seção veremos um algoritmo mais eficiente que os descritos anteriormente, que chamaremos de FLUXO-MAXIMOQ. A idéia fundamental deste algoritmo consiste em realizar vários empurras simultaneamente. Tais empurras simultâneos sào executados eficientemente, diminuindo assim, o tempo gasto em empurras nào saturadores, que é o gargalo da complexidade do algoritmo apresentado na seção anterior.

Note que se $\left(v=v_{0}, v_{1}, \ldots, v_{k}=w\right)$ é um caminho orientado no grafo residual, tal que $d\left(v_{i}\right)=d\left(v_{i+1}\right)+1$. é possível passar $\min \left\{e(v), \min \left\{r\left(v_{i}, v_{i+1}\right) \mid 0 \leq i<k\right\}\right\}$ fluxo de $v$ até $w$ realizando um empurra direto de $v$ até $w$. Para poder passar algum fluxo, este caminho deve ser formado por arestas admissiveis, cuja definiçâo formal está a seguir.

Definição 4.11 : Seja $R=(G, s, t, c)$ uma rede, $f$ um pré-fluxo em $R$ e $d$ uma rotulaçào válida em $R$. A aresta corrente $\{v, w\}$ de um vértice $v \in V-\{s, t\}$ é admissível se $r_{f}(v, w)>0$ e $d(v)=d(w)+1$.

A idéia do algoritmo consiste em armazenar caminhos formados por arestas admissiveis. Podemos criar subgrafos de arestas admissíveis. Porém, pelas propriedades de arestas admissiveis, estes subgrafos devem ser árvores.

Uma boa maneira de guardar árvores de arestas admissiveis é usar a estrutura de dados de árvores dinâmicas apresentada no capítulo 3. definindo o custo de cada aresta como sendo a sua capacidade residual. Com esta estrutura de dados, podemos realizar uma seqüência de $l$ operaçòes sobre essas árvores en tempo $O(l \log K)$. onde $I i$ é o tamanho máximo dessas árvores. Utilizaremos nesta seçào, as operaçòes raiz. custo. customin, tamanho, atualiza, enxerta e poda, definidas no capítulo 3. Nesta nova estrutura de dados, consideramos que as arestas das árvores estào direcionadas para a raiz, e se $\{v, w\}$ é uma aresta de uma árvore dinâmica, $\operatorname{com} w=p a i(v)$ entào o fluxo $f(v, w)$ estará armazenado implicitamente. isto é $f(v, v)=c(v, w)-c u s t o(v, w)$. Se $\{v \cdot w\}$ nào é uma aresta de uma árvore dinâmica. entào $f(v, w)$ ou $f(w, v)$ está armazenado explicitamente.

A seguir, temos a descriçào da funçào projcta( ( $)$. que manda fluxo de um vértice ativo $v$ até a raiz de sua árvore e poda as arestas saturadas até que $c(v)=0$ ou v' é raiz da árvore. 
procedimento projeta(vértice v):

real $\delta$

vértice $i$

repita

. $\delta=\min (e(v)$, custo $($ customin $(v)))$;

- atualiza $(v,-\delta)$;

- repita

. $\quad i=$ customin $(v)$;

- $\operatorname{poda}(i)$

- até que $v=\operatorname{raiz}(v)$ ou custo(customin $(v))>0$

.até que $\operatorname{raiz}(v)=v$ ou $e(v)=0$;

O algoritmo FLUXO-MAXIMOQ mantém a mesma fila $F$ de vértices ativos e chama o procedimento descarta até que a fila $F$ se torne vazia, como na seçào anterior. A diferença fundamental é que o procedimento descarta chama o procedimento empurrarerrotula-na-árvore ao invés de chamar o procedimento empurra-rerrotula. Além disso, o procedimento descarta insere todos os vértices que se tornaram ativos durante a aplicação do empurra-rerrotula-na-árvore. No início, as árvores sào os vértices isolados do grafo $G$. É o procedimento empurra-rerrolula-na-árvor que chama a rotina enxerta e faz as árvores aumentarem de tamanho. O tamanho das árores será limitado por um parâmetro I' que será escolhido mais tarde. A seguir, temos a descriçào do procedimento empurrarerrotula-na-árvore. 
procedimento empurra-rerrotula-na-árvore(vértice v):

vértice $w, i$;

/* É aplicável quando $v$ é um vértice ativo */

$/^{*} \quad * /$ seja $\{v, w\}$ a aresta corrente da lista de $v$;

$/^{*} \quad * / . \operatorname{se} d(v)=d(w)+1$ e $r_{f}(v, w)>0 / *$ se $\{v, w\}$ é admissível $* /$

$/^{*} 1 * /$. então se tamanho(v)+tamanho(w) $\leq K^{\prime}$

$/^{*} 1 \mathrm{a} * / . \quad$ então $\operatorname{enxerta}\left(v, w, r_{f}(v, w)\right)$;

$l^{*} * /$ projeta $(v)$

${ }^{*} 1 \mathrm{~b} * / . \quad \quad$ senão $/ * \operatorname{tamanho}(v)+\operatorname{tamanho}(w)>K^{*} /$

/* $* /$. empurra $(v)$;

$/^{*} \quad * / . \quad$ se $w \neq s$ e $w \neq t$ e $\operatorname{raiz}(w) \neq w$

${ }^{*} \quad * /$ então $\operatorname{projeta}(w)$

$/{ }^{*} 2 * / . \quad$ senão $/ * d(v)<d(w)+1$ ou $r_{f}(v, w)=0 * /$

${ }^{*} \quad * /$. se $\{v, w\}$ nào é a última aresta da lista de $i$

$/ * 2 \mathrm{a} * /$.

então troque a aresta corrente $\{v, w\}$ pela próxima aresta da lista de $v$

$/ * 2 b * /$.

/* $* /$.

/ * * $\quad *$.

/* $* /$.

/* $* /$. senão $/ *\{v, w\}$ é a última aresta da lista de $v^{*} /$

faça a primeira aresta da lista de $v$ a aresta corrente de $v$; para todo vértice $i$ filho de $v$ faça poda(i); rerrotula(v):

Teorema 4.6 : O algoritmo FLUXO-MÁXIMOQ é correto.

Prova: Para isto. basta mostrarmos que é lícito aplicar a operaçào enxerta. ou seja, que $v$ é raiz de uma árvore e que v e $u$ nào estào na mesma árvore.

Un vértice ativo só nào é raiz de uma árore após a aplicaçào do enxerta (caso 1a) ou do empurra (caso 1b), mas a operaçào projela ć aplicada logo em seguida. e esta transforma este vértice numa raiz ou num vértice com excesso mulo.

Vejamos porque ve w nào estào numa mesma árvore. É fácil ver que $d($ raiz $(w)) \leq$ $d(w)$. Como $d(v)=d(w)+1$ e vé raiz de alguma árvore. ela nào pode ser a raiz da árvore que contém $w$.

Lema 4.13 : A complexidade do algoritmo FLLAO-MAXMO巳 é O(nm log $K)+$ $O(I \log K)$, onde $I$ é o número de inserçòes na fila $F$. 
Prova: Para analisar a complexidade do algoritmo vamos analisar o tempo gasto em todas as chamadas do empurra-rerrotula-na-árvore. É imediato que o tamanho máximo de qualquer árvore dinâmica é no máximo $K$. O tempo gasto em cada operação empurrarerrotula-na-árvore é $O(1)$ mais o tempo gasto nas operaçòes rerrotula (caso $2 \mathrm{~b}$ ) mais o tempo gasto nas operações poda mais o tempo gasto nas operações projeta mais o tempo das demais operaçôes sobre árvores dinâmicas do procedimento.

O tempo total gasto em operaçòes rerrotulı é $O(m$ m. . pela demonstraçào do lema 4.11. O número de operaçòes sobre árvores dinâmicas executadas pelo projeta é da. mesma ordem que o número de operaçòes porla execuladas por ele. O número total de operações poda é no máximo o número total de operaçòes enxerta executadas durante todo o algoritmo. Através de um raciocínio análogo ao feito na demonstração do lema 4.8 podemos inferir que o número máximo de operações enxerta é $O(n m)$. Logo, o número de operações sobre árvores dinâmicas executadas pelo procedimento projeta mais o número das demais operaçòes poda (caso $2 \mathrm{~b}$ ) é $O(n m)$.

As demais operaçòes sobre árvores dinâmicas executadas em cada empurrarerrotula-na-árvore sào no máximo 3 (tamanho(v). tamanho(w) e raiz(w)). Pelo teorema 3.5, temos que o tempo total gasto em todas as chamadas do empurra-rerrotulana-árvore é $O\left(m n \log K^{\prime}\right)+O\left(I^{\prime} \log K^{\prime}\right)$, onde $I^{\prime}$ é o número de chamadas do procedimento empurra-rerrotula-na-árvor. Por um raciocínio análogo ao da demonstraçào do teorema 4.5 , temos que $I^{\prime}=O(m n)+1$. Portanto, a complexidade deste algoritmo é $O(m n \log K)+O\left(I \log K^{\prime}\right)$.

A seguir, temos o lema crucial deste capítulo.

Lema 4.14: O número de insergòes na fila $f: \therefore O\left(m ! n+\frac{n^{*}}{\kappa}\right)$.

Prova: Um vértice $v$ pode ser inserido na fila quando o seu rótulo é incrementado. ou quando ele se torna ativo (sugerimos a leitor, acompanhar esta demonstraçào observando a figura 4.1).

Pelo lema 4.T. o numero de vezes que ocorre incremento de rótulo é no máximo $2 n^{2}$. Por outro lado. um vértice pode tornar-se ativo nos casos la e 1 b do procedimento empurra-rerrotula-na-árvort. O número de inserçoes na fila $F$ ocorridas nos casos la e 1b é igual ao número de operaçòes poda ocorridas em todas as chamadas do projeta mais um para cada projeta, que é igual ao número de ocorrencias dos casos la e lb. O número máximo de operaçòes poda é $2 \mathrm{~m} n$. O número de ocorrências do caso la é no máximo $2 m n$ (número de operaçòes enxerta). Resta-nos contar o número de ocorrências do caso $1 \mathrm{~b}$.

Vamos subdividir o caso $1 \mathrm{~b}$ em três casos. O primeiro caso que consideraremos 
é quando o procedimento projeta $(w)$ causa alguma chamada da função poda: isto pode ocorrer no máximo $2 \mathrm{~nm}$ vezes. O segundo caso é quando o procedimento empurra causa a saturação de $\{v, w\}$ : este caso, pelo lema 4.8, pode ocorrer no máximo $2 m n$ vezes. Restanos agora analisar o terceiro caso, que é a nào ocorrência de nenhum dos dois primeiros casos.

Para analisar este caso, vamos chamar de $A_{v}$ a árvore a qual um vértice $v$ pertence e $|A|$ o número de vértices da árvore $A$. Além disso, dizemos que uma árvore $A$ é grande se $|A|>\frac{K}{2}$ e pequena, caso contrário. Assim, no início de cada passagem pela fila $F$, temos no máximo $\frac{2 n}{K}$ árvores grandes. Se ocorrer o caso $1 \mathrm{~b}$, ou $A_{v}$ ou $A_{w}$ (ou ambas) é uma árvore grande. Vamos considerar agora, mais dois subcasos dentro do último subcaso: o primeiro, quando $A_{v}$ é uma árvore grande e o segundo, quando $A_{v}$ é uma árvore pequena.

Considere o caso em que $A_{v}$ é uma árvore grande. Como o empurra $(v, w)$ não foi saturador, o excesso de $v$ se anulou, o que significa que o procedimento empurra-rerrotulana-árvore não será aplicado novamente a $v$ nesta passagem pela fila $F$. Portanto, se $A_{v}$ se alterou desde o início desta passagem pela fila $F$, entào contaremos este caso através das operaçôes poda e enxerta ocorridos mais recentemente em $A_{v}$. Como cada poda gera duas árvores, mas uma pode ser desprezada, pois é pequena. e cada enxerta gera uma árvore, até o fim do algoritmo teremos no máximo $4 \mathrm{~nm}$ destes casos. Suponha que $A_{v}$ nào tenha. se alterado desde o início desta passagem pela fila $F$. ('omo no início desta passagem pela fila $F$ tínhamos no máximo $\frac{2 n}{k}$ destas árvores. pelo lema 1.12. no algoritmo inteiro teremos no máximo $\frac{8 n^{2}}{\kappa^{\circ}}$ destes casos.

Considere agora o caso em que $A_{v}$ é uma árvore pequena. Como estamos analisando o caso $1 \mathrm{~b}, A_{w}$ deve ser grande. Como nào ocorreram chamadas da funçào poda e o empurra é nào saturador. temos que todo o excesso de $v$ foi transferido para a rajz de $A_{w}$. Como neste lema estamos contando o número de inserçòes em $F$ e isto ocorre só uma vez para a raiz de $A_{u}$ por passagem na fila $F$. podemos desprezar as demais ocorrências de $A_{w}$ ser grande, neste caso. Portanto, pelo mesmo raciocínio do caso anterior, podemos inferir que o número máximo de ocorrências destes casos é $4 m n+\frac{8 n^{3}}{\hbar^{3}}$.

Vamos agora. somar todas as estimativas:

$$
2 n^{2}+2 n m+2 n m+2 n m+2 n m+4 m n+\frac{8 n^{3}}{\Pi}+4 n+\frac{8 n^{3}}{K}=2 n^{2}+16 n m+\frac{16 n^{3}}{K} .
$$

Logo, o número de inserçoes na fila $F: O\left(m m+\frac{n^{\prime \prime}}{K^{\prime}}\right)$. 


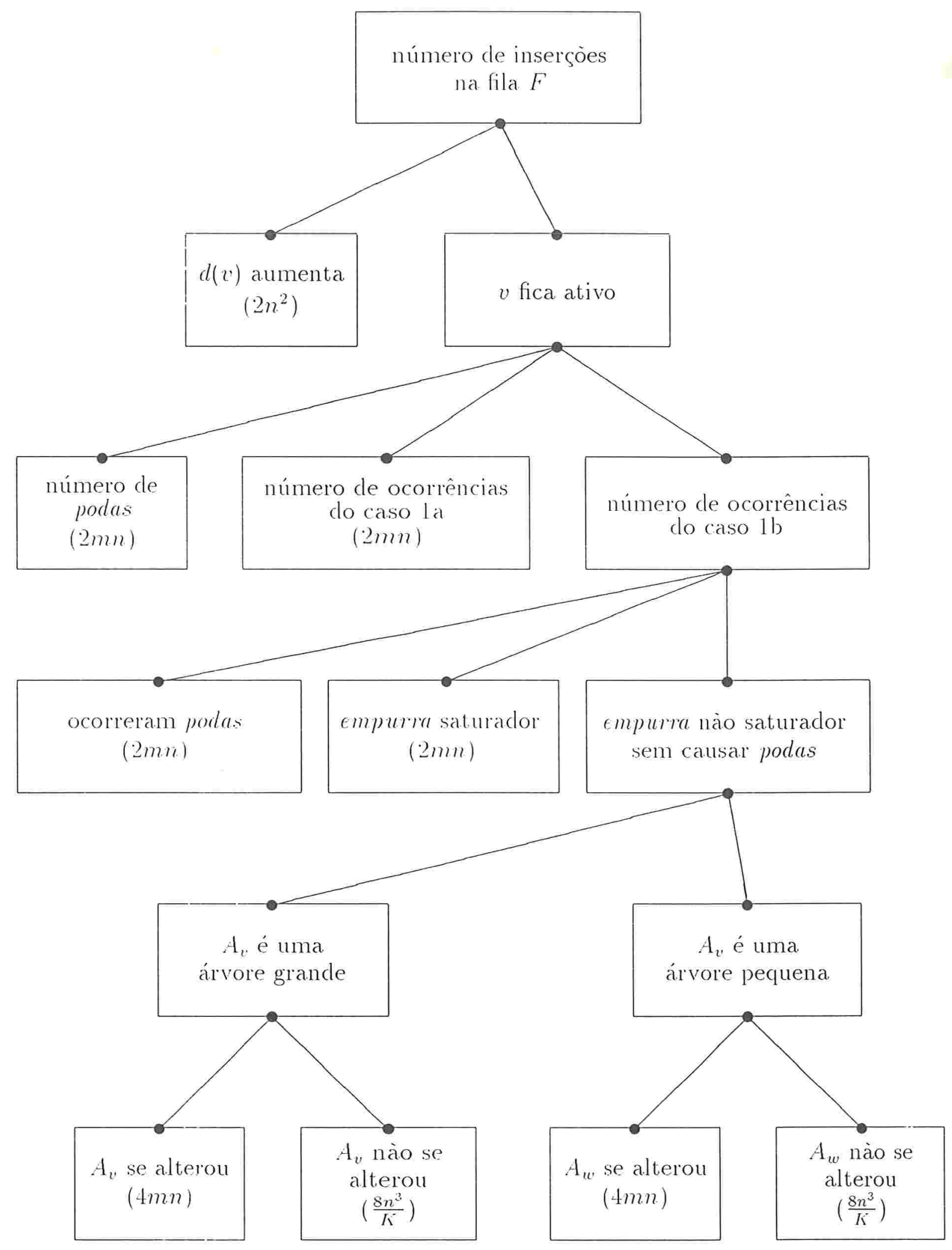

Figura 4.1 : Casos abordados na demonstraçào do lema t.14. 
Teorema 4.7: Se escolhermos $K=\frac{n^{2}}{m}$, a complexidade do algoritmo desta seção (usando árvores dinâmicas) é $O\left(n m \log \left(\frac{n^{2}}{m}\right)\right)$.

Prova: Imediata, a partir dos lemas 4.13 e 4.14.

\subsection{Comparando o Algoritmo de Goldberg-Tarjan e os do Capítulo 1}

Nesta seçào, selecionaremos as idéias dos algoritmos descritos no capítulo 1, que estào presentes no algoritmo de Cioldberg e Tarjan.

A demonstraçào do teorema t.l usa o teorema do fluxo máximo de Ford e Fulkerson. O algoritmo de Ford e Fullierson realiza aumentaçoes sobre caminhos de $s$ a $t$, enquanto que o algoritmo de Cioldberg-Tarjan realiza aumentaçòes sobre caminhos de um vértice ativo a um vértice qualquer.

Edmonds e Karp usaram a idéia de distância e esta é crescente durante a execuçào do algoritmo. como ocorre no algoritmo de Goldberg-Tarjan. Porém. a distância do algoritmo Elí é exata é é calculada a cada passo da execuçào do algoritmo, enquanto que no algoritmo de Goldberg- Tarjan é usada uma distância aproximada (rotulaçào válida), que é mantida durante a execuçào do algoritmo. Mais ainda. tanto no algoritmo EK quanto no algoritmo de Goldberg-Tarjan. o número de saturaçòes é $O(m n)$.

A idéia de distância também ocorre no algoritmo de Dinic, mas neste algoritmo a distância é mantida durante cada fase. É interessante notar que Goldberg e Tarjan abandonaram a idéia de fase. introduzida por Dinic; porém. introduziram a idéia de passagem sobre fila.

Karzanov introduziu a noģao de pré-fluxo. Vote que a clefiniçào de pré-fluxo de Karzanov é ligeiramente diferente da de Cioldherg c Tarjan. Mém disso. as operaçòes realizadas na funçào Empura lértice sào semelliantes às operaçoes do procedimento empurra.

Assim como o algoritmo de Goldberg-Tarjan, o algoritmo de Cherkasky realiza aumentações de vértices ativos para vértices quaisquer, mas de maneira muito diferente.

Galil introduziu o uso de árvores para representar caminhos aumentadores.

Galil e Naamad usaram implicitamente árvores dinâmicas; porém, com árvores 
balanceadas, ao invés de árvores enviesadas.

O Algoritmo de Sleator e Tarjan usa árvores dinâmicas, e neste caso, com árvores enviesadas; como no algoritmo de Goldberg-Tarjan.

Shiloach e Vishkin usaram fila para guardar os vértices ativos, assim como Goldberg e Tarjan.

Provavelmente, existem outros pontos em comum entre o algoritmo de Goldberg e Tarjan e aqueles apresentados no capítulo 1; porém. acreditamos que os pontos apresentados revelam os alicerces do algoritmo de Goldberg e Tarjan. 


\section{Apêndice A}

\section{Definições Básicas}

Definição A.1 : Um grafo é um par ordenado $(V, A)$ onde $V$ é um conjunto finito de elementos chamados vértices e $A$ é um conjunto de elementos chamados arestas, onde cada aresta é um conjunto de dois vértices.

Definição A.2 : Um grafo orientado é um par ordenado de $(V, A)$ onde $V$ é um conjunto finito de elementos chamados vértices e um $A$ é um conjunto de elementos chamados arestas, onde cada aresta é um par ordenado de vértices distintos.

Definição A.3 : Um caminho num grafo $G=(V, A)$ é uma seqüência da forma $\left(v_{0}, a_{1}, v_{1}, a_{2}, \ldots, a_{m}, v_{m}\right)$ com $m \geq 0$, onde os $v_{i}$ 's são vértices distintos de $G$ e $a_{i}=$ $\left\{v_{i-1}, v_{i}\right\}$ para $i=1, \ldots, m$ sào arestas distintas de $G$. Algumas vezes, por simplicidade, representamos um caminho pela seqüência de seus vértices (já que suas arestas ficam implicitamente definidas).

Definição A.4 : Um caminho orientado num grafo orientado $G=(V, A)$ é uma seqüência da forma $\left(v_{0}, a_{1} \cdot v_{1}, a_{2}, \ldots, a_{m}, v_{m}\right)$ com $m \geq 0$, onde os $v_{i}$ 's sào vértices distintos de $G$ e $a_{i}=\left(v_{i-1}, v_{i}\right)$ para $i=1, \ldots, m$ sào arestas distintas de $G$. Como na definiçào A.3, por simplicidade, podemos representar um caminho pela seqüência de seus vértices.

Definição A.5 : Um caminho num grafo orientado $G=(V, A)$ é uma seqüência da forma $\left(v_{0}, a_{1}, v_{1}, a_{2}, v_{2}, \ldots, a_{m}, v_{m}\right), \operatorname{com} m \geq 0$, onde os $v_{i}$ 's sào vértices e $a_{i}$ 's sào arestas de $G$ e, para $i=1, \ldots, m$ ou $a_{i}=\left(v_{i-1}, v_{i}\right)$ ou $a_{i}=\left(v_{i}, v_{i-1}\right)$. 
Definição A.6 : Seja $G=(V, A)$ um grafo (orientado ou não), e $c$ um caminho em $G$. O comprimento ou tamanho de $c$ é o número de arestas em $c$. Se $v$ e $w$ sào dois vértices consecutivos de $c$. entào dizemos que $v(w)$ é anterior (posterior) a $w(v)$.

Definição A.7 : Se $G=(V, A)$ é um grafo (orientado) e $u, v$ sào vértices distintos de $G$, a distância de $u$ a $v$ é o comprimento de um caminho (orientado) mínimo de $u$ a $v$. Se não existe um tal caminho, a distância é considerada infinita.

Definição A.8 : Um circuito num grafo $C i=(V, A)$ é uma seqüência da forma $\left(v_{0}, a_{1}, v_{1}, a_{2}, v_{2}, \ldots, a_{m}, v_{m}\right) \operatorname{com} m \geq 3$, tal que $v_{i} \in V,\left(v_{0}, a_{1}, v_{1}, a_{2}, v_{2}, \ldots, v_{m-1}\right)$ é um caminho, $v_{0}=v_{m}$ e $\left\{v_{m-1}, v_{m}\right\} \in A$.

Definição A.9 : Um circuito num grafo orientado $G=(V, A)$ é uma seqüência da forma $\left(v_{0}, a_{1}, v_{1}, a_{2}, v_{2}, \ldots a_{m}, v_{m}\right) \operatorname{com} m \geq 2$, tal que $v_{i} \in V .\left(v_{0}, a_{1}, v_{1}, a_{2}, v_{2}, \ldots, v_{m-1}\right)$ é um caminho, $v_{0}=v_{m}, a_{m} \in A$ e $a_{m}=\left(v_{m-1}, v_{m}\right)$ ou $a_{m}=\left(v_{m}, v_{m-1}\right)$.

Definição A.10 : Se $G=(V, A)$ é um grafo (orientado ou nào), entào dizemos que $G$ é conexo se para quaisquer dois vértices $v, w \in V$, existe um caminho de $v$ a $w$, em $G$.

Definição A.11 : Um grafó $G$ é uma árvore se $G$ nào possui circuitos e é conexo. Podemos distinguir um vértice $r$ de $G$ e dizer que $r$ é raiz da árvore $G$. Neste caso $G$ é uma árvore com raiz. Além disso, o tamanho de uma árvore é definido como o número de seus vértices.

Definição A.12 : Seja A uma árvore com raiz $r$. sejam $x$ y vértices de A tais que $y$ está no caminho de $x$ até $r$. Entào, dizemos que $x$ é descendente de $y$ e $y$ é ancestral de $x$.

Definição A.13 : Se $A$ é uma árvore com raiz $r$ e $x$ é um vértice de $A$, então dizemos que os descendentes de $x$ formam uma subárvore com raiz $x$.

Definição A.14 : Seja A uma árvore com raiz, e $x, y$ vértices de $A$. Se $\{x, y\}$ é uma aresta de $A$ e $x$ é descendente de $y$, dizemos que $y$ é pai de $x:(y=$ pai $(x))$ e $x$ é filho de $y$. Também dizemos que a aresta $(x, y)$ entra em $y$.

Definição A.15 : Seja $A$ uma árvore com raiz $r$, e sejam $x, y$ vértices distintos de $A$ e diferentes de $r$. Dizemos que $x$ é irmão de $y$ e que $x$ e $y$ são irmãos, se pai $(x)=\operatorname{pai}(y)$. 
Definição A.16 : Seja $A$ uma árvore com raiz. Um vértice $x$ de $A$, é uma folha se não possui filhos, e nó interno. caso contrário.

Definição A.17 : Seja $A$ uma árvore com raiz $r$. e $x$ um vértice de $A$. A profundidade de $x$ é definida indutivamente da seguinte forma:

$$
\text { profundidade }(x)= \begin{cases}0, & \text { se } x=r \\ \text { profundidade }(\text { pai }(x))+1, & \text { caso contrário. }\end{cases}
$$

Definição A.18 : Uma árvore com raiz é chamada balanceada se todas as suas folhas têm a mesma profundidade.

Definição A.19 : Seja $A$ uma árvore com raiz, e $R$ uma relaçào de ordem estrita definida sobre os vértices de $A$. Dizemos que $A$ é uma árvore ordenada pela relação de ordem $R$, se quaisquer dois vértices irmàos são comparáveis pela relaçăo $R$.

Definição A.20 : Seja $A$ uma árvore ordenada pela relaçào de ordem estrita $R, x$ um nó interno de $A$ e $\left\{x_{0}, x_{1}, \ldots, x_{k}\right\}$ os filhos de $x$ tais que $\left(x_{i}, x_{i+1}\right) \in R, i=0,1, \ldots, k-1$. O irmão vizinho direito(esquerdo) de $x_{i}\left(x_{i+1}\right)$ é $x_{i+1}\left(x_{i}\right), i=0,1, \ldots, k-1$. Se $z$ é irmào vizinho direito de $y$, entào $z$ e $y$ sào irmãos vizinhos. O vértice $x_{0}\left(x_{k}\right)$ é o filho mais a esquerda(direita) de $x$. Sejam $x$ e y duas folhas da árvore $A$. Se $\bar{x}$ e $\bar{y}$ são ancestrais de $x$ e $y$, respectivamente, tais que $\bar{x}$ e $\bar{y}$ sào irmàos. entào dizemos que $x$ está à esquerda (direita) de $y$ se $(\bar{x}, \bar{y}) \in R((\bar{y}, \bar{x}) \in R)$. 


\section{Apêndice B}

\section{Glossário}

página

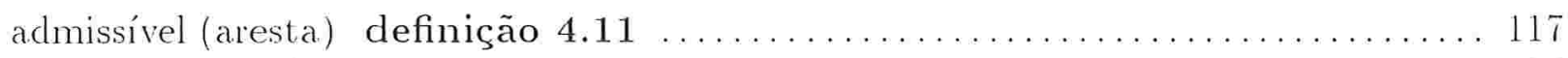

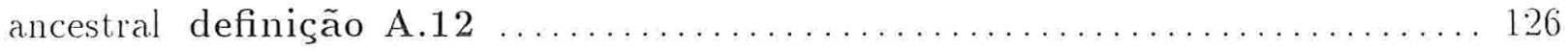

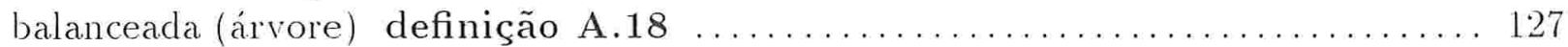

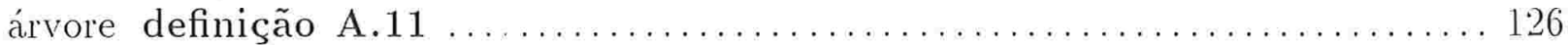

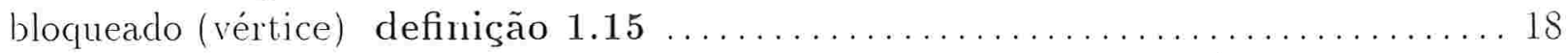

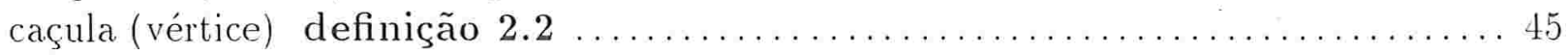

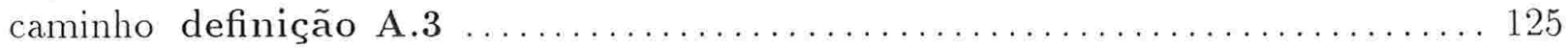

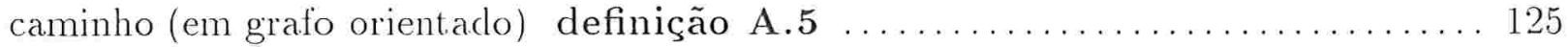

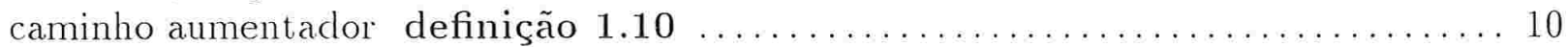

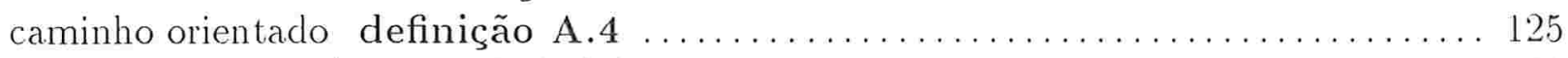

caminho esquerdo/direito definição $2.11 \ldots \ldots \ldots \ldots \ldots \ldots \ldots \ldots \ldots \ldots \ldots \ldots \ldots \ldots \ldots \ldots \ldots \ldots \ldots \ldots$

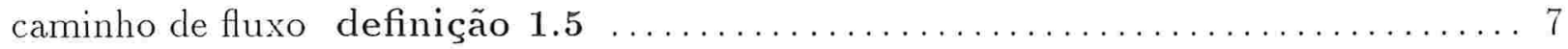

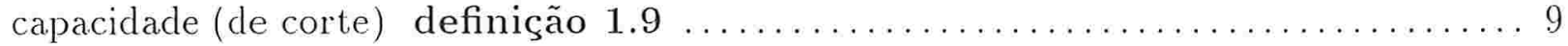

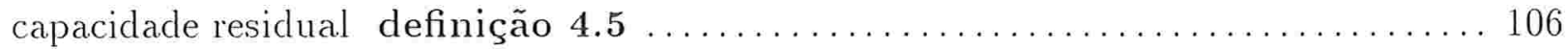

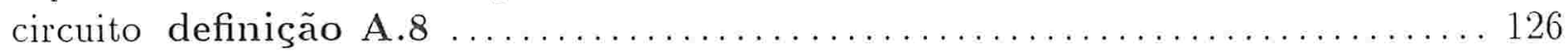

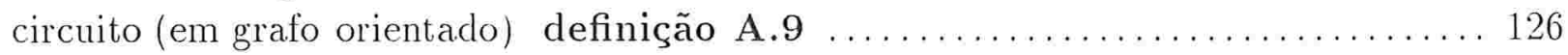

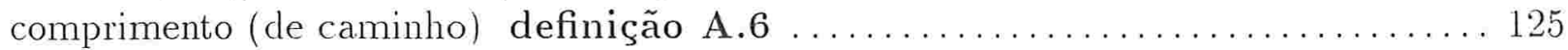

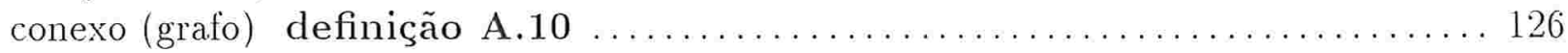

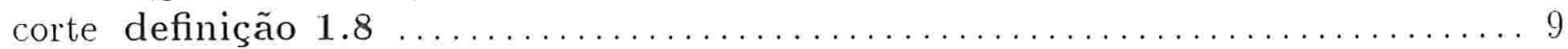

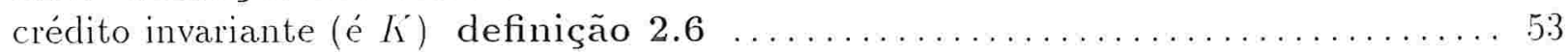

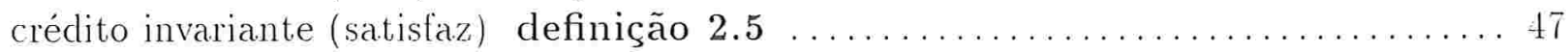

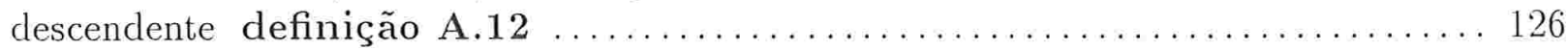

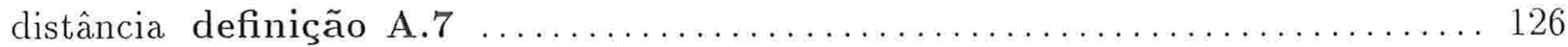

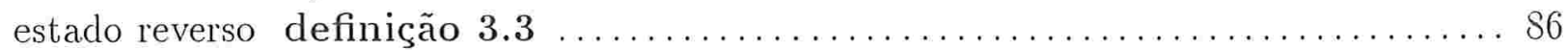

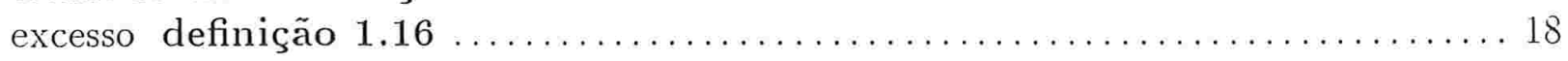




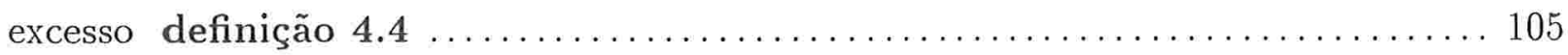

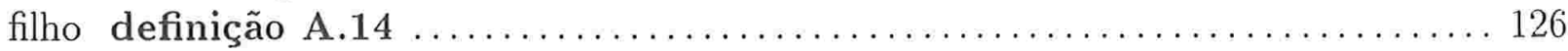

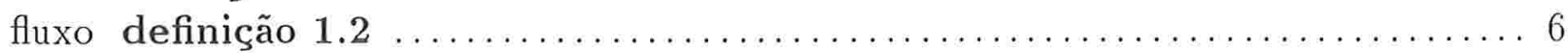

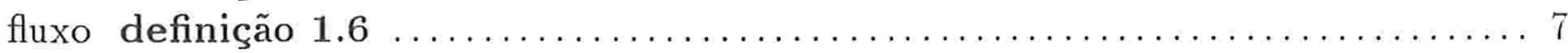

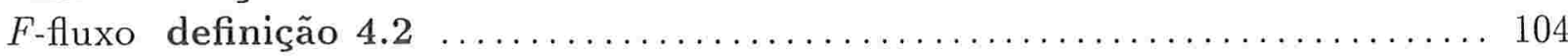

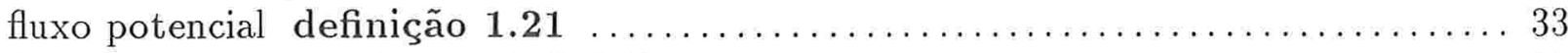

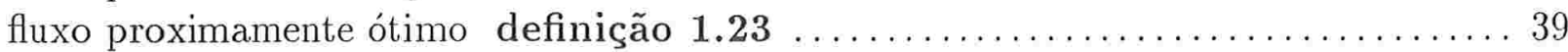

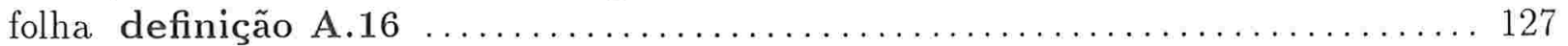

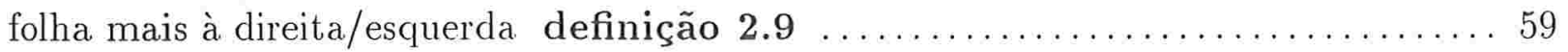

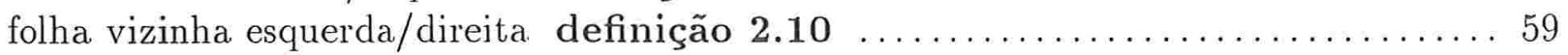

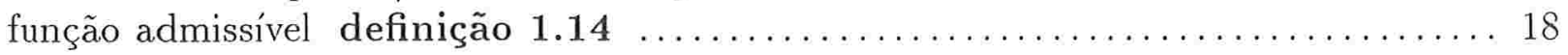

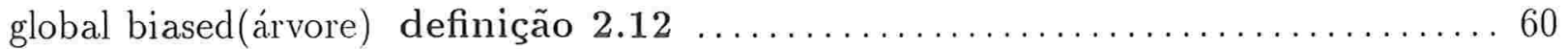

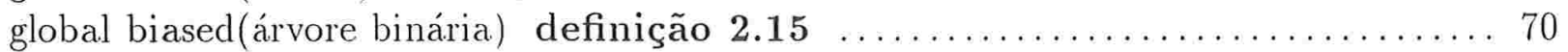

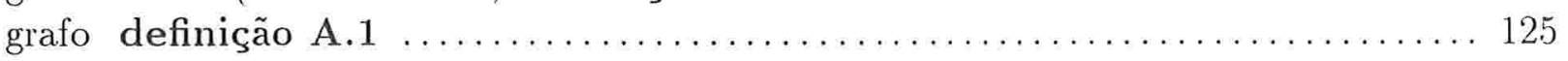

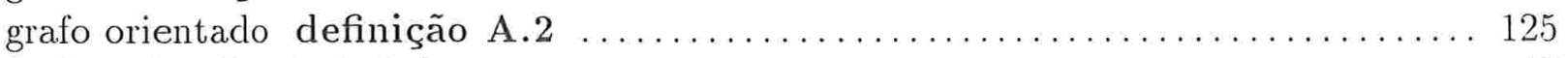

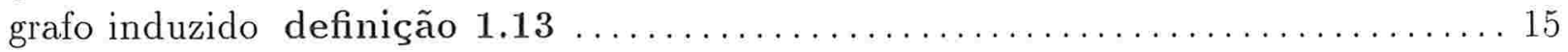

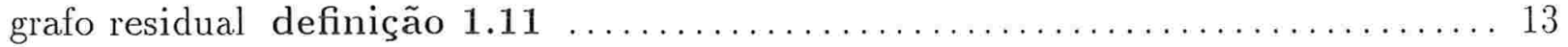

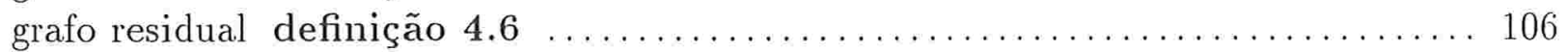

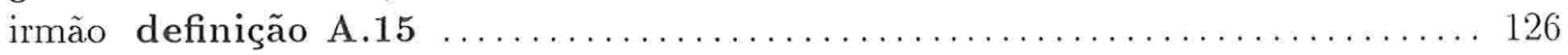

irmão vizinho esquerdo/direito definição A.20 $\ldots \ldots \ldots \ldots \ldots \ldots \ldots \ldots \ldots \ldots \ldots \ldots \ldots$

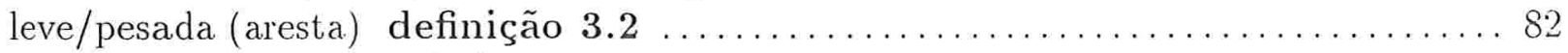

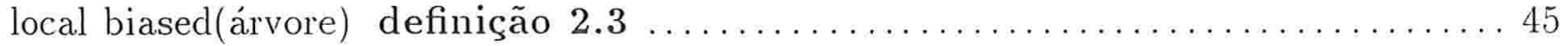

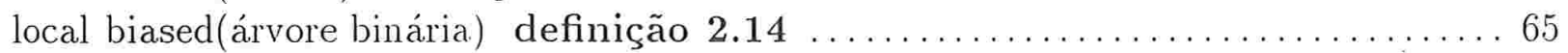

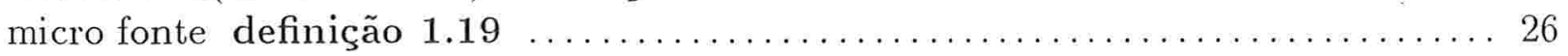

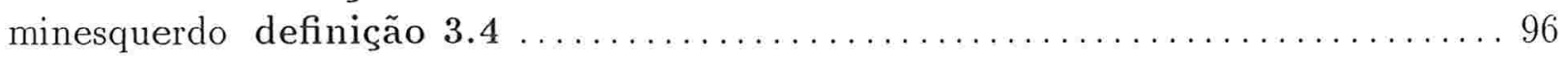

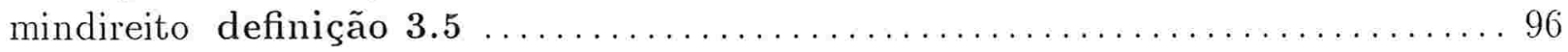

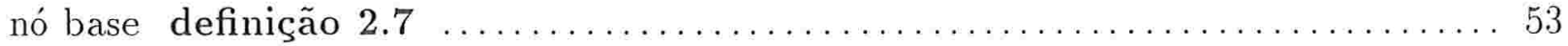

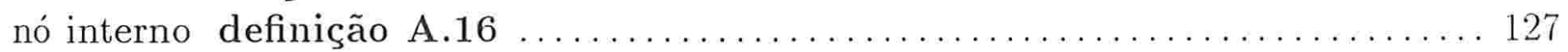

nó referência esquerdo/direito definição $2.13 \ldots \ldots \ldots \ldots \ldots \ldots \ldots \ldots \ldots \ldots \ldots \ldots \ldots \ldots \ldots \ldots$

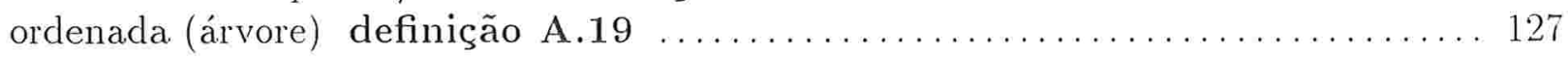

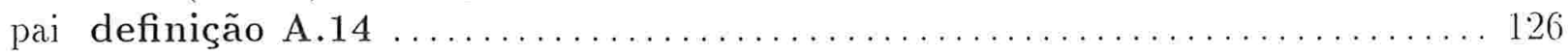

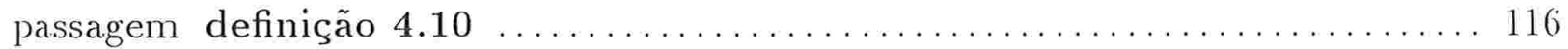

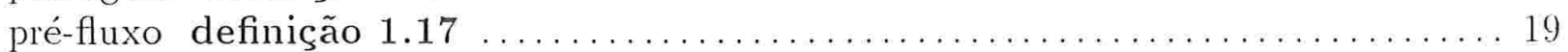

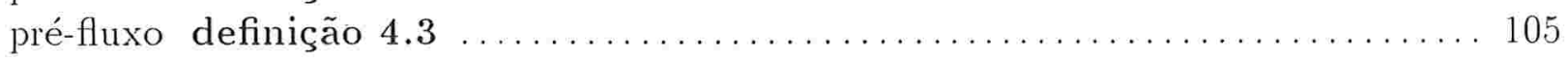

primeiro vizinho esquerdo/direito definição $2.8 \ldots \ldots \ldots \ldots \ldots \ldots \ldots \ldots \ldots \ldots . \ldots$

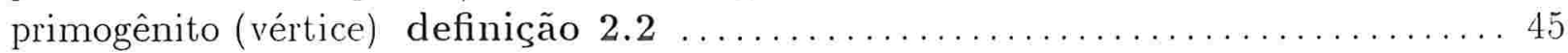

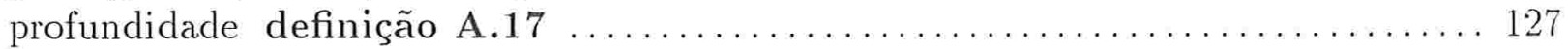

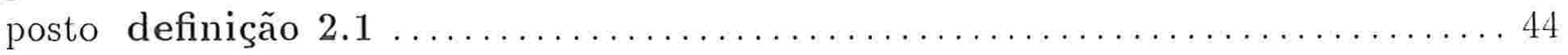

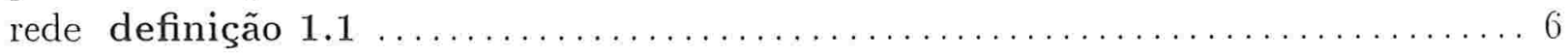

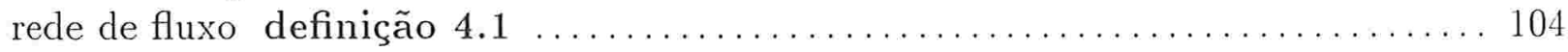

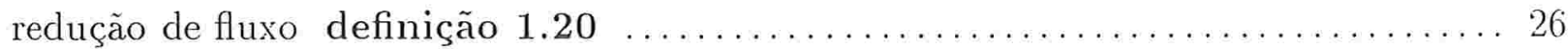

receberam fluxo (conjunto de vértices que) definição $1.22 \ldots \ldots \ldots \ldots \ldots \ldots . \ldots . \ldots 38$

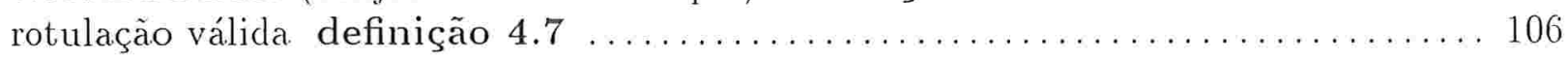




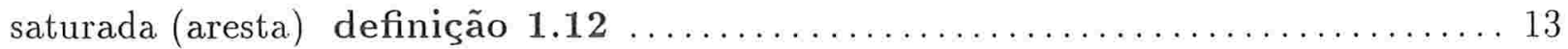

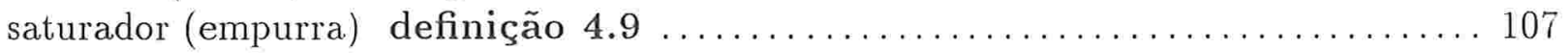

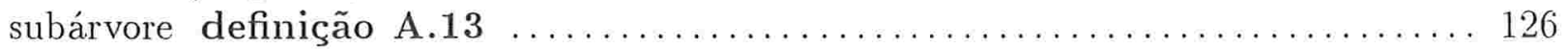

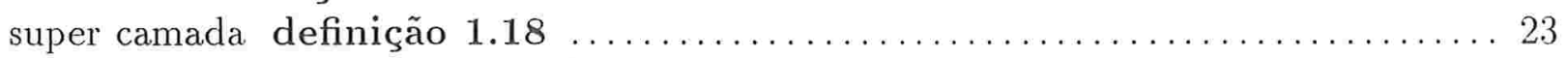

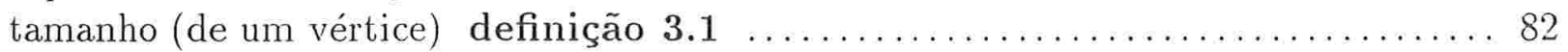

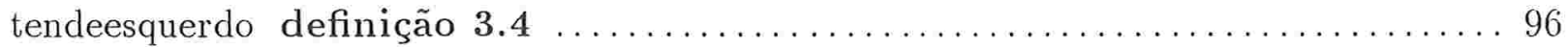

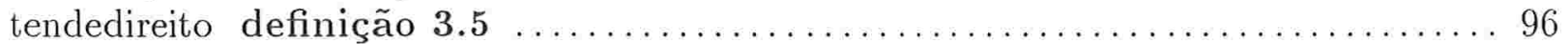

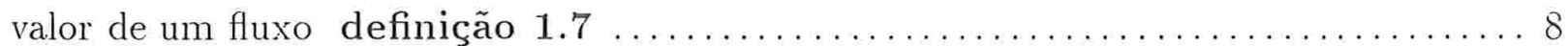

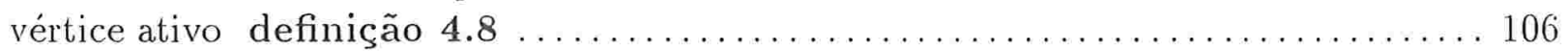




\section{Apêndice C}

\section{Sobre a Implementação}

A implementaçào do algoritmo de Goldberg e Tarjan foi feita com o objetivo de complementar o aprendizado. De fato, durante a implementaçào, as últimas dúvidas foram esclarecidas.

O programa foi feito em linguagem ( $C$. Ele está completamente modularizado e é possível utilizar somente a biblioteca de funçòes relerente às arvores enviesadas ou às árvores dinâmicas. O programa é constituído de 48 módulos, dos quais 8 sào referentes às árvores enviesadas, 22 sào referentes às árvores dinâmicas e o restante referente ao algoritmo do fluxo máximo. Além disso, os conteúdos dos nós das árvores enviesadas e das árvores dinâmicas sào totalmente configuráveis. O programa é constituído de aproximadamente duas mil linhas de código exigiu cerca de 130 horas de programaçào. O computador utilizado foi um 'PC-XT'(8086) e o compilador utilizado foi o 'TURBOC' da. Borland, sendo que o modelo de compilaçào utilizado foi 'large' e o programa executável gerado possui $100 \mathrm{~K}$ bytes.

$\mathrm{Na}$ programaçào foram utilizadas muitas variáveis do tipo ponteiro e muitas variáveis são alocadas dinamicamente. Desta forma, nào foi necessário fazer estimativas de espaços de memória e o tamanho do maior problema executável pelo algoritmo depende do tamanho da memória da máquina. No entanto, isto trouxe dificuldades na hora da depuraçào.

Uma das dúvidas sanadas durante a implementacio foi a respeito do item que uma folha de uma árvore enriesada representa. Isto gorou a obscraçào da página 89 após o lema 3.3 .

O programa foi testado, na maior parte das vezes, para problemas pequenos cerca de 25 vértices e 40 arestas - e notou-se que para problemas pequenos as árvores 
dinâmicas não cresceram muito e que o maior empurra utilizava apenas 2 arestas. Além disso, não foi encontrado nenhum exemplo em que a operação empurra-rerrotula-na-árvore recai no caso $2 b$. O maior exemplo testado possuía cerca de 300 vértices e 500 arestas e o tempo de execução foi de 5 horas. No entanto, esse dado não é muito representativo, uma vez que não foi comparado com outros algoritmos. 


\section{Bibliografia}

[1] N. Abramson, Information Theory and Coding, McGraw-Hill, New York, 1963.

[2] R. K. Ahuja and J. B. Orlin. A Fast and Simple Algorithm for the Maximum Flow Problem. Operations Research 37. No. 5. 748-759. 1989.

[3] S. W. Bent, D. D. Sleator, and R. E. Tarjan. Biased Search Trees. SIAM J. Comput. 14, No.3, 545-568, 1985.

[4] R. V. Cherkasky. Algorithm for construction of maximal flow in networks with complexity of $O\left(V^{2} \sqrt{E}\right)$ operations. Mathematical Methods of Solution of Economical Problems 7, 112-125, 1977. (Em Russo).

[5] U. Derigs and W. Meier. Implementing Goldberg's Max-Flow-Algorithm - A Computational Investigation. ZOR - Methods and Models of Operational Research 33, 383-403, 1989.

[6] E. A. Dinic. Algorithm for solution of a problem of maximum flow in networks with power estimation. Soviet Math. Dokl. 11. 127T-1280. 1970.

[7] J. Edmonds and R. M. Karp. Theoretical improvements in algorithmic efficiency for network flow problems. Journal of the ACM 19, 248-264. 1972.

[8] S. Even. Graph Algorithms. Computer Science Press. Potomac. MD. 1979.

[9] L. R. Ford, Jr. and D. R. Fulkerson. Maximal flow through a network. Canadian Journal of Math. 8. 399-40-1. 1956.

[10] L. R. Ford, Jr. and D. R. Fulkerson. Flows in Networks. Princeton Univ. Press. Princeton, NJ., 1962.

[11] H. N. Gabow. Scaling algorithms for network problems. Journal of Computer and System Sciences 31. 148-168. 1985.

[12] Z. Galil. An $O\left(V^{\frac{2}{3}} F^{\frac{2}{2}}\right)$ algorithm for the maximal flow problem. Acta Informatica 14, 221-242, 1980. 
[13] Z. Galil and A. Naamad. An $O\left(E V \log ^{2} V\right)$ algorithm for the maximum flow problem. Journal of Computer and System. Sciences 21, 203-217, 1980.

[14] A. V. Goldberg and R. E. Tarjan. A new approach to the maximum flow problem. Proc. 18th Annual ACM Symp. on the Theory of Computing, 136-146, 1986.

[15] A. V. Karzanov. Determining the maximal flow in a network by the method of preflows. Soviet Math. Dokl. 15, 434-437, 1974.

[16] V. M. Malhotra, M. Pramodh Kumar, and S.N. Maheshwari. An $O\left(|V|^{3}\right)$ algorithm for finding maximum flows in networks. Inform. Process. Lett. 7, 277-278, 1978.

[17] Y. Shiloach and U. Vishkin. An $O\left(n^{2} \log n\right)$ parallel max-flow algorithm. Journal of Algorithms 3, 128-146, 1982.

[18] D. D. Sleator and R. E. Tarjan. A data structure for dynamic trees. Journal of Computer and System Sciences 26, 362-391, 1983.

[19] R. E. Tarjan. Amortized Computational Complexity. SIAM J. Alg. Disc. Meth. 6, No.2, 306-318, 1985.

[20] R. E. Tarjan. A Simple Version of Karzanov Blocking Flow Algorithm. Operations Research Letters 2, No. 6. 265-267. 1983. 